\title{
Atmospheric Process Evaluation of Mobile Source Emissions
}

Center for Environmental

Research and Technology

University of California

Riverside, $C A$

NREL technical monitor:

B. Bailey

\section{NPEI}

DISTRIBUTION OF THIS DOCUMENT IS UNLIMITED

National Renewable Energy Laboratory

1617 Cole Boulevard

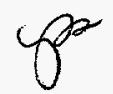

Golden, Colorado 80401-3393

A national laboratory of the U.S. Department of Energy Managed by Midwest Research Institute

for the U.S. Department of Energy

Under Contract No. DE-AC36-83CH10093

Prepared under Subcontract Number XCC-4-14161-01

July 1995 
This publication was reproduced from the best available camera-ready copy submitted by the subcontractor and received no editorial review at NREL.

\section{NOTICE}

This report was prepared as an account of work sponsored by an agency of the United States government. Neither the United States government nor any agency thereof, nor any of their employees, makes any warranty, express or implied, or assumes any legal liability or responsibility for the accuracy, completeness, or usefuiness of any information, apparatus, product, or process disclosed, or represents that its use would not infringe privately owned rights. Reference herein to any specific commercial product, process, or service by trade name, trademark, manufacturer, or othenwise does not necessarily constitute or imply its endorsement, recommendation, or favoring by the United States government or any agency thereof. The views and opinions of authors expressed herein do not necessarily state or reflect those of the United States government or any agency thereof.

Available to DOE and DOE contractors from:

Office of Scientific and Technical Information (OSTI)

P.O. Box 62

Oak Ridge, TN 37831

Prices available by calling (615) 576-8401

Available to the public from:

National Technical Information Service (NTIS)

U.S. Department of Commerce

5285 Port Royal Road

Springtield, VA 22161

(703) $487-4650$ 


\section{DISCLAIMER}

Portions of this document may be illegible in electronic image products. Images are produced from the best available original document. 


\section{Contents}

Abbreviations iv

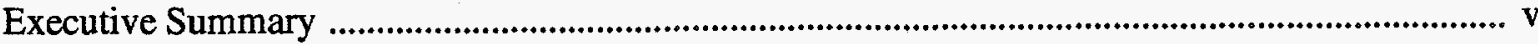

1.0 Introduction

2.0 Emission Data of Alternative Fuel Vehicles .................................................................................. 3

2.1 Background

2.2 Methanol

2.3 Ethanol

2.4 Natural Gas

2.5 LPG-Propane

2.6 Reformulated Gasoline

2.7 Evaporative and Running Loss Emissions

2.8 Developing Emission Factors for AFVs: Chemical Species

3.0 Mobile Source Emission Inventory and Modeling …................................................................ 23

3.1 Review of Models

3.2 Application of EMFAC and MOBILE for Alternative Fuels

4.0 Governing Processes and Air Quality Models

4.1 Introduction

4.2 Approaches to Air Quality Modeling

4.3 Parameterization of Processes in Models

4.4 The Governing Equation and Numerical Solution

4.5 Survey of Existing Models

4.6 Model Performance

5.0 Representation of Chemical Processes

5.1 Chemical Basis of Ozone Formation

5.2 Chemical Mechanisms

6.0 Fuel and Compound Reactivity Assessment

6.1 Quantification of Reactivity

6.2 Chemical Basis of Reactivity

6.3 Assessments of Factors Affecting Reactivity

6.4 Development of General Reactivity Scales

6.5 Model Evaluations of Reactivity Scales

6.6 Environmental Chamber Assessments

6.7 Scenario-Specific Modeling Assessments

7.0 Recommendations for Future Research

7.1 Emissions

7.2 Chemistry

7.3 Modeling

8.0 References 


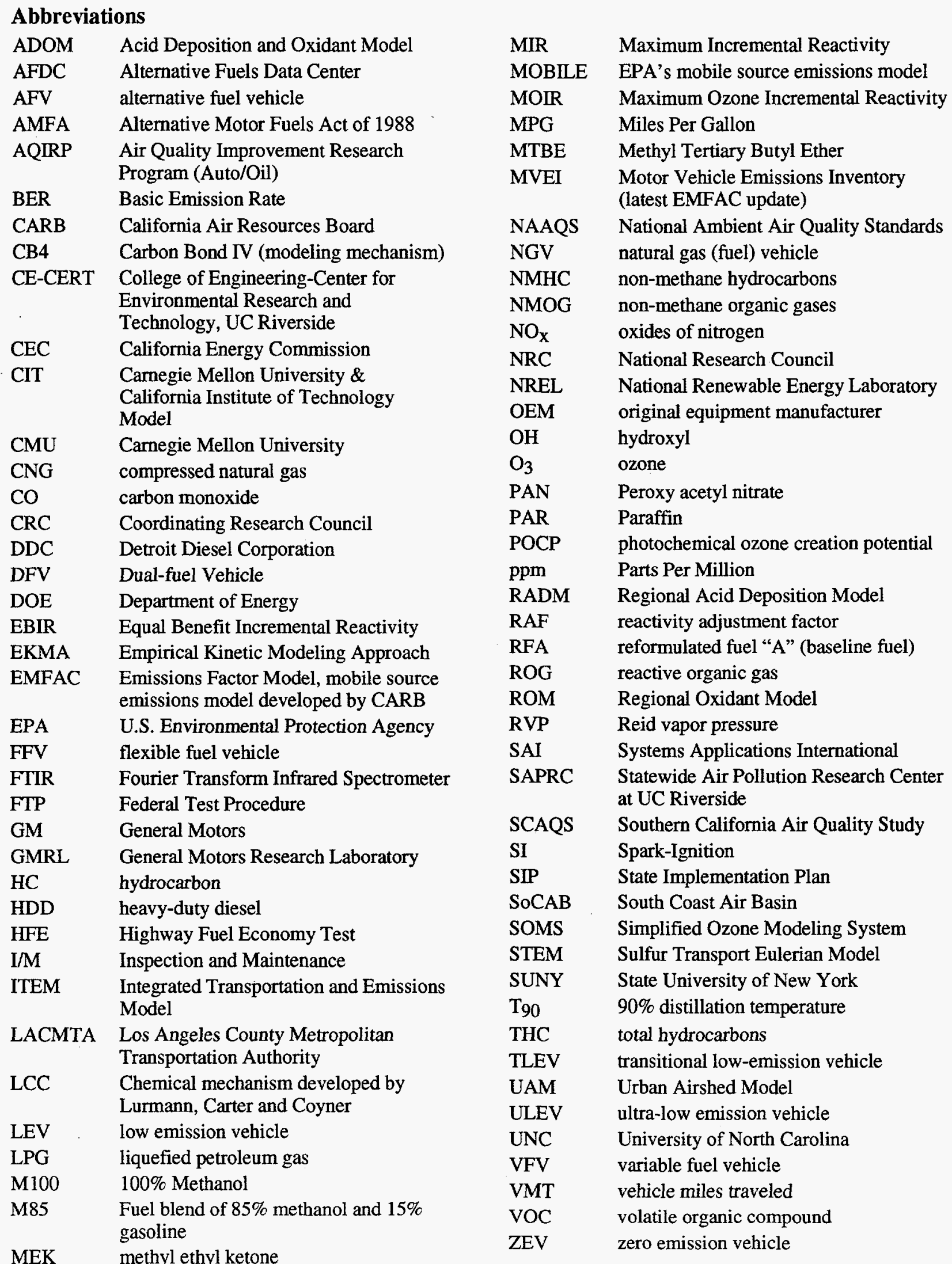




\section{EXECUTIVE SUMMARY}

\section{ATMOSPHERIC PROCESS EVALUATION OF MOBILE SOURCE EMISSIONS}

\section{COLLEGE OF ENGINEERING- CENTER FOR ENVIRONMENTAL RESEARCH AND TECHNOLOGY UNIVERSITY OF CALIFORNIA, RIVERSIDE}

\section{Background}

- During the past two decades there has been a considerable effort in the U.S. to develop and introduce into society an alternative to the use of gasoline and conventional diesel fuel for transportation. The primary motives for this effort have been twofold: energy security and improvement in air qualitymost notably ozone, or smog.

- The overall process for the evaluation of the ozone impacts of alternative fuel use is discussed in detail in this report and consists of the following distinct but coupled stages:

1) The quantification of the mass emission rate and chemical species of running loss, evaporative, and tailpipe emissions;

2) The determination of the contribution of these emissions to the total emission inventory for the specific urban area to be evaluated;

3) The development and evaluation of chemical mechanisms for predicting the atmospheric transformations by which the emitted pollutants form ozone and other secondary pollutants;

4) The development and evaluation of complex urban and regional airshed models for the prediction of the change in the atmospheric ozone and other pollutant concentrations resulting from changes in emissions;

5) The applications of these models and emissions data to the assessment of the air quality impacts of alternative fuels over the full range of applicable conditions; and

6) An assessment of the uncertainties of each of these stages and an evaluation of the uncertainty of the overall impact assessment.

\section{Emissions Data for Alternative Fuel Vehicles}

- A robust and up-to-date data base of emissions tests of vehicles operating on different alternative fuels is necessary to evaluate the environmental impact of alternative fuel vehicles (AFVs). This should include information on the in-use emission rates of tailpipe emissions of non-methane organic gases (NMOG), oxides of nitrogen $\left(\mathrm{NO}_{\mathrm{x}}\right)$, and carbon monoxide $(\mathrm{CO})$; an evaluation of the running loss and evaporative emissions of these vehicles; emission measurements from low and high mileage vehicles; and a detailed characterization of the chemical composition of the exhaust. Most importantly, the vehicles from which these data are derived should be representative of the types of engines, fuel systems, and emission control technologies that will appear on the road. 
- Many of the early alternative fuel programs involved small fleets of either retrofitted production gasoline vehicles, specially-built demonstration vehicles, or production vehicles up-fitted by an original equipment manufacturer (OEM). The focus of these early programs was primarily on technology development issues such as fuel metering systems, engine design and on-road performance, rather than quantifying emissions reductions.

- Research to date has provided insight into the chemical composition of the exhaust of AFVs and information that can be used for simple comparisons with gasoline vehicles. It has not, however, been particularly useful in the determination of a fleet average emissions rate in grams/mile. This is because the tests to date have been conducted mostly at low mileages and on only a small number of predominantly developmental vehicles. The variability of the emissions rate from vehicle-to-vehicle is also large for all vehicle types regardless of fuel. These factors make it difficult to quantify the mass emission rates for AFVs operating on any fuel, and hence, difficult to quantify future air quality improvements due to the use of alternative fuels.

- The quality and quantity of emissions data have improved considerably over the past few years and should continue to improve as a result of programs such as the Auto/Oil Air Quality Improvement Research Program (AQIRP), the Alternative Motor Fuels Act of 1988 (AMFA), the CleanFleet programs, and the programs being conducted at the California Air Resources Board (CARB) to establish a reactivity-based emission standard for alternative fuels.

- CARB has established a reactivity-based emission standard for alternative fuels to coincide with its future emission standards. Such standards use "reactivity adjustment factors" (RAFs) to adjust the NMOG mass emission rate for the different ozone formation potentials of the chemical species in the emissions. As part of this program, CARB has done extensive testing of AFVs that can meet its advanced emissions standards and are representative of future technologies. The testing procedure involves the detailed characterization of the chemical components in the NMOG portion of the exhaust, so-called speciation. The speciated data collected by CARB for this program is one of the most consistent and comprehensive sources of data available on alternative fuels.

- There are significant differences in the NMOG species for vehicles operating on different alternative fuels. Because the reactivity of individual chemical species differs, these distributions must be accounted for in the chemical mechanisms used to determine the impact of alternative fuels.

- The CleanFleet program is a demonstration project using alternative fuel Federal Express delivery vans operating in the Los Angeles area. The vans for this project were provided by the OEMs and are generally representative of the technologies that were commercially available in 1992. NMOG speciated exhaust and evaporative emissions are being collected over the duration of the project at three different mileage points. This program should provide valuable information about the possible effects of in-use deterioration of AFVs.

- Federal legislation, most notably AMFA, has resulted in several successful programs; e.g., the United States Department of Energy's (DOE's) Alternative Fuels Utilization Program, that have accelerated the use and testing of AFVs nationwide. Under AMFA, the Federal government is purchasing as many AFVs as possible to stimulate production. These vehicles are obtained directly from the OEMs and thus represent the most current vehicle technology. Emissions tests are performed at several mileage intervals. These tests will also provide valuable information about the effects of in-use deterioration of AFVs. 


\section{Mobile Source Emission Inventory and Modeling}

- Mobile emission source estimates, on an urban scale, are generated by emissions inventory models that use two main processing steps. The first step consists of determining a set of emission factors that specify the rate at which emissions are generated. In the second step, the vehicle activity is estimated. The emission inventory is then calculated by multiplying the results of these two steps together.

- The two predominant emissions inventory models are the Emissions Factor Model (EMFAC) and MOBILE. EMFAC is used by CARB to estimate on-road vehicle emission. It uses California specific data. MOBILE is used by the U.S. Environmental Protection Agency (EPA) to estimate on-road emissions for states other than California. It uses national data.

- At the present time, mobile source emission inventories from current gasoline and diesel vehicles appear to be underestimated by as much as a factor of three. This situation needs to be better understood and corrected and should be considered the highest research priority. If not corrected, any valid assessment of alternative fuels or any other transportation measure designed to improve air quality will be virtually impossible.

- The emissions factors developed by EMFAC and MOBILE are based on the Federal Test Procedure (FTP). The FTP certification test is designed with a specific driving trace (speed vs. time), which is intended to reflect actual driving conditions. The effectiveness of the FTP cycle in representing actual emissions has been the subject of considerable controversy in recent years. In particular, the inadequacy of the FTP in accounting for different modes of operation (acceleration, deceleration, idle, etc.) is considered a critical problem that needs to be addressed.

- The base emission rates developed from FTP data are modified through the use of correction factors, which are used to adjust the emission rate to account for the use of different sections in the FTP cycle, temperatures, and non-FTP speeds. As almost no data are available to develop correction factors specific to AFVs, the correction factors developed for gasoline vehicles must be also be used to model AFVs.

- The EMFAC and MOBILE models differ considerably in the methods used to approach certain aspects of developing emission factors, including the effects of tampering, fleet characterization, emitter categories, deterioration rates, and operational mode. For example, EMFAC separates out the cold start, hot stabilized, and hot start portions of the FTP, while MOBILE combines these segments together to generate a composite emissions factor.

- The effects of methanol vehicles on the emissions inventory have been investigated by Systems Applications International (SAI) for AQIRP and by Carnegie Mellon University (CMU) for CARB. These studies describe methods that can be used to develop emission inventories for AFVs.

- To accurately determine the impact of alternative fuels on the emissions inventory, the following are minimum needs: zero mile emission rates for AFVs by vehicle class and technology group, deterioration rates for AFVs, cumulative mileage per vehicle class and technology group, penetration rates of AFVs into the vehicle fleets, and corrections factors to adjust the FTP-based base rates for AFVs to non-FTP conditions. Unfortunately, few or no data are available on any of these topics with the exception of zero, or low mile rates. 
- Until improved data are available, we recommend the following procedures for estimating emissions rates from AFVs:

1) Use the speciated emissions data from the most recent testing by CARB to determine the reactivity of the emissions for vehicles operating on different fuels and chemical profiles for more complicated airshed modeling.

2) Unless evidence shows otherwise, mass emission rates of the various AFVs should be based on the certified emission standard that the vehicles meet, particularly for NMOG. This does not imply that there cannot be differences between the mass emissions rates of vehicles operating on different fuels. In particular, emission rates for NMOG and CO for natural gas vehicles (NGVs) appear to be lower than those from other AFVs.

3) Speed correction factors, deterioration rates, and other modal emission parameters used for gasoline should be used to calculate emission factors for AFVs.

4) Procedures have previously been developed to model evaporative emissions for methanol vehicles. For alcohol fuel vehicles these should be used along with more current data. Evaporative emissions for vehicles operating on gaseous fuels should be considered zero.

\section{Air Quality Models}

- Air quality models are numerical representations of the atmospheric system governing the fate of pollutants emitted into the atmosphere. The predictions from a model have been evaluated with observations of chemical species in the atmosphere, the model can be treated as a surrogate for the real system and used to predict how volatile organic compounds (VOCs) and $\mathrm{NO}_{\mathrm{x}}$ emissions affect ozone in various environmental scenarios.

- Air quality models can vary greatly in complexity and the amount of input data they require. Simple "box" models represent the polluted atmosphere by a discrete air parcel that moves over the air basin and receives emissions, which then react in a single well-mixed parcel. Complex "grid" models divide the air mass into multiple vertical and horizontal cells where the chemical reactions and (where applicable) emissions occur, and represent transport and diffusion of the pollutants between the cells. The grid models provide the most comprehensive representation of any airshed and provide the only means to predict observed pollution levels in real-world pollution episodes. For that reason, they are also referred to as "comprehensive" models. However, because of their greater computational demands, they generally use more simplified chemical mechanisms than can be used in box models.

- A number of different processes must be parameterized in air quality models, including the inventory of emissions from all sources, gas and aqueous phase chemistry, transport, mixing, and scavenging. Of these processes, primarily the emission inventory and the compound chemistry will be changed by introducing alternative fuels. However, the other processes will influence the impact of these changes.

- The most complex models have large input data requirements, and much of the input information they require is highly uncertain. For this reason, their ozone $\left(\mathrm{O}_{3}\right)$ predictions may be no more reliable than predictions of much more simplified box models. Furthermore, their large demands on computer and analysis time severely limits the number of cases that can be examined. This is a significant impediment to assessing multiple options, to evaluating how impacts vary with environmental 
conditions, and to conducting the sensitivity calculations necessary to understand how various factors affect the results.

- Although box models oversimplify transport and diffusion and provide limited information on spatial variability, they can represent the chemical transformations in greater detail, and are more than adequate for representing the wide range of chemical conditions that affect how changes in VOC and $\mathrm{NO}_{x}$ emissions will affect $\mathrm{O}_{3}$ formation. They have the major advantage that $\mathrm{O}_{3}$ impacts under a large number of conditions can be systematically examined. A comprehensive set of simple model scenarios will provide more information concerning the range of relative $\mathrm{O}_{3}$ impacts for variable environmental conditions than can be obtained with a much more limited number of more complex model simulations.

\section{Evaluation of Airshed Models}

- Because of their complexity, uncertainties, and approximations, airshed models need to be tested by comparing their predictions with observations before they can be used with confidence. While such models are frequently tested using ozone data, most studies are incomplete in that model estimates have not been directly compared with observations of VOC and $\mathrm{NO}_{\mathrm{x}}$ concentrations. Because many factors affect ozone, one does not know whether a model that can predict $\mathrm{O}_{3}$ is giving "the right answer for the wrong reason."

- The few studies that have done so indicate that grid models underpredict precursor concentrations by significant factors. Current model estimates of ozone peaks are consistently lower than corresponding observations by about $20 \%$. Some believe that this is a result of the underestimation of urban VOC emissions from mobile sources. However, recent sensitivity studies conducted by Harley et al. (1993) show that underestimating the VOC emission rate cannot be the only or possibly even the primary reason for the underpredictions of the ozone peaks. It can be argued that some of this problem can be attributed to numerical errors associated with solving the mass conservation equation.

- There is evidence that one source of error in model predictions, which has not been adequately addressed, is the accuracy of the numerical schemes used in the models to represent the transport phenomena. We recommend a careful examination of this in addition to the physics and chemistry of air quality models before these models are routinely applied to examine the effect of alternative fuels.

- The evaluation of the current generation of air quality models suggests that they might require substantial improvement before they can be used to provide reliable estimates of the effects of fuel substitution on ozone and other secondary pollutants.

\section{Chemical Mechanisms}

- The chemical mechanism is the portion of the airshed model that represents the chemical transformations of the emitted pollutants and how they form ozone and other oxidized products. Chemical mechanisms must appropriately take all the chemical factors affecting ozone formation into account if their ozone predictions are to be credible.

- Current chemical mechanisms have many uncertainties. Hundreds of types of organic compounds have been identified in speciated emissions inventories, and they all react in different ways and at 
different rates, and have differing effects on ozone formation. Laboratory and environmental chamber data are available to develop and test the mechanisms for only a subset of these, and there are gaps in our understanding of important details of the atmospheric reactions of all but the simplest VOCs. For this reason, even some of the most extensively studied VOCs are represented in airshed models using parameterized mechanisms that are adjusted to fit environmental chamber data. For the other VOCs, their reactions are either derived by analogy with mechanisms for compounds that have been studied, or they are represented as if they reacted the same way as the other compound.

- The rate constants for at least the initial atmospheric reactions of almost all important VOCs have been measured or can be estimated with a reasonable level of confidence. Mechanistic data and environmental chamber results are available for enough representative compounds to allow parameterized mechanisms to be developed to represent reactions of more than 100 types of VOCs. Such a mechanism has been incorporated in a box model and used to estimate the ozone reactivities of most VOCs measured from vehicle emissions. It still uses a highly simplified representation of the subsequent reactions of these species, designed mainly to represent the overall photooxidation and ozone formation processes. Box models can potentially incorporate much more complex mechanisms than this, but given the current state of knowledge of atmospheric reactions of VOCs, any additional complexity would be largely speculation, which would not necessarily improve the model's predictive capability.

- Because comprehensive models are very computationally intensive, and most of the computer time is taken up in processing the chemistry, most chemical mechanisms used in such models are highly condensed. Such mechanisms were developed and optimized to simulate current ambient mixtures, and were not designed for use for evaluating scenarios where the emissions speciation may change significantly, such as widespread implementation of AFVs. Because box models can incorporate more complex mechanisms, this is one advantage of using them for AFV evaluations. However, advances in software and computer capabilities are permitting implementation of more complex mechanisms in comprehensive models, and we recommend that such models be used in future evaluations.

\section{Reactivity Assessment}

- Because of differences in their mechanisms and rates of reaction, VOCs can differ greatly in their effects on ozone formation, or their "reactivities." The factors affecting a VOC's reactivity are its reaction rate, how much ozone is formed by the VOC's direct reactions, the effect of the VOC's reactions on the rates of reaction of other VOCs [by affecting the levels of hydroxyl $(\mathrm{OH})$ radicals that react with VOCs], and the reactivities of the VOCs products. In addition, the amount of ozone formation caused by a VOC differs depending on the environment where it is emitted. The level of $\mathrm{NO}_{\mathrm{X}}$ is the most important single factor, because no ozone can be formed if $\mathrm{NO}_{\mathrm{X}}$ is absent, and VOCs have their greatest effect on ozone (their maximum reactivities) when $\mathrm{NO}_{\mathrm{X}}$ is abundant. However, other environmental factors will also affect a VOC's reactivity.

- Two general types of approaches can be used for assessing ozone impacts of VOCs: conducting scenario-specific assessments or developing general VOC reactivity scales. A scenario-specific assessment is a model simulation whose objective is to estimate, as accurately as possible given the limitations of the available data and the type of model employed, the air quality impacts of some specific emissions change in a specific airshed scenario. A general reactivity scale is a method for 
ranking ozone impacts applicable for a generic set of conditions (such as, for example, high $\mathrm{NO}_{\mathrm{x}}$ conditions or conditions most favorable for ozone formation), or derived with the intention of being generally applicable.

- Examples of scenario-specific assessments include modeling studies of methanol fuel substitution carried out by Russell and co-workers (Russell, 1990; Russell et al., 1989, 1990) using a comprehensive model, and by Chang and co-workers (Chang et al., 1989, 1990) using box models, and include the modeling being carried out by AQIRP. Methanol substitution modeling results thus far indicate that such substitution is beneficial, but that the benefits are less in downwind areas. AQIRP results thus far indicate that changing aromatic, olefin, sulfur, and oxygenate content of gasolines can be beneficial, but lead to only small decreases $(<5 \%)$ in ozone concentrations.

- Most general reactivity scales are based on "incremental reactivities" of VOCs. This is defined as the change in ozone caused by adding a small amount of the VOC to the emissions, divided by the amount added. This takes into account the effects of all aspects of the organic's reaction mechanism, and also the effects of the environment where the VOC is emitted. Because it depends on environmental conditions, the incremental reactivity of a VOC under ambient conditions cannot practically be measured directly, but can be estimated by computer model calculations. Although strictly measuring only effects of small VOC changes, calculations have shown that the incremental reactivity of a VOC can provide a reasonably good approximation of the effects of larger VOC emissions changes, up to $\sim 25 \%$ or more of the total VOC emissions. However, the incremental reactivity of a VOC varies significantly with $\mathrm{NO}_{\mathrm{x}}$ levels and other environmental conditions, and for many types of VOCs ratios.

- Because reactivity depends on environmental conditions, different scales are needed to address different environmental conditions. Among the scales that have been developed are the Maximum Incremental Reactivity (MIR) scale, derived from impacts of the VOCs on peak ozone concentrations under high $\mathrm{NO}_{x}$ conditions where $\mathrm{O}_{3}$ is most sensitive to VOC emissions; the Maximum Ozone Incremental Reactivity (MOIR) scale, derived from impacts of VOCs on peak ozone concentrations under lower $\mathrm{NO}_{\mathrm{x}}$ conditions most favorable for $\mathrm{O}_{3}$ formation, and various "base-case" scales designed to represent conditions of specific episodes.

- The MIR scale is used to calculate the reactivity adjustment factors in CARB's reactivity-based emissions standards. This is used because it represents conditions most sensitive to VOC emissions changes. However, for AFV assessments, we recommend using a range of reactivity scales to determine the distribution of impacts in a wide variety of environmental conditions. The predictions of reactivity scales should be verified using comprehensive model calculations.

\section{Recommendations for Future Research}

- The data base of emissions must continue to be improved, in both quality and quantity, if a fair assessment of AFVs is to be made.

- Procedures for collecting and evaluating emissions data for gasoline and AFVs need to be improved so that they more accurately simulate driving conditions that occur in the real world. This should include the continued development of analytical instrumentation for on-road and real-time emission evaluation and the development of improved chassis dynamometer testing protocols. 
- A comprehensive analysis of the propagation of uncertainties throughout the entire fuel and vehicle system must be conducted. The overall uncertainty of the analysis is important from a policy perspective. From a research perspective, is important to know which of the many uncertainties are the most important in affecting the ozone impact prediction, and where research resources need to be directed to reduce this uncertainty.

- In the long term, the most valuable research for improving our ability to predictively model ozone formation from vehicle emissions will be aimed at improving our understanding of the fundamental atmospheric processes involved. For atmospheric chemistry, this includes elucidating the reaction pathways and products formed in the oxidations of VOC species, such as aromatics, which are currently represented in the model with parameterized mechanisms. This also includes improving the accuracy of the computational methods used to represent transport and diffusion.

- In the more immediate term, the priorities for atmospheric chemistry research include improving the quality and comprehensiveness of the mechanism evaluation data base, improving the level of chemical detail that can be represented in comprehensive models, and improving our ability to quantify the effects of chemical mechanism uncertainties on airshed model results.

- Complex grid models are not appropriate for systematic uncertainty analysis because of the many variables that would need to be examined in any comprehensive propagation of error analysis. The use of such complex, highly computer intensive models would not be practical for this task. Thus, atmospheric processes would have to be represented using box models or reactivity scales calculated by box models. Complex models have an important supporting role in error analysis, however, in ensuring that the results obtained from simpler models are reasonable given the range of conditions occurring in real atmospheres. More research and global analysis are needed to understand the uncertainty of these models. 


\subsection{Introduction}

During the past two decades there has been a considerable effort in the U.S. to develop and introduce into society an alternative to the use of gasoline and conventional diesel fuel for transportation. The primary motives for this effort have been twofold: energy security and improvement in air quality-most notably ozone, or smog. The anticipated improvement in air quality is associated with a decrease in the atmospheric reactivity, and sometimes a decrease in the mass emission rate, of the organic gas and $\mathrm{NO}_{\mathrm{X}}$ emissions from alternative fuels when compared to conventional transportation fuels. Quantification of these air quality impacts is a prerequisite to decisions on adopting alternative fuels. The purpose of this report is to present a critical review of the procedures and data base used to assess the impact on ambient air quality of mobile source emissions from alternative and conventional transportation fuels and to make recommendations as to how this process can be improved.

For the purpose of this report, we will define alternative transportation fuels as methanol, ethanol, compressed natural gas (CNG), liquefied petroleum gas (LPG), and reformulated gasoline. Most of our discussion will center on light-duty AFVs operating on these fuels. Other advanced transportation technologies and fuels such as hydrogen, electric vehicles, and fuel cells, will not be discussed. However, the issues raised herein can also be applied to these technologies and other classes of vehicles, such as heavy-duty diesels (HDDs).

An evaluation of the overall impact of AFVs on socièty requires consideration of a number of complex issues. It involves the development of new vehicle technology associated with engines, fuel systems, and emission control technology; the implementation of the necessary fuel infrastructure; and an appropriate understanding of the economic, health, safety, and environmental impacts associated with the use of these fuels. This report will address only the steps necessary to properly evaluate the impact of AFVs on ozone air quality.

The overall process for evaluating of the ozone impacts of alternative fuel use consists of the following distinct but coupled stages:

- The appropriate quantification of the mass emission rate and chemical species of running loss, evaporative, and tailpipe emissions

- The accurate determination of the contribution of these emissions to the total emission inventory of a specific urban area

- The development and evaluation of chemical mechanisms for predicting the atmospheric transformations by which the emitted pollutants form ozone

- The development and evaluation of complex urban and regional airshed models for the prediction of the change in the atmospheric ozone and other pollutant concentrations resulting from changes in emissions

- The applications of these models and emissions data to the assessment of the air quality impacts of alternative fuels over the full range of applicable conditions

- An assessment of the uncertainties of each of these stages and an evaluation of the uncertainty of the overall impact assessment. 
Before an air quality model is used to estimate air quality impacts, it is necessary to establish the reliability of its components and of the model as a whole. For example, the chemical mechanism incorporated in the model must be tested by comparing its estimates of the concentrations of ozone and associated species with corresponding measurements from carefully controlled smog chamber experiments using a full range surrogate of $\mathrm{VOC}$ and $\mathrm{NO}_{\mathrm{X}}$ emissions. In addition, the predictions of the full model should be compared to actual observed ozone concentrations for the urban area.

This report provides a critical review of each of the above steps. We begin in Section 2 with a summary of the emissions data base presently available for AFVs and a review of the research programs currently in progress. Specific attention will be given to the technologies represented by the vehicles tested, the chemical speciation of the exhaust from various fuels, and the mass emission rates of these vehicles. This is followed in Section 3 with a critical evaluation of the emission models used to obtain mobile source emissions inventories, i.e., EPA's MOBILE model and CARB's EMFAC suite of models. In Section 4 we review and evaluate the current generation of air quality models used to predict how emissions affect air quality, and briefly discuss how the various governing processes involved are represented in the models. In Section 5, we review the chemistry of ozone formation and the chemical mechanisms that have been used to represent these reactions. In Section 6, we discuss how the reactivity of VOC emissions can be assessed.

Our recommendations on future research are given in Section 7. These include areas of research and emission testing needed to decrease the uncertainty of air quality predictions. Improving the quality of the emissions data is clearly a critical area of research, particularly for the representation of emissions from different driving modes and in-use deterioration factors. For modeling effects of AFV use, our major recommendation is that any assessment of the effects of alternative fuel use include estimates of the magnitudes of all the major uncertainties involved, and a determination of how the uncertainties affect the results of the overall assessment. 


\subsection{Emission Data of Alternative Fuel Vehicles}

\subsection{Background}

The most important requirement for evaluating the environmental impact of AFVs is a robust and representative data base of the emissions from vehicles operating on the different fuels. This should include information on the in-use emission rates of tailpipe emissions of $\mathrm{NMOG}^{1}, \mathrm{NO}_{\mathrm{x}}$, and $\mathrm{CO}$; an evaluation of the running loss and evaporative emissions of these vehicles; emission measurements from low and high mileage vehicles; and a detailed characterization of the chemical composition of the exhaust. Most importantly, the vehicles from which these data are derived should be representative of the types of engines, fuel systems, and emission control technologies that will appear on the road.

This section provides an overview of the current status of emissions data available for AFVs. Specific attention is given to whether the available data can be used to evaluate the environmental impacts of AFVs, and to what extent the data meet the requirements stated above. The information is based on an extensive search of the published literature, and personal contacts from industry, regulatory agencies, and federal laboratories. More than 150 technical papers and reports of emissions tests on alternative fuel engines and AFVs were reviewed. These references are included in Section 8.0. This information represents a snapshot in time, as the data base for alternative fuel vehicles is expanding rapidly.

Over the past two decades, numerous programs have been designed to further develop AFV technology. Most have involved small fleets of either retrofitted production gasoline vehicles, specially-built demonstration vehicles, or production vehicles that have been up-fitted by an OEM. Many of the fleets have been either bi-fuel or variable-fuel ${ }^{2}$. For the most part, the goals of these programs focused on technology development issues such as fuel/material compatibility, fuel metering systems, engine design, and on-road performance and drivability. Few of these initial fleets were designed-or intended-to meet any certification standard or fuel economy goal, although limited emissions and fuel economy data were collected on most. An assessment of the environmental impact of these vehicles was done primarily by examining the chemical composition of the exhaust and comparing it to comparable vehicles operating on gasoline. With more detailed hydrocarbon (HC) speciation of exhaust and evaporative emissions, our understanding of the chemical nature of the exhaust has increased considerably, especially in recent years. Over the past several years, CARB has used this chemical information to develop RAFs for most alternative fuels used for certifying advanced vehicles. The reactivity issue will be discussed more extensively in subsequent sections.

1 Organic compounds are specified differently throughout this document in keeping with the literature. The term non-methane organic gas (NMOG) is used in conjunction with vehicle emission tests. The terms reactive organic gases (ROGs) and volatile organic compounds (VOCs) are used in subsequent chapters.

2 The terms flexible fuel vehicle (FFV) and variable fuel vehicle (VFV) are manufacturers' designations for vehicles that can operate on variable fuel blends. A shorthand notation is typically used for methanol/gasoline fuels that describes the volume percent of the fuel that is methanol. M0, for example, denotes zero percent methanol, while M85 is a mixture of $85 \%$ methanol and $15 \%$ gasoline.

The bi-fuel designation is used for vehicles that can operate on two different fuels, but not simultaneously. These vehicles typically have on-board storage for both fuels (e.g., gasoline and natural gas). 
It is important to recognize that while the studies to date have provided chemical composition information about the exhaust and, to some extent, information on relative emission rates compared to gasoline vehicles, they are not generally useful in determining a fleet average emissions rate in $\mathrm{g} / \mathrm{mile}$. This is because the tests to date have been conducted mostly at low mileages and on only a limited number of predominantly developmental vehicles. We have also observed that the variability of the emissions rate from vehicle-to-vehicle is large for all vehicle types regardless of fuel. These factors, in turn, have made it difficult to quantify the mass emission rates for AFVs operating on any fuel, and hence, difficult to quantify future air quality improvements resulting from the use of alternative fuels. The lack of sufficient emissions data for methanol fuel vehicles, for example, has resulted in considerable range of predictions of the impact of these vehicles on ozone air quality. These differences ranged from predictions of an $80 \%$ improvement in ozone air quality (Gray and Alson, 1989) to, in some cases, an increase in ozone production (AQIRP ${ }^{3}, 1992 \mathrm{a}$ ). These differences in the predictions of future air quality were not the result of uncertainty in the reactivity of the exhaust species, but in the lack of knowledge of the in-use mass emission rates of the NMOG species, $\mathrm{NO}_{\mathrm{X}}$, and $\mathrm{CO}$ used in the air quality calculations.

The situation has improved considerably during the past few years as a result of several important factors:

- Federal legislation, most notably AMFA, has resulted in several successful programs (e.g., the United States Department of Energy's [DOE's] Alternative Fuels Utilization Program) that have accelerated the use and testing of AFVs nationwide.

- CARB has established a reactivity-based emission standard for alternative fuels to coincide with its future emission standards. This has resulted in continued pressure to further develop AFVs and has established a clear emission target for vehicle manufacturers and the retrofit industry to meet. AFV emission rates have decreased dramatically over the past several years because of the emissions challenges set by the transitional low-emission vehicle (TLEV), low-emission vehicle (LEV), ultra low-emission vehicle (ULEV), and zero-emission vehicle (ZEV) standards ${ }^{4}$ (Bailey, 1994).

- EPA, CARB, DOE, and industry (through AQIRP) have collectively developed the analytical procedures needed to provide reliable emission measurements of AFVs. In addition, several large AFV testing programs are now under way-most notably the AMFA and the CleanFleet AFV demonstration programs, and the CARB LEV certification testing and RAF evaluation programs.

In general, however, the available data still suffer from many of the shortcomings discussed above. Following is a brief overview of the emissions data currently available for AFVs and a summary of the programs presently under way. For convenience, we have divided this section by fuel type. Tables summarizing the recent emissions testing of vehicles for each fuel are included at the end of each subsection.

3 The Auto/Oil Air Quality Improvement Research Program was established in 1989 by 14 oil companies and 3 domestic automobile manufacturers to develop data on vehicle emissions, air-quality, modeling studies, and economic analyses that could be used to help legislators and regulators meet the nation's clean air goals.

4 For low-emission vehicles, emission standards are set for 50,000 miles and 100,000 miles. These emissions standards in grams per mile for NMOG, NOx, and CO, respectively, are: $0.125,0.4$, and 3.4 for TLEV; 0.075 , 0.2, and 3.4 for LEV; 0.04, 0.2, 1.7 for ULEV; and 0, 0 , and 0 for ZEV at 50,000 miles; and $0.156,0.6$, and 4.2 for TLEV; $0.090,0.3$, and 4.2 for LEV; 0.055, 0.3, and 2.1 for ULEV; and 0,0 , and 0 for ZEV at 100,000 miles. 


\subsection{Methanol}

To date, methanol fuel vehicles have been the most extensively tested of the AFVs. This is primarily because of an early perception of EPA, CARB, and the California Energy Commission (CEC) that methanol would be the most likely alternative fuel to strongly penetrate the gasoline market. As early as 1981 methanol demonstration fleets were in operation in California (Nichols, 1983). This interest in methanol fuel vehicles has sparked research at a number of institutions, including EPA (Black and Gabele, 1991; Gabele and Knapp, 1993; Gabele and Black, 1993; Gabele, 1990; Bruetsch and Hellman, 1992; Hellman and Piotrowski, 1990); CARB (1991a, 1991b); AQIRP (1992a, 1992b); CEC (Blackburn, 1994) General Motors (GM) (Kirwan, 1993; Williams et al., 1990) and foreign auto makers (Myung et al., 1991; Myung et al., 1993; Nishide et al., 1992). While future technologies are included in some of these programs (see below), much of the published research to date has been performed on a limited number of prototype vehicles. As discussed above, this information is primarily useful in understanding the chemistry of the exhaust or in making simple comparisons with gasoline vehicles. It is questionable whether it is adequate for quantifying of methanol emission rates of vehicles that would operate on the road. Additionally, most tests were performed on vehicles that had been driven less than 50,000 miles. As such, the effects of aging on methanol AFVs are not well known. It has been observed, however, that the efficiency of the catalyst in controlling formaldehyde emission deteriorates with mileage (Black and Gabele, 1991; Gabele and Knapp, 1993).

Although most methanol fuel vehicles tested have been prototypes, production vehicles and vehicles delivered straight from the OEMs have also been tested, including tests for certification. Currently planned or available production vehicles include the Chevrolet Lumina, the Chrysler Dodge Spirit/Plymouth Acclaim, Chrysler Dodge Intrepid, and the Ford Taurus, all of which are FFVs that can operate on different blends of gasoline and methanol (DOE, 1994). The fleets for the ongoing AMFA and CleanFleet programs also contain methanol vehicles from the OEMs. AQIRP is reporting emissions from 1993 production model FFVs and variable fuel vehicles (VFVs) operating on M0, M10, and M85. GM has published emissions data on a production model VFV Lumina (Kirwan, 1993). These vehicles, as well as most of those tested since the late 1980 s, are typically equipped with a closed loop feedback system, fuel injection metering, and three-way catalysts.

Heavy-duty methanol engines and dedicated methanol vehicles, which are designed to run on a single fuel, have also been studied. EPA (Bruetsch and Hellman, 1992, Hellman and Piotrowski, 1990), CARB (1991a), GM (Williams et al., 1990), and the AQRIP (1992b) have all tested prototype vehicles dedicated to run on methanol fuels. Heavy-duty vehicles fueled by methanol (and other alternative fuels) have been dynamometer tested at the Los Angeles County Metropolitan Transportation Authority (LACMTA) in Los Angeles, CA (Dunlap et al., 1993, Unnasch et al., 1993) and at the CARB facility in El Monte, CA (Montemayor et al., 1992). West Virginia University has developed a transportable heavy-duty vehicle emissions testing laboratory that has been used to conduct chassis dynamometer tests on heavy-duty vehicles operated on methanol and other alternative fuels (Wang et al., 1993a). Caterpillar (Richards, 1990, Waldman, 1990), Detroit Diesel Corporation (DDC) (Miller and Savonen, 1990) and other institutions, such as the Southwest Research Institute (Carroll et al., 1990; Bechtold et al., 1991) have also published dynamometer test results for HDD engines operating on methanol. The CEC is testing M100 and M85 school buses with DDC 6V92 engines as part of the Safe School Bus Clean Fuel Efficiency Demonstration Program. A summary of the more recent methanol vehicle emissions programs is given in Table 2.1. 
Table 2.1. Summary of Recent Emissions Tests on Methanol Fuel Vehicles and Engines

\begin{tabular}{|c|c|c|c|c|}
\hline Source & Reference & Vehicles Studied & Fuel Type & Comments \\
\hline Acurex & $\begin{array}{l}\text { Montemayor, } \\
1992\end{array}$ & Asphalt Hauler & Meth/Avocet & $\begin{array}{l}\text { CARB 8-mode Chassis Test } \\
\text { Cummins L-10 Engine }\end{array}$ \\
\hline \multirow[t]{3}{*}{ AMFA } & Kelly, 1994 & $\begin{array}{l}\text { Taurus (7) } \\
\text { Lumina (7) }\end{array}$ & M85, FFV & Phase 1 \\
\hline & & 1993 Dodge Spirit (78) & M85, FFV & Phase 2, Summer 1994 \\
\hline & & $\begin{array}{l}1992 \text { Ford Econoline Van (16) } \\
1993 \text { Ford Econoline Van }(3)\end{array}$ & M85, FFV & Phase 3, Fall 1994 \\
\hline \multirow[t]{4}{*}{ AQIRP } & Gorse, 1994 & 1993 Production FFV/VFVs & $\mathrm{M}(0,10,85)$ & Completed \\
\hline & Gorse, 1994 & Production FFV/VFVs & & $\begin{array}{l}\text { High speed and acceleration } \\
\text { driving cycle } \\
\text { In Progress }\end{array}$ \\
\hline & AQIRP, 1992a & $\begin{array}{l}\text { Chrysler (4) } \\
\text { Ford (7) } \\
\text { GM (8) }\end{array}$ & M10, M85 & Prototypes \\
\hline & AQIRP, 1992b & $\begin{array}{l}\text { Lumina } \\
1988 \text { Nissan Sentra } \\
1989 \text { Toyota Corolla }\end{array}$ & $\begin{array}{l}\text { M85 } \\
\text { M100 } \\
\text { M100 }\end{array}$ & Prototypes \\
\hline \multirow[t]{2}{*}{ CEC } & Blackburn, 1994 & $\begin{array}{l}1991 \text { Ford Taurus } \\
1993 \text { Ford Taurus } \\
1992 \text { Chevrolet Lumina (2) } \\
1992 \text { Mitsubishi Galant }\end{array}$ & M0, M85 & $\begin{array}{l}\text { Speciated HCs on some vehicles } \\
\text { Federal Test Procedure (FTP), } \\
\text { Highway Fuel Economy (HFE) } \\
\text { test }\end{array}$ \\
\hline & Hill, 1994 & Heavy-Duty School Buses & M85, M100 & $\begin{array}{l}\text { DDC 6V-92 Engines } \\
\text { Low Mileage }\end{array}$ \\
\hline \multirow[t]{3}{*}{ CARB } & CARB, 1994a & $\begin{array}{l}1995 \text { Ford Taurus } \\
1994 \text { Dodge Spirit/Plymouth } \\
\text { Acclaim }\end{array}$ & M0-M85 & Certification Tests \\
\hline & CARB, 1991a & $\begin{array}{l}1986 \text { Ford Crown Victoria (2) } \\
1989 \text { Toyota Corolla } \\
1987 \text { Ford Crown Victoria (4) } \\
1988 \text { Chevy Corsica (10) } \\
1988 \text { Nissan Stanza } \\
1990 \text { Toyota Corolla } \\
1990 \text { Plymouth Voyagers (10) } \\
\text { (from SCAQMD) } \\
1986 \text { Toyota Camry } \\
1988 \text { Chevy Corsica } \\
1989 \text { Crown Victoria } \\
\text { VW Jetta }\end{array}$ & $\begin{array}{l}\text { M85, FFV } \\
\text { M85, FFV } \\
\text { M85, FFV } \\
\text { M85, FFV } \\
\text { M85, FFV } \\
\text { M85, FFV } \\
\text { M85, FFV } \\
\text { M85 } \\
\text { Meth, VFV } \\
\text { Meth } \\
\text { M90 }\end{array}$ & 11th Interim Report \\
\hline & CARB, 1991b & $\begin{array}{l}1991 \text { VW Jetta, FFV } \\
1991 \text { Chevrolet Lumina VFV } \\
1990 \text { Dodge Spirit (Auto/Oil) } \\
1990 \text { Chevrolet Lumina ( } 2 \text { from } \\
\text { Auto/Oil) } \\
1989 \text { Dodge Caravan (Auto/Oil) } \\
1988 \text { Dodge Caravan (Auto/Oil) } \\
\text { 1988 Chevrolet Corsica ( } 2 \text { from } \\
\text { Auto/Oil) }\end{array}$ & M85 & $\begin{array}{l}\text { RAF Program } \\
\text { TLEV Vehicles } \\
\text { Speciated HCs }\end{array}$ \\
\hline Caterpillar & $\begin{array}{l}\text { Waldman, } 1990 \\
\text { Richards, } 1990\end{array}$ & Caterpillar 3406 Engine & Methanol & Heavy-Duty Engine \\
\hline CleanFleet & $\begin{array}{l}\text { Battelle Memorial } \\
\text { Institute, } 1994\end{array}$ & 1992 FFV Ford Vans (3) & M85 & $\begin{array}{l}3 \text { rounds of emissions tests } \\
1 \text { round of evaporative tests } \\
\text { Speciated HCs }\end{array}$ \\
\hline
\end{tabular}


Table 2.1 (Cont.)

\begin{tabular}{|c|c|c|c|c|}
\hline Source & Reference & Vehicles Studied & Fuel Type & Comments \\
\hline $\begin{array}{l}\text { Coordinating } \\
\text { Research } \\
\text { Council }\end{array}$ & $\begin{array}{l}\text { Hoekman \& } \\
\text { Jensen, } 1993\end{array}$ & 1987 Ford Crown Victoria & M85 & $\begin{array}{l}\text { Tested at } 16 \text { labs } \\
\text { Study interlab variability }\end{array}$ \\
\hline $\mathrm{DDC}$ & \begin{tabular}{|l|} 
Miller and \\
Savonen, 1990 \\
\end{tabular} & DDC 6V-92TA & & Heavy-Duty Engine \\
\hline EA Mueller & $\begin{array}{l}\text { Bechtold et al., } \\
1991 \\
\end{array}$ & $\begin{array}{l}\text { Detroit Diesel Corp. 8V-71 } \\
\text { Model Year } 1979\end{array}$ & & Heavy-Duty Engine \\
\hline \begin{tabular}{l|} 
EPA \\
(Research \\
Triangle Park)
\end{tabular} & Gabelle, 1994 & $\begin{array}{l}1991 \text { VFV } \\
1993 \text { Lumina } \\
1993 \text { FFV }\end{array}$ & $\begin{array}{l}\text { M85 } \\
\text { M85 } \\
\text { M85 }\end{array}$ & $\begin{array}{l}\text { Vehicles for Phase } 2 \text { of AMFA } \\
\text { program } \\
\text { Speciated HCs }\end{array}$ \\
\hline $\begin{array}{l}\text { EPA } \\
\text { (Research } \\
\text { Triangle Park) }\end{array}$ & $\begin{array}{l}\text { Gabele and Black, } \\
1993\end{array}$ & $\begin{array}{l}1991 \text { Lumina } \\
1991 \text { Taurus }\end{array}$ & M20, M85 & $\begin{array}{l}\text { Vehicles for Phase } 1 \text { of AMFA } \\
\text { Program } \\
\text { Speciated HCs }\end{array}$ \\
\hline $\begin{array}{l}\text { EPA } \\
\text { (Research } \\
\text { Triangle Park) }\end{array}$ & $\begin{array}{l}\text { Gabele \& Knapp, } \\
1993\end{array}$ & 1987 Ford Crown Victoria & M85, FFV & Vehicle mileage was 25,000 \\
\hline $\begin{array}{l}\text { EPA } \\
\text { (Ann Arbor) }\end{array}$ & \begin{tabular}{|l|} 
Bruetsch and \\
Hellman, 1992 \\
\end{tabular} & VW Jetta & M100 & Dedicated Vehicle \\
\hline \begin{tabular}{l|} 
EPA \\
(Research \\
Triangle Park)
\end{tabular} & $\begin{array}{l}\text { Black and Gabele, } \\
1991\end{array}$ & $\begin{array}{l}1987 \text { Ford Crown Victoria (2) } \\
1988 \text { Chevy Corsica }\end{array}$ & $\begin{array}{l}\mathrm{M} 85 \\
\mathrm{M}(25,50,85, \\
100) \\
\end{array}$ & $\begin{array}{l}\text { Speciated HCs } \\
\text { Evaporative }\end{array}$ \\
\hline \begin{tabular}{l|} 
EPA \\
(Research \\
Triangle Park)
\end{tabular} & Gabele, 1990 & 1988 GM VFV Corsica & $\begin{array}{l}\mathrm{M}(0,25,50 \\
85,100)\end{array}$ & $\begin{array}{l}\text { Speciated } \mathrm{HCs} \\
\text { Evaporative }\end{array}$ \\
\hline $\begin{array}{l}\text { EPA } \\
\text { (Ann Arbor) }\end{array}$ & $\begin{array}{l}\text { Hellman and } \\
\text { Piotrowski, } 1990\end{array}$ & $\begin{array}{l}\text { Toyota Corolla } \\
\text { Nissan Sentra } \\
\end{array}$ & M100 & Dedicated Vehicles \\
\hline GM & Kirwan, 1993 & Chevrolet VFV Lumina (3) & M85 & Production Vehicle \\
\hline$\overline{\mathrm{GM}}$ & $\begin{array}{l}\text { Williams et al., } \\
1990\end{array}$ & $\begin{array}{l}\text { VFV (1) } \\
\text { Dedicated Methanol Vehicle (1) }\end{array}$ & $\begin{array}{l}\text { M15, M50 } \\
\text { M85, M100 }\end{array}$ & One Dedicated Vehicle \\
\hline Hyundai & Myung, 1993 & 1991 Hyundai Scoupe & M85, FFV & Prototype \\
\hline Hyundai & Myung, 1991 & Prototype Vehicle & M85, FFV & Prototype \\
\hline LACMTA & Dunlap, 1993 & Transit Buses & $\begin{array}{l}\text { M100 } \\
\text { Meth/Avocet }\end{array}$ & $\begin{array}{l}\text { Heavy-Duty } \\
\text { Chassis Dynamometer }\end{array}$ \\
\hline Nissan & $\begin{array}{l}\text { Nishide et al., } \\
1992\end{array}$ & 1991 FFV NX Coupe & M0, M85 & Prototype \\
\hline Nissan & $\begin{array}{l}\text { Kajima et al., } \\
1991\end{array}$ & 3 different vehicle/engine types & M85 & Prototype \\
\hline $\begin{array}{l}\text { Orange } \\
\text { County } \\
\text { Transp. } \\
\text { Authority }\end{array}$ & $\begin{array}{l}\text { Unnasch et al., } \\
1993\end{array}$ & Gillig 40TB96 Phantom Buses & $\begin{array}{l}\text { Methanol } \\
\text { +Avocet }\end{array}$ & $\begin{array}{l}\text { Cummins L-10 Engine } \\
\text { Chassis Dynamometer tests at } \\
\text { LACMTA }\end{array}$ \\
\hline $\begin{array}{l}\text { Southwest } \\
\text { Research } \\
\text { Institute }\end{array}$ & Carroll et al., 1990 & Detroit Diesel Corp. 6V-92TA & & Heavy-Duty Engine \\
\hline Toyota & $\begin{array}{l}\text { Yasuda et al., } \\
1989\end{array}$ & Toyota Corolla Sedan & & Prototype \\
\hline $\begin{array}{l}\text { West Virginia } \\
\text { University } \\
\end{array}$ & Wang et al., 1993a & Heavy-Duty Vehicles & Methanol & Chassis Dynamometer \\
\hline
\end{tabular}


Some of the ongoing programs that provide useful information for the development of methanol emission factors are described here in more detail.

AQIRP has several ongoing studies involving methanol vehicles (Gorse, 1994). A series of emission tests has been completed on 1993 production FFVs and VFVs operating on M0, M10 and M85, and the results should be available shortly. In addition, emission tests on production FFV and VFV methanol vehicles over the EPA high speed/high acceleration driving cycle have been completed and are being analyzed.

Several studies have been previously published by AQIRP regarding methanol AFVs (AQIRP, 1992a, 1992b). Although the vehicles used in these studies are not very representative of current technology, the results were used to conduct urban airshed model (UAM) calculations, which are discussed in greater detail later in this report. In particular, these studies outline procedures for calculating emission factors for methanol vehicles that can be used in the EMFAC and MOBILE emission models (AQIRP, 1993a). The first study reported the effects of methanol/gasoline mixtures on vehicle emissions from a fleet of 19 pre-1990 prototype FFVs and VFVs using gasoline, M10 and M85 (AQIRP, 1992a). These vehicles were supplied by Chrysler (four vehicles/two models), Ford (seven vehicles/three models) and GM (eight vehicles/ two models) and had mileages ranging between 9,000 and 33,000. In the second study, three prototype dedicated methanol vehicles (M85 Chevrolet Lumina, M100 Nissan Sentra, M100 Toyota Corolla) were tested (AQIRP, 1992b).

CARB has also developed a relatively large emissions data base on methanol vehicles as a result of several programs. Much of CARB's more recent work has focused on the development of RAFs for AFVs. These RAFs are designed to provide a comparison of the different reactivities of the NMOG portion of the exhaust from vehicles operated on different fuels. The reactivity of the exhaust emissions can then be compensated for when the vehicles are certified. The development of RAFs requires the full speciation of measurable NMOG in the exhaust, and thus provides considerable insight into the exhaust chemical composition. CARB has conducted tests on LEV- and TLEV-certified methanol vehicles as part of this program (CARB, 1991b, 1994b). Other work on methanol vehicles is included in the Alternative Fuel and Advanced Technology Vehicle Fleet Program Eleventh Interim Report, which was issued in July 1991 (CARB, 1991a). Most vehicles in this report were representative of late-1980s technology. CARB is currently involved in testing of methanol delivery vans for the CleanFleet program.

Other ongoing programs that involve methanol vehicles include the AMFA (Kelly, 1994) and CleanFleet programs (Battelle Memorial Institute, 1994). In the first phase of the AMFA program, seven 1991 FFV M85 Ford Tauruses and seven 1991 VFV Chevy Luminas were tested for emissions. This phase of the project is essentially complete. Seventy-eight 1993 M85 Dodge Spirits are currently being tested in Phase 2. In Phase 3, which was initiated toward the end of the summer in 1994, an additional 19 Ford M85 Econoline vans are to be tested. The testing procedure for the AMFA program includes FTP tests with full speciation on $15 \%$ of the vehicles. When possible, vehicles are tested at $4,000,10,000$ and 20,000 miles so that in-use deterioration rates can be obtained. Data from these tests are continually added to the National Renewable Energy Laboratory's (NREL's) Alternative Fuels Data Center (AFDC). EPA is among the institutions currently involved in testing AMFA fleet vehicles for Phases 1 and 2 (Gabele and Black, 1993; Gabele, 1994). The CleanFleet program has just released early emissions results for its fleet vehicles. This report covers the first round of emissions tests, which were performed on methanol vans with mileages ranging from 5,300 to 6,500. Additional tests are planned at approximately 14,000 miles and at the end of the project. 


\subsection{Ethanol}

The emissions database for ethanol fuel vehicles is considerably smaller than that for methanol vehicles, although it is growing. Ethanol vehicles have been incorporated into several ongoing programs including the AMFA and AQIRP programs. Twenty-five 1992 E85 Luminas are currently being tested as part of Phase 2 of the AMFA program and, in 1995, E85 Ford Tauruses will be incorporated into Phase 4 of this program (Kelly, 1994). AQIRP is also planning to test E85 FFVs and VFVs over the FTP and the EPA high speed/high acceleration driving cycle during the last two quarters of 1994 (Gorse, 1994). Another AQIRP evaluation of ethanol vehicles operating on E0 and E85 is expected to commence by early 1995.

In addition to these current studies are some published results on ethanol vehicle emissions. A study was done by the EPA comparing FTP emissions of two 1992 VFV Chevrolet Luminas operating on ethanol and indolene (Samulski, 1994). Gabele, et al. have also done some emissions testing on vehicles using E85 and E10 as part of the AMFA cooperative program with DOE (Gabele and Black, 1993).

CARB has conducted some emissions tests on E85 vehicles. Some of this work was performed as part of the program to develop RAFs for alcohol TLEVs (CARB, 1991b). In earlier tests, CARB collected emissions data from two FFV Ford Crown Victorias operated on E95 and E85 (CARB, 1989). These vehicles were not designed to operate on ethanol and, as such, were not optimized for low emissions. An FFV Ford Crown Victoria tested on E85 was also included in the Alternative Fuel and Advanced Technology Vehicle Fleet Program Eleventh Interim Report.

Among the institutions that have tested ethanol fuel vehicles are the Istanbul Technical University (Karaosmanoglu et al., 1993) and the AVL-List GmbH (Quissek et al., 1992). Chassis and engine dynamometer emissions test results are available for heavy-duty engines operating on ethanol (King and Prakash, 1992; Carroll et al., 1990; Bechtold et al., 1991). A summary of recent emissions tests of ethanol fuel vehicles is given in Table 2.2.

\subsection{Natural Gas}

Emission measurements on NGVs indicate that these vehicles have the best potential to meet the CARB ULEV emissions standard. To date, most of the published emissions data for light-duty NGVs have used vehicles converted to $\mathrm{CNG}$ operation using aftermarket conversion kits. Many were bi-fuel vehicles, designed to operate on both gasoline and CNG. Both open and closed loop control systems have been tested. For the most part, these converted vehicles were not optimized for CNG use. As with methanol demonstration vehicles, emission data from these vehicles can be used for obtaining chemical speciation on the exhaust, but are not always useful for determining mass emission rates needed in air quality calculations. 
Table 2.2. Summary of Recent Emissions Tests on Ethanol Fuel Vehicles and Engines

\begin{tabular}{|c|c|c|c|c|}
\hline Source & Reference & Vehicles Studied & Fuel Type & Comments \\
\hline \multirow[t]{2}{*}{ AMFA } & Kelly, 1994 & 1992 Luminas (25) & E85 & Phase 2 \\
\hline & Kelly, 1994 & E85 Taurus & E85 & Phase 4 \\
\hline \multirow[t]{2}{*}{ AQRIP } & Gorse, 1994 & E85 FFVs/VFVs & E85 & High speed \& acceleration driving cycle \\
\hline & & Several FFVs/VFVs & E0, E85 & Commences 3rd quarter 1994 \\
\hline $\begin{array}{l}\text { AVL-List } \\
\text { GmbH }\end{array}$ & $\begin{array}{l}\text { Quissek, et al., } \\
1991\end{array}$ & Ethanol Engines & & \\
\hline Canada & $\begin{array}{l}\text { King and Prakash, } \\
1992\end{array}$ & $\begin{array}{l}40 \mathrm{ft} \text { Bus from } \\
\text { Motor Coach Industries }\end{array}$ & Ethanol & $\begin{array}{l}\text { Heavy-Duty Vehicle } \\
\text { DDC Engine } \\
\text { Chassis Dynamometer Tests }\end{array}$ \\
\hline \multirow[t]{3}{*}{ CARB } & CARB, 1991b & $\begin{array}{l}1991 \text { VW Jetta } \\
1991 \text { Chevrolet Lumina }\end{array}$ & $\mathrm{E} 85$ & $\begin{array}{l}\text { RAF Program } \\
\text { TLEV Vehicles } \\
\text { Speciated HCs }\end{array}$ \\
\hline & CARB, 1991a & Ford Crown Victoria & E85 & 11th Interim Report \\
\hline & CARB, 1989 & Ford Crown Victoria (2) & E85, E95 & \\
\hline \begin{tabular}{l|} 
EPA \\
(Research \\
Triangle Park) \\
\end{tabular} & Gabele, 1994 & $\begin{array}{l}1993 \text { Lumina } \\
1993 \text { FFV }\end{array}$ & $\begin{array}{l}\text { E85 } \\
\text { E85 }\end{array}$ & Vehicles for Phase 2 of AMFA program \\
\hline $\begin{array}{l}\text { EPA } \\
\text { (Ann Arbor) }\end{array}$ & Samulski, 1994 & Chevy Lumina (2) & E85 & \\
\hline $\begin{array}{l}\text { EPA } \\
\text { (Ann Arbor) } \\
\end{array}$ & $\begin{array}{l}\text { Gabele and Black, } \\
1993\end{array}$ & $\begin{array}{l}1991 \text { Lumina } \\
1991 \text { Taurus } \\
\end{array}$ & $\begin{array}{l}\text { E85 } \\
\text { E85 } \\
\end{array}$ & Vehicles for Phase 1 of AMFA program \\
\hline
\end{tabular}

Although the situation will change in the near future, few emissions data are available on production NGVs other than low mileage and some certification data (CARB, 1994a). CARB and EPA's Research Triangle Park laboratory have both performed speciated emissions tests on NGVs (Black and Gabele, 1991; Gabele, et al., 1990, CARB, 1991a, 1994b). From our assessment, the most representative data base is that developed by CARB as part of its program to develop RAFs for CNG vehicles (CARB, 1994b). In particular, the vehicles for this program were chosen to represent future technology vehicles. Currently, CARB is involved in testing CNG delivery vans for the CleanFleet program.

For testing retrofitted CNG vehicles, several programs have reported highly variable emissions, with some emissions higher than comparable gasoline fuel vehicles (Colorado Department of Health, 1993; AFDC, 1994; Urban Consortium Energy Task Force, 1994; Cox et al., 1994). On further review, however, we found that many of these conversion kits are not necessarily representative of current or future technologies. Nevertheless, this has resulted in controversy related to a potential requirement for full certification of all vehicles equipped with conversion kits. At a minimum, these results show the importance of the technical quality of the kits, post-conversion assurance of proper operation, and periodic maintenance checks.

Although the data base is small, results from in-use production vehicles have shown significantly lower emissions than those of converted vehicles. Production CNG vehicles have been certified to meet ULEV standards (CARB, 1994a). In recently published results from the CleanFleet program, a production Dodge CNG van demonstrated lower emissions relative to the control vans than any fleet of AFVs. The Dodge van showed reductions in $\mathrm{CO}, \mathrm{NO}_{\mathrm{x}}$, and $\mathrm{NMOG}$ mass emissions and reductions in the calculated 
ozone reactivity of the NMOG portion of the exhaust (Battelle Memorial Institute, 1994). A CNG vehicle from an OEM was studied by the City of Houston and demonstrated favorable emissions results (Urban Consortium Energy Task Force, 1994).

Natural gas is also being promoted as an alternative fuel for heavy-duty vehicles. The use of natural gas in heavy-duty engines is promising from an environmental perspective because of the low reactivity of the VOCs and the low particulate emissions compared to HDD engines. In addition, required space and payload for storage cylinders is typically less of a problem on heavy-duty vehicles. The Southwest Research Institute and the Gas Research Institute have worked in concert with several OEMs to develop stoichiometric, lean burn, and dual-fuel natural gas engines. A number of HDD engines from different manufacturers have been converted to natural gas operation and subsequently tested for emissions including engines from Cummins (Meyer et al., 1992; Sharp et al., 1993), GM (Snyder and Boschi, 1993), Hercules (Cole et al., 1993; Meyer et al., 1991), Tecogen (Norman, 1991), Volvo (Beaty et al., 1992), Caterpillar (Waldman, 1990) and DDC (Jeske, et al., 1991), among others. Data are also available for chassis dynamometer tests of CNG-HDD vehicles (Crane and King, 1992; Dunlap et al., 1993; Unnasch et al., 1993; Wang et al., 1993a, 1993b; Fritz and Egbuonu, 1993, Urban Consortium Task Force, 1994). Additional studies of engine dynamometer tests of CNG fuel engines are described in publications by Jaaskelainen and Wallace, 1993a, 1993b; Karim et al., 1993; Swain et al., 1993; Varde et al., 1992.

Currently, several ongoing projects could provide more information on in-use emissions of current technology production vehicles. For example, approximately 451992 CNG Dodge Ram vans are being tested along with a limited number of CNG Chevy pickups in Phase 2 of the AMFA program. Other tests of converted CNG vehicles are already under way. Future work, as part of Phase 4 of the project, will include the testing of CNG fuel minivans from Chrysler.

The CleanFleet program has just released low mileage emissions results from nine CNG fuel delivery vans from Ford, Dodge, and Chevrolet with mileages ranging from 4,300 to 11,600. The Dodge CNG van is the only production AFV used in the CleanFleet. As discussed above, the Dodge van demonstrated both favorable mass and reactivity-weighted emissions. The CNG vans from Chevrolet and Ford also demonstrated lower $\mathrm{CO}$ and reactivity weighted NMOG emission when compared to the control vans. Only the $\mathrm{NO}_{\mathrm{x}}$ emissions from the Ford van were greater than those from the gasoline vans.

AQIRP has several programs currently involving CNG vehicles (Gorse, 1994). Tests using CNG vehicles over the EPA high speed/high acceleration driving cycle are expected to be completed over the last two quarters of 1994. An evaluation of CNG prototype vehicles on several fuels is also in progress. A summary of recent emissions tests on CNG vehicles is given in Table 2.3.

\subsection{LPG-Propane}

Although LPG is the third most popular fuel worldwide (after gasoline and diesel fuel), research and development of LPG fuel light-duty vehicles has lagged behind that of other AFVs. The reason for this is that the propane industry has not marketed propane as a fuel for transportation as aggressively as the other fuel industries (Lyons and McCoy, 1993). Limited participation from the OEMs has also resulted in a considerably smaller vehicle fleet to study. Thus, most published emissions tests have been performed on retrofitted vehicles. 
Table 2.3. Summary of Recent Emissions Tests on CNG Fuel Vehicles and Engines

\begin{tabular}{|c|c|c|c|c|}
\hline Source & Reference & Vehicles Studied & Fuel Type & Comments \\
\hline AQIRP & Gorse, 1994 & CNG vehicles & $\mathrm{CNG}$ & $\begin{array}{l}\text { In progress } \\
\text { Prototypes over a wide range of } \\
\text { fuels } \\
\text { Also High Speed \& Acceleration } \\
\text { Driving Cycles }\end{array}$ \\
\hline \multirow[t]{2}{*}{ AMFA } & Kelly, 1994 & $\begin{array}{l}\text { 1992, } 1994 \text { Dodge Ram Van (45) } \\
1992 \text { Chevy Pickups }\end{array}$ & $\begin{array}{l}\text { CNG } \\
\text { CNG }\end{array}$ & Phase 2 \\
\hline & Kelly, 1994 & Chrysler Minivans & $\mathrm{CNG}$ & Phase 4 \\
\hline $\begin{array}{l}\text { Arizona Dept. } \\
\text { Environmental } \\
\text { Quality }\end{array}$ & Cox, et al., 1994 & $\begin{array}{l}21 \text { vehicles model year } 1983 \text { - } \\
1993\end{array}$ & $\mathrm{CNG}$ & In-use data \\
\hline CEC & Blackburn, 1994 & 1992 GMC Sierra Pick-up & $\mathrm{CNG}$ & \\
\hline \multirow[t]{3}{*}{$\overline{\mathrm{CARB}}$} & CARB, 1994a & $\begin{array}{l}1994 \text { Chrysler Minivan } \\
1994 \text { Chrysler Full-size }\end{array}$ & $\mathrm{CNG}$ & Certification Tests \\
\hline & CARB, $1994 b$ & $\begin{array}{l}1991 \text { Chevrolet Lumina } \\
1992 \text { Chevrolet Sierra } \\
1992 \text { Chevrolet Corsica } \\
1992 \text { Ford Ranger } \\
\text { 1992 Ford Crown Victoria } \\
\text { 1991 Plymouth Acclaim } \\
\text { 1990 Dodge Caravan }\end{array}$ & $\mathrm{CNG}$ & $\begin{array}{l}\text { RAF program } \\
\text { LEV, ULEV Vehicles } \\
\text { Speciated HCs }\end{array}$ \\
\hline & CARB, 1991a & $\begin{array}{l}1990 \text { Buick LeSabre } \\
1990 \text { Ford Taurus } \\
1990 \text { Dodge Dynasty (2) } \\
1990 \text { Chevy Astro Van } \\
1990 \text { Ford Club Wagon } \\
\text { 1990 Ford F350XLT Truck }\end{array}$ & CNG & $\begin{array}{l}\text { 11th Interim Report } \\
\text { Dual-Fuel Vehicles }\end{array}$ \\
\hline Caterpillar & Waldman, 1990 & Caterpillar 3406 Engine & CNG & Heavy-Duty Engine \\
\hline $\begin{array}{l}\text { Colorado Dept. } \\
\text { of Health }\end{array}$ & $\begin{array}{l}\text { Colorado Dept. of } \\
\text { Health, } 1993\end{array}$ & GRI \& ANGI Certification Kits & CNG & $\begin{array}{l}\text { In-Use Vs. Certification } \\
\text { Highly variable results }\end{array}$ \\
\hline $\begin{array}{l}\text { Houston, } \\
\text { City of }\end{array}$ & $\begin{array}{l}\text { Urban Consortium } \\
\text { Energy Task Force }\end{array}$ & & CNG & In-use data \\
\hline LACMTA & $\begin{array}{l}\text { Dunlap, et al., } \\
1993\end{array}$ & Transit Buses & $\mathrm{CNG}$ & $\begin{array}{l}\text { Heavy-Duty } \\
\text { Chassis Dynamometer }\end{array}$ \\
\hline $\begin{array}{l}\text { Michigan, } \\
\text { University of }\end{array}$ & Varde, et al., 1992 & Spark-Ignition (SI) Engine (2) & $\mathrm{CNG}$ & Engine Dynamometer \\
\hline $\begin{array}{l}\text { Orange County } \\
\text { Transportation } \\
\text { Authority }\end{array}$ & $\begin{array}{l}\text { Unnasch, et al., } \\
1993\end{array}$ & Gillig 40TB96 Phantom Buses & CNG & $\begin{array}{l}\text { Cummins L10 Engine } \\
\text { Chassis Dynamometer tests at the } \\
\text { LA County MTA }\end{array}$ \\
\hline \multirow{5}{*}{$\begin{array}{l}\text { Southwest } \\
\text { Research } \\
\text { Institute }\end{array}$} & $\begin{array}{l}\text { Crane and King, } \\
1992\end{array}$ & Caterpillar 1Y540 & CNG & $\begin{array}{l}\text { Heavy-Duty Engine } \\
\text { Engine Dynamometer }\end{array}$ \\
\hline & $\begin{array}{l}\text { Snyder and } \\
\text { Boschi, } 1993\end{array}$ & A GM 7.0 L engine & CNG & Medium-duty Engine \\
\hline & Beaty, et al., 1993 & Volvo 9.6L diesel engine & $\mathrm{CNG}$ & Heavy-Duty Engine \\
\hline & Cole, et al., 1993 & $\begin{array}{l}\text { Hercules GTA3.7L } \\
\text { Hercules GTA5.6L }\end{array}$ & CNG & Medium-Duty Engines \\
\hline & Sharp, et al., 1993 & Cummins L10-240G Engine & $\mathrm{CNG}$ & Heavy-Duty Engine \\
\hline \multirow[t]{2}{*}{. } & $\begin{array}{l}\text { Fritz and } \\
\text { Egbuonu, } 1993\end{array}$ & $\begin{array}{l}1988 \text { Ford F700 Trucks (2) } \\
1986 \text { GMC Trucks (2) }\end{array}$ & $\mathrm{CNG}$ & $\begin{array}{l}\text { Heavy-Duty } \\
\text { Chassis Dynamometer }\end{array}$ \\
\hline & Meyer, et al., 1992 & A $320 \mathrm{~kW}$ diesel Engine & $\mathrm{CNG}$ & Heavy-Duty Engine \\
\hline
\end{tabular}


Table 2.3. (Cont.)

\begin{tabular}{|c|c|c|c|c|}
\hline Source & Reference & Vehicles Studied & Fuel Type & Comments \\
\hline & Meyer, et al., 1991 & Hercules 3.7L Engine & CNG & Medium-Duty Engine \\
\hline Tecogen Inc. & Norman, 1991 & TecoDrive 7000 & CNG & Medium-Duty Engine \\
\hline $\begin{array}{l}\text { Toronto, } \\
\text { University of }\end{array}$ & $\begin{array}{l}\text { Jaaskelainen, } \\
\text { 1993a } \\
\text { Jaaskelaimen, } \\
\text { 1993b }\end{array}$ & Nissan SR20DE & CNG & Engine Dynamometer \\
\hline $\begin{array}{l}\text { West Virginia } \\
\text { University }\end{array}$ & $\begin{array}{l}\text { Wang, et al., } \\
1993 \mathrm{~b}\end{array}$ & $\begin{array}{l}12 \text { CNG fueled transit buses with } \\
\text { Cummins L } 10 \text { engines }\end{array}$ & CNG & $\begin{array}{l}\text { Heavy-Duty Vehicles } \\
\text { Chassis Dynamometer }\end{array}$ \\
\hline
\end{tabular}

The most comprehensive emissions studies to date on LPG vehicles have been done by CARB, which has released speciated emissions data that were used to obtain preliminary RAFs for LPG fuel vehicles (CARB, 1994b). Seven converted LPG vehicles were used for these tests. Of these, five were able to attain the LEV standard and two attained the ULEV standard. CARB is currently involved in testing the emissions of LPG fuel vehicles for the CleanFleet program.

Similar to the situation with CNG vehicles, the quality of a conversion kit can have a substantial effect on the emissions performance of an LPG vehicle. Earlier studies by CARB of in-use converted LPG vehicles found higher $\mathrm{CO}$ and NMOG emissions for these vehicles compared to the unconverted gasoline vehicles (Lyons and McCoy, 1993). Investigation of the conversion equipment showed that, in some cases, the systems had been improperly installed and/or maintained. The Colorado Department of Health has also done some testing of in-use converted LPG vehicles (Colorado Department of Health, 1993). These results were compared to the new vehicle emissions certification standards and to emissions results of vehicles used to achieve certification of the particular conversion kit. The results show that the emissions from retrofitted LPG vehicles were highly variable, and in some cases were higher than those of comparable gasoline vehicles.

Other research organizations that have tested or are now testing LPG vehicles include GM (Hilden et al., 1991), the Southwest Research Institute (Bass et al., 1993), and the AMFA, Auto/Oil AQIRP and CleanFleet programs. This should eventually lead to a significantly improved database for LPG fuel vehicles. The results from low mileage tests of propane fleet vehicles in the CleanFleet program are now available. Tests on LPG conversions are part of the AMFA program (Kelly, 1994). Currently, it is planned to test the vehicles both before and after the conversions. The Auto/Oil AQIRP plans to test LPG fuel vehicles over the EPA high speed/high acceleration driving cycle during the last two quarters of 1994 (Gorse, 1994). The Auto/Oil AQIRP is also currently testing some prototype LPG fuel vehicles. A summary of recent emissions test on LPG fuel vehicles is given in Table 2.4.

\subsection{Reformulated Gasoline}

Probably the most extensive investigation to date of reformulated gasoline emissions is AQIRP (1990, 1991a, 1991b, 1991c, 1991d). The fleet used in these tests was divided into two groups: current vehicles and older vehicles. The current fleet consisted of 201989 model year vehicles with mileages ranging from 10,000 to 30,000 , and the older fleet consisted of 14 vehicles with model years from 1983 to 1985 and mileages ranging from 40,000 to 80,000 . The fuel metering systems on the current vehicles were mostly fuel injection, and those on the older vehicles were primarily carburetion. 
Table 2.4. Summary of Recent Emissions Tests on LPG Fuel Vehicles and Engines

\begin{tabular}{|c|c|c|c|c|}
\hline Source & Reference & Vehicles Studied & Fuel Type & Comments \\
\hline AQIRP & Gorse, 1994 & LPG vehicles & LPG & $\begin{array}{l}\text { In progress } \\
\text { Some prototypes over a wide range } \\
\text { of fuels } \\
\text { Also High Speed/Acceleration } \\
\text { Driving Cycle }\end{array}$ \\
\hline AMFA & Kelly, 1994 & Converted LPG Vehicles & LPG & $\begin{array}{l}\text { Tests done before and after } \\
\text { conversion }\end{array}$ \\
\hline CARB & CARB, 1994b & $\begin{array}{l}1991 \text { Lumina } \\
1992 \text { Taurus } \\
1992 \text { Century } \\
\text { 1993 Euro Lumina } \\
1992 \text { Century } \\
\text { 1993 Taurus } \\
\text { 1993 Regal } \\
\end{array}$ & $\begin{array}{l}\text { LPG } \\
\text { LPG } \\
\text { LPG } \\
\text { LPG } \\
\text { LPG } \\
\text { LPG } \\
\text { LPG }\end{array}$ & $\begin{array}{l}\text { RAF Program } \\
\text { LEV, ULEV Vehicles } \\
\text { Speciated HCs }\end{array}$ \\
\hline CARB & CARB, 1991a & $\begin{array}{l}1989 \text { Oldsmobile Delta } 88 \\
1990 \text { Pontiac } 6000\end{array}$ & $\begin{array}{l}\text { LPG, DFV } \\
\text { LPG, DFV }\end{array}$ & 11th Interim Report \\
\hline $\begin{array}{l}\text { Colorado } \\
\text { Dept of } \\
\text { Health }\end{array}$ & $\begin{array}{l}\text { Colorado Dept. of } \\
\text { Health, } 1993\end{array}$ & Impco Certification Kits & LPG & $\begin{array}{l}\text { In-Use vs. Certification } \\
\text { Highly Variable Results }\end{array}$ \\
\hline EPA & Gabele, 1994 & 1993 Ford F-150 & LPG & $\begin{array}{l}\text { Vehicles for Phase } 2 \text { of the AMFA } \\
\text { Program }\end{array}$ \\
\hline Finland & $\begin{array}{l}\text { Nylund and } \\
\text { Riikonen, } 1991 \\
\text { Nylund and Kyto, } \\
1993\end{array}$ & $\begin{array}{l}\text { Finnish Sisu Truck } \\
\text { MAN bus }\end{array}$ & LPG & \\
\hline GM & Hilden et al., 1991 & 1990 Buick Le Sabre & LPG & \\
\hline $\begin{array}{l}\text { Southwest } \\
\text { Research } \\
\text { Institute } \\
\end{array}$ & Bass et al., 1993 & 1992 Lumina & LPG & LPG Conversion \\
\hline
\end{tabular}

The effects of changing a number of different fuel formulation parameters on emissions of total hydrocarbons (THCs), non-methane hydrocarbons ( $\mathrm{NMHCs),} \mathrm{CO}, \mathrm{NO}_{\mathrm{x}}$, benzene, 1,3-butadiene, formaldehyde, acetaldehyde, and evaporative and running loss emissions were examined. Included among the fuel parameters investigated were composition variables (aromatics, methyl tertiary butyl ether [MTBE], olefins, and the $90 \%$ fuel distillation temperature [T90]), Reid vapor pressure (RVP), oxygenates, and sulfur. Speciation was performed on at least one test per fuel/vehicle type to estimate the reactivity of the exhaust. The emissions results from these tests were incorporated into an air quality modeling program to determine the net effect of the emissions reductions caused by reformulated gasoline in comparison to methanol (AQIRP, 1991e, 1992a, 1993a).

Unfortunately, although AQIRP examined numerous reformulated fuels, those formulations differ from the planned specifications of Federal and California reformulated gasoline, and thus are of limited use for future air quality modeling. AQIRP has completed testing on current fleet gasoline vehicles operated on California Phase 2 gasoline fuels as part of a program to compare FTP speciated exhaust emissions with those from an EPA high speed/high acceleration driving cycle (Gorse, 1994). These data are currently being analyzed. 
Both CARB and EPA are involved in programs to study the effects of reformulated fuels. CARB has published the speciated emissions data used to derive RAFs for Phase 2 reformulated gasoline (CARB, 1993a), and is currently involved in emissions tests on reformulated gasoline delivery vans from the CleanFleet program. EPA has been involved in an impact analysis study of reformulated gasolines. As part of this program, EPA has compiled an extensive data base of emissions tests using reformulated fuels and performed in-house testing of the effects of different fuel reformulations.

Low mileage emissions from nine reformulated gasoline vans in the CleanFleet demonstration program have been reported (Battelle Memorial Institute, 1994). The nine vans varied in mileage from 2,400 to 11,100 and were representative of Ford, Chevrolet, and Dodge models. The average emissions for these vans were generally less than those of the control vans, but no emissions measurements for reformulated gasoline fuel vans were statistically different than the control vans.

Hoekman performed tests comparing the exhaust emissions from conventional and reformulated gasoline fuel vehicles (Hoekman, 1992). The reformulated fuels were blended to have a lower vapor pressure and distillation temperature, and an $11 \%$ concentration of MTBE. Nineteen vehicles were used for this study, with model years ranging from 1970 to 1989 and mileages ranging from 9,000 miles to 146,000 miles. The vehicles were classified into the following groups: non-catalyst, oxidation catalyst, three-way catalyst, and three-way catalyst with feedback. The results showed that the VOC emissions were reduced by $6 \%$ using reformulated gasoline. Detailed speciation was performed to determine the reactivity of the hydrocarbons. The results showed no statistically significant difference in the mass-normalized (i.e., $g$ of ozone/g of NMOG) reactivity between the standard gasoline and the reformulated gasoline. Thus, the primary reactivity benefit observed was caused by the reduction in mass emission rates. This has been observed by other researchers as well, and points to the need to establish deterioration rates for emission control systems used in vehicles operating on reformulated gasolines.

ARCO has developed a reformulated gasoline called EC-X, and has compared emissions results for this fuel and for gasoline. EC-X reductions relative to industry average gasoline have been found for NMOG $(41 \%), \mathrm{CO}(33 \%), \mathrm{NO}_{\mathrm{X}}(14 \%)$ and toxics (45\%) (Lippincott et al., 1993). ARCO also supplied EC-X to several automobile manufacturers to test in some of their prototype advanced technology vehicles. Specifications on these vehicles were not released because of their proprietary nature. However, reductions of NMOG (35\%), CO (35\%), and $\mathrm{NO}_{\mathrm{X}}(26 \%)$ were reported (ARCO, 1994). Speciation results were reported for different compound classes and for toxics. ARCO has also examined the effects of using oxygenated fuels in a Detroit Diesel Corporation (DDC) prototype Series 60 engine in conjunction with Southwest Research Institute (Liotta and Montalvo, 1993).

The effects of gasoline reformulation on exhaust emissions have also been examined by den Otter et al. at Shell Research Ltd. (den Otter, et al., 1993). For these tests four vehicles were used with mileages ranging from 10,000 to 17,000 . Three of the four vehicles were not equipped with catalysts to simulate the European market, where most cars do not have catalysts. The emissions while operating under four different fuels were investigated using the FTP with $\mathrm{HC}$ speciation. Reductions were observed in $\mathrm{HC}$, $\mathrm{CO}$, and $\mathrm{NO}_{\mathrm{X}}$ emissions. As could be expected, however, these reductions were small compared to the reductions caused by adding a catalyst. A summary of recent emissions tests on reformulated gasoline fuel vehicles is given in Table 2.5. 
Table 2.5. Summary of Recent Emission Tests on Reformulated Gasoline Fuel Vehicles

\begin{tabular}{|c|c|c|c|c|}
\hline Source & Reference & Vehicles Studied & Fuel Type & Comments \\
\hline $\mathrm{ARCO}$ & ARCO & 1990 Vehicles (10) & EC-X & ARCO EC-X gasoline tested \\
\hline ARCO & \begin{tabular}{|l|} 
Liotta and \\
Montalvo, 1993 \\
\end{tabular} & DDC 1991 Series 60 & Reformulated & $\begin{array}{l}\text { Oxygenated Fuels } \\
\text { Heavy-Duty Engine }\end{array}$ \\
\hline ARCO & $\begin{array}{l}\text { Lippincott et al., } \\
1993 \\
\end{array}$ & Passenger Cars (31) & EC-X & ARCO EC-X gasoline tested \\
\hline AQIRP & Gorse, 1994 & Current Fleet Gasoline Vehicles & $\begin{array}{l}\text { California } \\
\text { Phase } 2\end{array}$ & $\begin{array}{l}\text { High speed/High acceleration } \\
\text { driving cycle } \\
\text { Testing complete } \\
\text { Data being analyzed }\end{array}$ \\
\hline AQIRP & Gorse, 1994 & Current and Older Fleet Vehicles & Reformulated & $\begin{array}{l}\text { Follow to AMOT matrix study in } \\
\text { from Phase } 1 \\
\text { In progress }\end{array}$ \\
\hline AQIRP & $\begin{array}{l}\text { AQIRP, 1990, } \\
1991 \mathrm{a}, \mathrm{b}, \mathrm{c}, \mathrm{d}\end{array}$ & \begin{tabular}{|l|}
1989 Model (20)- Current Fleet \\
1983-1985 Model (14)-Older Fleet
\end{tabular} & Reformulated & $\begin{array}{l}\text { Results used in Air Quality } \\
\text { Modeling }\end{array}$ \\
\hline CARB & CARB, 1993 & & \begin{tabular}{|l|} 
California \\
Phase 2 \\
\end{tabular} & $\begin{array}{l}\text { RAF Program } \\
\text { Speciated HCs }\end{array}$ \\
\hline Chevron & Hoekman, 1992 & $\begin{array}{l}19 \text { vehicles model years } \\
1970 \text { to } 1990\end{array}$ & Reformulated & \\
\hline Shell & $\begin{array}{l}\text { den Otter et al., } \\
1993\end{array}$ & 1989 and 1990 Vehicles (4) & Reformulated & $\begin{array}{l}3 \text { vehicles were non-catalyst to } \\
\text { represent current European Fleet }\end{array}$ \\
\hline
\end{tabular}

\subsection{Evaporative and Running Loss Emissions}

For the most part, the data presented in the previous sections were tailpipe measurements for vehicles operating over the FTP. In addition to tailpipe measurements, evaporative and running loss emissions from AFVs must be considered in emissions inventory and air quality modeling. Although the data base is very small, some speciated evaporative emissions data for AFVs (mostly methanol and ethanol) and several other ongoing studies address this issue. EPA is probably the best source for this information (Gabele, 1990; Gabele and Knapp, 1993; Gabele and Black, 1993, Black and Gabele, 1991). In their most recent work, Gabele and Black collected data from the AMFA fleet vehicles, which are representative of future technologies and thus appropriate for use in modeling AFVs (Gabele and Black, 1993).

Several other organizations have generated speciated evaporative emissions results. Speciated evaporative emissions were collected as part of the early AQIRP on methanol vehicles (AQIRP, 1992a). These results were included in the air quality modeling studies done by SAI for AQIRP. The results of this study will be discussed later. The vehicles involved in the earlier phases of AQIRP were older, however, and may not have been equipped with the most current evaporative control technology. The AMFA and CleanFleet demonstration programs are collecting evaporative emissions. About $15 \%$ of the evaporative emissions data collected for the AMFA program will be speciated. The CleanFleet program has scheduled evaporative emissions measurements as part of the second round of emissions tests, which will be performed at approximately 14,000 miles (Battelle Memorial Institute, 1994). 


\subsection{Developing Emission Factors for AFVs: Chemical Species}

To obtain an estimate of the environmental impact of AFVs, the emission measurements described above must provide information on the mass emission rates for $\mathrm{CO}, \mathrm{NO}_{\mathbf{x}}$, and NMOG; the chemical species of the NMOG for each fuel type; and the mass emission rate during on-road operation of the different AFVs, such as speed correction factors. In the next section, we will describe how the current models process this type of information to generate emission inventories for motor vehicles and how these models could be used for application to alternative fuels. Unfortunately, the data base for AFVs is considerably smaller than that for gasoline vehicles and, as we have mentioned before, many of the data are from development vehicles. Although several ongoing programs will provide new information, the variability in the AFV data base is now quite large and limits us from saying anything definitive about the overall emission rates of these vehicles. The situation is better regarding the chemical composition of the exhaust species, however.

In our opinion, the best currently available data base for exhaust emission characteristics of AFVs is that generated by CARB in its effort to develop RAFs (CARB, 1991, 1993a, 1994b). In particular, this data base contains a detailed HC species profile of the exhaust, which allows for the identification of the chemical species of the different alternative fuels. The vehicles used in this work are also certified and representative of future technology that may eventually be part of the vehicle fleet. We have analyzed this data base with particular emphasis on the chemical species profile of the different fuels. A summary of this analysis is presented here.

Speciated emissions data from the CARB RAF data base (CARB 1991b, 1993a, 1994b) are presented in Tables 2.6 - 2.10 for methanol (M85), ethanol (E85), natural gas, propane, and reformulated gasoline, respectively. The tables include a listing of the average percentage contribution, and standard deviation, of the major chemical species and chemical classes to the total NMOG mass, and of the mass emission rate in $\mathrm{g} /$ mile for total $\mathrm{NMOG}, \mathrm{CO}$, and $\mathrm{NO}_{\mathrm{x}}$. These numbers represent a composite average of the data and, in some cases, vehicles from more than one future certification class. The fleet consisted of vehicles from more than one certification class and with different mileage accumulation. A summary of the average, high, and low mileage for the various vehicles in each fuel class is presented in Table 2.11. For the most part, each fuel type was represented with vehicles that have similar control technology and comparable mileage. Unfortunately, the fleet did not contain any high mileage vehicles, nor did it contain data for a single vehicle with multiple tests with increased mileage accumulation. Thus, there is little information on the deterioration rates or on the in-use emission characteristics of these vehicles. Also, only the major chemical components of the NMOG mass are listed in Tables $2.6-2.10$. The species not included, however, compose a relatively small percentage of the NMOG mass; i.e., less than $20 \%$ for reformulated and industrial average gasoline and less than $10 \%$ for the other alternative fuels. The complete list of species is available on request. 
Table 2.6. Emissions Profile for Methanol (M85) Fuel Vehicles. Percentage Breakdown of NMOG Species in Tailpipe Emissions.

\begin{tabular}{|l|c|c|}
\hline & Average & $\begin{array}{c}\text { Standard } \\
\text { Deviation }\end{array}$ \\
\hline By Category (in \%) & & \\
\hline Light End & 3.75 & 1.00 \\
\hline Mid-Range & 9.10 & 2.03 \\
\hline Carbonyl & 87.15 & 2.76 \\
\hline By Species (in \%) & & \\
\hline Methanol & 80.04 & 4.45 \\
\hline Formaldehyde & 6.12 & 2.60 \\
\hline Toluene & 1.47 & 0.36 \\
\hline n-butane & 1.14 & 0.71 \\
\hline Ethene & 0.98 & 0.36 \\
\hline Methylbutane & 0.68 & 0.35 \\
\hline m- \& p-xylenes & 0.53 & 0.59 \\
\hline Propene & 0.46 & 0.14 \\
\hline o-xylene & 0.40 & 0.17 \\
\hline Ethylbenzene & 0.39 & 0.09 \\
\hline n-pentane & 0.36 & 0.22 \\
\hline $1,2,4-t r i m e t h y l b e n z e n e$ & 0.30 & 0.20 \\
\hline Acetaldehyde & 0.25 & 0.23 \\
\hline Ethane & 0.24 & 0.22 \\
\hline Propane & 0.05 & 0.09 \\
\hline $\begin{array}{l}\text { Total Mass Emissions } \\
\text { (g/mi) }\end{array}$ & & \\
\hline Total NMOG & 0.20 & 0.08 \\
\hline CO & 1.77 & 0.67 \\
\hline NOx & 0.25 & 0.13 \\
\hline Derived from Studies & $t h e$ \\
\hline
\end{tabular}

Derived from Studies by the California Air Resources Board (CARB, 1991b, 1994b)
Table 2.7. Emissions Profile for Ethanol (E85) Fuel Vehicles. Percentage Breakdown of NMOG Species in Tailpipe Emissions.

\begin{tabular}{|c|c|c|}
\hline & Average & $\begin{array}{l}\text { Standard } \\
\text { Deviation }\end{array}$ \\
\hline \multicolumn{3}{|l|}{ By Category (in \%) } \\
\hline Light End & 12.20 & 2.38 \\
\hline Mid-Range & 4.71 & 2.34 \\
\hline Carbonyl & 83.08 & 3.92 \\
\hline \multicolumn{3}{|l|}{ By Species (in \%) } \\
\hline Ethanol & 72.77 & 3.91 \\
\hline Acetaldehyde & 7.82 & 0.98 \\
\hline Ethene & 4.81 & 0.64 \\
\hline Formaldehyde & 1.86 & 0.51 \\
\hline Ethyne & 1.76 & 0.65 \\
\hline Butane & 1.36 & 0.60 \\
\hline Ethane & 1.75 & 1.02 \\
\hline Toluene $+\mathrm{C}_{8} \mathrm{H}_{18}$ & 0.75 & 0.33 \\
\hline m \& p-Xylenes & 0.63 & 0.31 \\
\hline Propene & 0.46 & 0.10 \\
\hline $\begin{array}{l}\text { 2,2,4-Trimethylpentane } \\
\text { +alkene }\end{array}$ & 0.39 & 0.17 \\
\hline 2-Methylpropene & 0.23 & 0.04 \\
\hline Propane & 0.17 & 0.20 \\
\hline o-xylene & 0.14 & 0.12 \\
\hline $1,2,4$-Trimethylbenzene & 0.14 & 0.12 \\
\hline 3-Ethyltoluene & 0.10 & 0.09 \\
\hline 1,3,5-Trimethylbenzene & 0.06 & 0.05 \\
\hline \multicolumn{3}{|l|}{$\begin{array}{l}\text { Total Mass Emissions } \\
(\mathrm{g} / \mathrm{mi})\end{array}$} \\
\hline Total NMOG & 0.28 & 0.04 \\
\hline $\mathrm{CO}$ & 2.58 & 1.23 \\
\hline $\mathrm{NO}_{\mathrm{X}}$ & 0.25 & 0.16 \\
\hline
\end{tabular}

Derived from Studies by the California Air Resources Board (CARB, 1991b) 
Table 2.8. Emissions Profile for Natural Gas Fuel Vehicles. Percentage Breakdown of NMOG Species in Tailpipe Emissions.

\begin{tabular}{|l|c|c|}
\hline & Average & $\begin{array}{c}\text { Standard } \\
\text { Deviation }\end{array}$ \\
\hline By Category (in \%) & & \\
\hline Light End & 91.71 & 3.89 \\
\hline Mid-Range & 2.40 & 2.67 \\
\hline Carbonyl & 5.90 & 2.43 \\
\hline & & \\
\hline By Species (in \%) & & \\
\hline Ethane & 64.67 & 13.07 \\
\hline Propane & 16.00 & 6.51 \\
\hline Ethene & 5.09 & 2.29 \\
\hline Formaldehyde & 4.18 & 1.92 \\
\hline Methylbutane & 2.15 & 2.16 \\
\hline Propene & 0.72 & 0.34 \\
\hline Acetaldehyde & 0.72 & 0.31 \\
\hline & & \\
\hline $\begin{array}{l}\text { Total Mass Emissions } \\
\text { (g/mi) }\end{array}$ & & \\
\hline CH4 & 0.77 & 0.56 \\
\hline Total NMOG & 0.04 & 0.03 \\
\hline CO & 0.83 & 0.68 \\
\hline NO & 0.23 & 0.14 \\
\hline
\end{tabular}

Derived from Studies by the California Air Resources Board (CARB, 1994b)
Table 2.9. Emissions Profile for LPG-Propane Fuel Vehicles. Percentage Breakdown of NMOG Species in Tailpipe Emissions.

\begin{tabular}{|l|c|c|}
\hline & Average & $\begin{array}{c}\text { Standard } \\
\text { Deviation }\end{array}$ \\
\hline By Category (in \%) & & \\
\hline Light-End & 93.54 & 2.73 \\
\hline Mid-Range & 3.44 & 2.38 \\
\hline Carbonyl & 3.01 & 2.25 \\
\hline & & \\
\hline By Species (in \%) & & \\
\hline Propane & 74.32 & 6.90 \\
\hline Ethene & 5.52 & 1.82 \\
\hline Ethane & 4.55 & 4.60 \\
\hline Propene & 4.04 & 1.06 \\
\hline Formaldehyde & 1.82 & 1.38 \\
\hline Methylpropane & 1.57 & 0.43 \\
\hline Acetaldehyde & 0.62 & 0.31 \\
\hline 2-Methylpropene & 0.21 & 0.08 \\
\hline 1-Butene & 0.20 & 0.07 \\
\hline & & \\
\hline Total Mass Emissions & & \\
(g/mi) & & \\
\hline Total NMOG & 0.09 & 0.02 \\
\hline CO & 1.59 & 0.80 \\
\hline NO & 0.15 & 0.08 \\
\hline
\end{tabular}

Derived from Studies by the California Air Resources Board (CARB, 1991b, 1994b) 
Table 2.10. Emissions Profile for Industry Average and Phase 2 Gasoline Fuel Vehicles. Percentage Breakdown of NMOG Species in Tailpipe Emissions.

\begin{tabular}{|c|c|c|c|c|}
\hline & \multicolumn{2}{|c|}{ Industry Average } & \multicolumn{2}{|c|}{ Phase 2 Gasoline } \\
\hline & Average & $\begin{array}{l}\text { Standard } \\
\text { Deviation }\end{array}$ & Average & $\begin{array}{l}\text { Standard } \\
\text { Deviation }\end{array}$ \\
\hline \multicolumn{5}{|l|}{ By Category (in \%) } \\
\hline Light-End & 35.06 & 10.67 & 32.95 & 5.85 \\
\hline Mid-Range & 62.74 & 11.22 & 64.10 & 6.32 \\
\hline Oxygenates & 2.22 & 1.07 & 2.94 & 1.56 \\
\hline \multicolumn{5}{|l|}{ Light-End Species (in \%) } \\
\hline Ethane & 7.50 & 4.83 & 4.59 & 2.92 \\
\hline Ethene & 4.89 & 0.97 & 5.79 & 1.72 \\
\hline Ethyne & 1.99 & 1.69 & 2.56 & $1 . \overline{44}$ \\
\hline Butane & 6.13 & 2.03 & 1.48 & 0.96 \\
\hline Propene & 2.33 & 0.44 & 3.62 & 1.21 \\
\hline Propane & 0.41 & 0.24 & 0.48 & 1.45 \\
\hline Methylbutane & 7.34 & 4.53 & 8.48 & 2.44 \\
\hline Pentane & 2.80 & 0.68 & 1.11 & 0.45 \\
\hline 1-Butene & 0.35 & 0.11 & 0.48 & 0.20 \\
\hline 2-Methylpropene & 0.98 & 0.55 & 3.93 & 1.57 \\
\hline \multicolumn{5}{|l|}{ Mid-Range Species (\%) } \\
\hline 2-Methylpentane & 4.64 & 1.20 & 2.98 & 0.93 \\
\hline 3-Methylpentane & 2.37 & 0.47 & 1.52 & 0.60 \\
\hline n-Hexane & 2.14 & 0.92 & 0.80 & 0.26 \\
\hline Benzene & 5.13 & 1.61 & 3.81 & 1.35 \\
\hline 2,2,4-Trimethylpentane & 4.01 & 0.82 & 9.11 & 1.49 \\
\hline Toluene & 6.74 & 1.41 & 8.30 & 1.57 \\
\hline Ethylbenzene & 2.38 & 0.84 & 2.58 & 0.90 \\
\hline m \& p-Xylenes & 6.00 & 1.91 & 5.18 & 1.58 \\
\hline o-Xylenes & 2.36 & 0.87 & 2.01 & 0.65 \\
\hline 1,2,4-Trimethylbenzene & 2.33 & 1.23 & 1.28 & 0.67 \\
\hline \multicolumn{5}{|l|}{ Oxygenates (\%) } \\
\hline Formaldehyde & 1.23 & 0.79 & 1.82 & 1.29 \\
\hline \multicolumn{5}{|l|}{$\begin{array}{l}\text { Total Mass Emissions } \\
(\mathrm{g} / \mathrm{mi})\end{array}$} \\
\hline Total NMOG & 0.08 & 0.03 & 0.08 & 0.03 \\
\hline $\mathrm{CO}$ & 0.84 & 0.38 & 1.28 & 0.71 \\
\hline $\mathrm{NO}_{\mathrm{X}}$ & 0.30 & 0.23 & 0.21 & 0.17 \\
\hline
\end{tabular}

Derived from Studies by the California Air Resources Board (CARB, 1993a) 
Table 2.11 Vehicle Mileage for Tested Alternative Fuels Vehicles

\begin{tabular}{|l|c|c|c|c|}
\hline \multirow{2}{*}{ Fuel } & \multicolumn{4}{|c|}{ Mileage } \\
\cline { 2 - 5 } & Low & High & Standard \\
Derage & Deviation \\
\hline Methanol (M85) & 9,100 & 15,600 & 11,415 & 2,613 \\
\hline Ethanol (E85) & 9,100 & 9,300 & 9,200 & 141 \\
\hline LPG-Propane & 2,400 & 38,400 & 18,367 & 12,303 \\
\hline Natural Gas & 1,600 & 18,300 & 11,162 & 6,454 \\
\hline Reformulated Gasoline & 725 & 25,000 & 10,276 & 6,057 \\
\hline RF-A & 7,350 & 22,000 & 13,971 & 4,704 \\
\hline
\end{tabular}

Derived from Studies by the California Air Resources Board (CARB, 1991b, 1993a, 1994b)

The CARB data illustrate several important points regarding alternative fuels. As expected, there are significant differences in the chemical composition of the exhaust species for the different fuels. The chemical makeup for methanol, ethanol, natural gas, propane, and gasoline are very different and reflect the characteristics of the fuel. However, the variation in the chemical speciation of a given fuel type is much less dramatic. For example, methanol vehicles operating on M85 resulted in approximately $86 \%$ of the NMOG mass to be methanol $(80 \% \pm 4.5 \%)$ and formaldehyde $(6 \% \pm 2.6 \%)$. Similarly, ethanol vehicles operating on E85 had approximately $80 \%$ of the NMOG mass to be ethanol $(73 \% \pm 3.9 \%)$ and acetaldehyde $(7.8 \% \pm 1.0 \%)$. With the exception of gasoline, we probably can anticipate no major variation in the species profile as the emission data base becomes larger to include a broader range of emission control technologies and higher mileage vehicles. Thus, we recommend that the species profiles contained in Tables 2.6-2.10 be considered for use in the evaluation of the different alternative fuels and that the emission inventory and chemical mechanism contained in air quality models include the explicit consideration of the major compounds identified in these tables. The one caveat is that for natural gas and propane we need to review the percentage contribution of methane, ethane, and propane contained in the fuel, as there can be differences in the fuel composition in different parts of the country.

The CARB data also show that significant differences of the mass emission rates for total NMOG, $\mathrm{NO}_{\mathrm{X}}$, and $\mathrm{CO}$ can occur depending on the fuel. The greatest difference occurs for NMOG emission rates of natural gas and propane vehicles compared to those of other alternative fuels, although other smaller differences occur for $\mathrm{NO}_{\mathrm{x}}$ and $\mathrm{CO}$ for all of the fuels. These differences point for the need to carefully consider both the fuel and the vehicle emission standard for which the vehicle is certified when forecasting exhaust emission rates. It also points to the difficulty of including in any environmental analysis the impact of conversion kits if they have not been certified in some manner.

Finally, we want to emphasize that the data presented here do not include high mileage vehicles. In fact, little information is available on deterioration effects as a function of mileage for in-use AFVs. Several studies have shown that in-use emissions of all vehicles, including those operating on alternative fuels, can be highly variable and much higher than obtained from certification measurements (Colorado 
Department of Health, 1993; Cox et al., 1994; Urban Consortium Energy Task Force, 1994). At present, our opinion is that none of the available data substantiate the use of deterioration rates for AFVs that are different from those used for gasoline vehicles. The AMFA and CleanFleet programs may provide information that could be used to formulate fuel-specific deterioration rates, but these data have yet to be obtained. 


\subsection{Mobile Source Emission Inventory and Modeling}

In this section, the current approaches used for mobile source emission inventory modeling are reviewed, and the various procedures used for generating emission factors for conventional vehicles and AFVs are identified and compared. A rather extensive description of the input parameters used in the current generation of emission models is provided here to underscore the level of detail needed to modify them for use for alternative fuels. At present, the models used by EPA and CARB provide approximations of vehicle emissions based on statistical analyses of large emission data bases. The theoretical development of the functions, and the specific data bases used internally in the models are beyond the scope of this review. In the previous section we provided a summary of the emission data currently available for AFVs. Our intent here is to discuss how those data can be used to generate the AFV contribution to mobile source emission inventories.

\subsection{Review of Models}

Mobile source emissions estimates used throughout the U.S. for developing air pollution abatement strategies are generated by emission inventory models. The predominant models are the EMFAC modeling suite (CARB, 1993b), developed by CARB, and MOBILE (EPA, 1989), developed by EPA. Although the details may vary slightly, both models use two basic steps to calculate an emission inventory. The first step consists of determining a set of emission factors that specify the rate at which emissions are generated. In the second step, vehicle activity is estimated. The emission inventory for each pollutant is then calculated by multiplying the results of these two steps together.

The current methods used for determining emission factors are based on laboratory-established emission profiles for a wide range of vehicles with different types of emission control technologies and mileage accumulation. The emission factors are produced based on average driving characteristics embodied in a pre-determined driving cycle and, until recently, almost entirely based on the FTP (1989). This test cycle was originally developed in 1972 as a certification test and has a specified driving profile (speed versus time), which is intended to reflect actual driving conditions on arterial roads and highways. Emissions of $\mathrm{CO}, \mathrm{NO}_{\mathrm{x}}$, and $\mathrm{HC}$ are integrated and collected in separate bags for each of the three sections of the cycle and then used as base emission rates. The adequacy of the FTP to represent current on-road driving behavior has been a subject of considerable research in recent years (CRC-APRAC, 1991; 1992; 1994). EPA has initiated a program to investigate the applicability of the FTP and revise it (Markey, 1993). It is generally agreed that the current methods underestimate the actual emissions of gasoline vehicles by as much as a factor of three. This has a profound effect on any assessment of AFVs and will naturally lead to an underestimation of their impact. Thus, any improvement in the methods used to calculate mobile source inventories of gasoline vehicles will also improve our ability to assess the environmental impact of AFVs. We think that this should be made a high priority. This issue will be discussed later in this document.

Adjustments are made to the base emission rates through a set of correction factors. For each FTP bag there are correction factors which are used to adjust the basic emission rates to reflect the observed differences between different modes of operation. There are also temperature correction factors and speed correction factors, used to adjust the emission rates for non-FTP speeds. These speed correction 
factors are derived from limited off-cycle testing (speeds greater than $57 \mathrm{mi} / \mathrm{h}$, accelerations greater than $3.3 \mathrm{mi} / \mathrm{h}-\mathrm{s}$ ) performed on laboratory dynamometers.

Originally, these emission models were not designed to evaluate the impact of reformulated fuels, new technologies, and new control strategies. Recent revisions have allowed them to address the use of reformulated gasoline. These models are in a constant state of change. For example, both EMFAC and MOBILE are being modified to include the impact of several alternative fuels, and to improve the models prediction of emissions from current in-use gasoline vehicles.

Both EMFAC and MOBILE are statistical models. Each step in the process of generating an emission factor is determined empirically by using a look-up table or a statistically derived function. In addition to these established and approved models, new, disaggregate models based on modal emissions data and functional representations of on-road vehicle operation are being developed. One such model is the Integrated Transportation and Emissions Model (ITEM) (Barth and Norbeck, 1993). ITEM is expected to be able to produce emission inventories with greater accuracy as a large data base of modal emission data is assembled. Comparisons of EMFAC, MOBILE, and ITEM are now under way (Barth and Norbeck, 1994).

\subsubsection{EMFAC Specifications}

EMFAC (CARB, 1993b) is CARB's computer model for estimating on-road mobile source emissions for California vehicles. It consists of three computer programs: WEIGHT (E7FWT), EMFAC7F and BURDEN. It is usually referred to as the EMFAC suite (Maldonado, 1991, 1992; CARB, 1993b) but has also been referred to as the Motor Vehicle Emissions Inventory (MVEI) program (Maldonado et al., 1993). The data that provide the basis for EMFAC are obtained from extensive testing of motor vehicles conducted by CARB and EPA. The output from EMFAC can then be used, along with estimates of vehicle activity, in air quality modeling inventory calculations such as BURDEN (CARB, 1993b) and in microscale models such as CALINE (Benson, 1984).

The latest version of EMFAC is EMFAC7F. This version produces composite emission factors for:

- Total organic gases

- Carbon monoxide

- Oxides of nitrogen

- Exhaust particulate matter

- Particulate matter due to tire wear

- Evaporative emissions

- Fuel economy data.

The magnitudes of the above emission factors are obtained by empirical parameterization of:

- The emitting process (e.g., cold start emissions, hot soak evaporative emissions, etc.) 
- The vehicle type (e.g., light-duty auto, heavy-duty truck), and technology group (catalyst, non-catalyst, diesel)

- Ambient temperature

- Vehicle speed

- Calendar year (composite emission factors available for each year from 1975 to 2010).

EMFAC allows the user to specify any calendar year from the above domain and can incorporate adjustment factors from a look-up table for up to 25 temperatures and 25 speeds.

\subsubsection{MOBILE Specifications}

MOBILE (EPA, 1989) is the EPA's computer model used to estimate on-road motor vehicle emissions for states other than California. Similar to EMFAC, this model estimates exhaust, evaporative, running loss, idling, and refueling emission rates of $\mathrm{HCs}, \mathrm{CO}$, and $\mathrm{NO}_{\mathrm{x}}$ in units of $\mathrm{g} /$ mile. The emission factors are calculated for a fleet of vehicles representing the 25 model years previous to the calendar year of interest. In addition, it calculates emission factors for eight types of highway vehicles over a range of user-specified conditions, such as average speed and ambient temperature. The latest versions of MOBILE are MOBILE5 and its modified version MOBILE5a.

MOBILE is similar to EMFAC, but has several key differences:

- MOBILE calculates composite FTP exhaust emissions (cold start, hot stabilized, and hot start), whereas EMFAC calculates hot and cold start emissions separately from hot stabilized emissions

- MOBILE uses average U.S. distributions, while EMFAC uses California-specific emission standards and vehicle mileage and age distributions

- Unlike the EMFAC suite, MOBILE does not have a vehicle activity program component such as BURDEN to do inventory estimates. The inventory calculations are done per state under EPA's guidance and using activity data, such as vehicle miles traveled (VMT) obtained from two sources: 1) Highway Performance Monitoring Service; and 2) Travel Demand Forecasting Model.

The most salient features of the models EMFAC, MOBILE and ITEM are outlined in Table 3.1.

\subsubsection{Evaluation and Comparison of EMFAC and MOBHE}

During the past few years, numerous studies have shown that under most on-road operating conditions actual vehicle emissions can differ dramatically from EMFAC and MOBILE predictions (CRC-APRAC, 1991; 1992; 1994; Fujita et al., 1991). Our understanding of the reasons leading to this discrepancy has improved considerably in recent years, and numerous research programs funded by CARB, EPA, DOE, and the Coordinating Research Council (CRC) are currently under way to improve the procedures for estimating emission inventories of mobile sources (CRC-APRAC, 1991, 1992, 1994; Markey, 1993). A study done in 1991 by SAI (1991) identified strengths and weaknesses in the EMFAC and MOBILE models. In this report we add to their findings and update their evaluation, by including all the changes done in the latest versions of the models and addressing their use for alternative fuels. 
Table 3.1. Features of Different Emissions Inventory Models

\begin{tabular}{|l|l|l|l|l|}
\hline MODELS & $\begin{array}{l}\text { Pre-processor } \\
\text { programs }\end{array}$ & $\begin{array}{c}\text { Domain of } \\
\text { Applicability }\end{array}$ & \multicolumn{1}{|c|}{ Activity } & \multicolumn{1}{|c|}{ Alternative Fuels } \\
\hline MOBILE & $\begin{array}{l}\text { TECH } \\
\text { IM240 data }\end{array}$ & $\begin{array}{l}\text { Regional, state, } \\
\text { and national level }\end{array}$ & VMT & $\begin{array}{l}\text { Not calculated yet, but } \\
\text { emission rate equations } \\
\text { could be modified. } \\
\text { Models the effects of } \\
\text { reformulated gasoline, has } \\
\text { added Phase 2 gasoline. }\end{array}$ \\
\hline $\begin{array}{l}\text { EMFAC- } \\
\text { BURDEN }\end{array}$ & CALIMFAC & $\begin{array}{l}\text { Regional, } \\
\text { California level }\end{array}$ & $\begin{array}{l}\text { VMT/day (for } \\
\text { exhaust) } \\
\text { trip/day (for cold-hot } \\
\text { starts) } \\
\text { vehicle population } \\
\text { (for diurnal, rest } \\
\text { losses) }\end{array}$ & $\begin{array}{l}\text { Models the effects of } \\
\text { added Phase 2 gasoline and } \\
\text { oxygenates benefits. }\end{array}$ \\
\hline ITEM & $\begin{array}{l}\text { Requires travel } \\
\text { demand data }\end{array}$ & $\begin{array}{l}\text { Regional emission } \\
\text { inventory \& } \\
\text { facility specific } \\
\text { simulation }\end{array}$ & $\begin{array}{l}\text { Detailed factors } \\
\text { integrated in model } \\
\text { (percentage cold } \\
\text { start, acceleration, } \\
\text { deceleration., } \\
\text { VMT/day, etc.) }\end{array}$ & $\begin{array}{l}\text { Capable, but no available } \\
\text { data yet }\end{array}$ \\
\hline
\end{tabular}

Both models are used to estimate the emission factors by vehicle class, which are expressed as grams of pollutant emitted for a measure of vehicle activity, such as miles traveled. These emission factors are calculated using a series of Basic Emission Rate (BER) equations, which are determined separately for vehicles of each model year. In this section, a brief discussion of some of the pertinent parameters used in EMFAC and MOBILE is given, with an emphasis on how the models differ.

\subsubsection{Fleet Characterization}

The fleet characterization component of the models includes vehicles of different technologies and emission standards. Fleet characterization is made up of two parts:

1. a registration distribution that describes the number and type of vehicles of various ages and technology types (SAI, 1991), and

2. an annual mileage accumulation rate for vehicles of each age.

EMFAC and MOBILE calculate fleet distributions differently. EMFAC uses California-specific data while MOBILE uses national data. EMFAC also disaggregates vehicles in more detail than does MOBILE, using technology-based sales fractions of catalyst, non-catalyst, and diesel vehicles (SAI, 1991). Both EMFAC and MOBILE are now using a 25-year life span for vehicles. Fluctuations of sales, etc. are not well represented in either EMFAC or MOBILE, because they use average registration distributions that smooth out real-world fluctuations. Furthermore, MOBILE assumes that the use of 
diesel vehicles increases continually in relation to gasoline fuel vehicles after 1986; but this is contrary to actual sales data of the past few years (SAI, 1991). Neither EMFAC nor MOBILE address out-of-country vehicles (not subject to US. standards), military vehicles, and unregistered vehicles.

Mileage accumulations are used in developing the basic emission rate equations by vehicle class and in determining the fraction of vehicle miles traveled for a particular model-year within a vehicle class (SAI, 1991). Both EMFAC and MOBILE use the same mileage accumulation rates. The annual mileage accumulation rates for most vehicle types have been updated on the latest version of MOBILE (MOBILE5) (EPA, 1993b). Further, the registration distributions by age of truck categories has also been refined. Similarly, the latest version of EMFAC, EMFAC7F, has improved cumulative rates and travel fractions of all vehicle classes and technology types (CARB, 1993b). A preprocessor program for EMFAC uses some of these data to generate base rates that consist of zero mile rates and deterioration factors. EMFAC multiplies the deterioration rate by the cumulative mileage and then adds this to the zero mile rate to determine the basic emission rate. This basic emission rate can be determined for any model year light-duty vehicle at any point during its lifetime. The basic emission rates are then multiplied by several correction factors to obtain the basic emission factor, or model year emission factor, which is the output of EMFAC.

\subsubsection{Treatment of Tampered Vehicles}

MOBILE eliminates data on tampered vehicles from its data set of in-use vehicles used to calculate BERs, and adds these effects to the program at a later stage as an input. Because the tampering data used by MOBILE are collected under a voluntary testing program, tampered vehicles may be under represented in MOBILE because owners of tampered vehicles would not likely submit their vehicles for testing. EMFAC, on the other hand, leaves tampered vehicles in its data set, allowing them to influence the calculated basic emission rates. EMFAC uses not only data from voluntary testing, but also data collected under inspection/maintenance and random roadside testing programs. Thus, the EMFAC procedure gives a more accurate accounting of the effects of tampering (SAI, 1991).

\subsubsection{Treatment of Emitter Categories}

EMFAC and MOBILE both separate vehicles by emitter categories in their preprocessing programs to determine the zero mile and deterioration rates. The following points illustrate their differences in this regard.

- MOBILE uses four emitter categories, and EMFAC uses five

- The emitter categories in EMFAC are defined as multiples of the pollutant standard, and those in MOBILE are defined in terms of standard deviations from the observed means in the data

- EMFAC defines emitter categories separately for $\mathrm{NO}_{\mathrm{x}}, \mathrm{CO}$, and $\mathrm{HCs}$, and MOBILE combines the categories for the latter two. $\mathrm{NO}_{\mathrm{X}}$ emissions are assumed to be at the base level in MOBILE.

Neither EMFAC nor MOBILE can accurately estimate the emissions of super emitters. Super emitters are the class of vehicle that emits the largest amount of pollutants relative to the standard. However, even though the assumptions about the proportion and BERs of super emitters have been extensively criticized, the 1991 study by SAI revealed that the composite emission rates were relatively insensitive to the BERs 
assumed for super emitters, but were more sensitive to the assumed population of this emitter class. Analyses of remote sensing data may help improve the estimate of the population in different emitter classes.

\subsubsection{Deterioration Rates}

EMFAC uses deterioration rates only for vehicles in the "normal" emitter category, but MOBILE uses deterioration rates for all emitter categories. CALIMFAC, the preprocessing program of EMFAC, treats deterioration with age by shifting vehicles from one emitter category to the next. It also assumes that there are no non-normal emitters among new vehicles based on the fact that engine families are certified to meet FTP emission standards. The SAI study of 1991 found that changes in the emissions levels of the emitter categories have a higher impact in EMFAC than in MOBILE (SAI, 1991).

The models also differ in their definition of, and assumptions regarding, the "flexpoint" (emissions are assumed to deteriorate at one rate up to a particular mileage level and at another rate thereafter). In MOBILE this point is 50,000 miles for all pollutants and model-year vehicles, but in EMFAC the point varies for different pollutants and model years. In MOBILE, the second deterioration rate is always greater than the first, but in EMFAC it is always less than the first. In the latest version of MOBILE, the basic emission rate equations for all three pollutants for all 1981 and later model year light-duty vehicles and light-duty trucks were revised on the basis of data collected from IM240 testing (EPA, 1993b). In this revised version, the new BERs reflect emissions deterioration, which is greater than that assumed in former versions of the model. The latest version of EMFAC also uses new BERs (CARB, 1993b).

\subsubsection{Seasonal Effects}

The latest version of MOBILE offers the option to have emission factors calculated as of January 1 or July 1 of a given year, the older versions calculated emission factors as of January 1 (EPA, 1993b). The month specified will affect the calculated emission factors in two ways:

- By changing the composition of the fleet (July 1 emission factors will reflect an additional six months of fleet turnover, or replacement of older vehicles by new vehicles)

- The modeling of the effects of reformulated gasoline. If the month selected is January, winter season reformulated gasoline rules will be applied, and if the month selected is July, summer season reformulated gasoline rules will be applied.

\subsubsection{Operational Mode}

The weighting of different exhaust operating modes (for example, cold start, hot start, stabilized) is very important in determining total exhaust emission rates. Emissions during the cold start mode are extremely high in comparison to stabilized emissions. In addition, the reactivity of emissions from each mode are very different, and this will be true for AFVs also. MOBILE and EMFAC have different methods to treat these operating modes. MOBILE combines emissions from all three operating modes into its reported emissions factors, but EMFAC keeps them separate, using area-specific vehicle activity data to calculate tonnages of emissions from all the various operating modes (SAI, 1991). This is more advantageous when obtaining emissions inventories, because the speciation of emissions is different among all the operating modes. Because EMFAC collects the emissions data separately for each 
operating mode using the FTP, this method is more straightforward. CALIMFAC estimates and reports mode-specific emission equations, which EMFAC uses to calculate incremental cold and hot start emissions in grams per trip (SAI, 1991). The Federal Tier 1 exhaust emission standards for all pollutants are now included in MOBILE5 (the former model contained only the CO standards) (EPA, 1993b).

\subsubsection{Evaporative Emissions}

The evaporative emissions can exceed exhaust emissions in a variety of different situations. Both MOBILE and EMFAC treat this emission category in less detail than exhaust emissions. Evaporative emissions include diurnal, hot soak, running losses, refueling losses, and crankcase emissions. MOBILE expresses the diurnal and hot soak emission equations as a standard emission level, which has added to it the contributions from insufficient canister purging, poor maintenance, system defects, and vehicle tampering. MOBILE5 also includes the impact of oxygenated fuels on exhaust and evaporative HC emissions (EPA, 1993b). The evaporative emission rates for 1981 and later model year light-duty vehicles and light-duty trucks were revised for MOBILE5 on the basis of data collected from IM240 testing, to reflect the in-use rates of failure on functional tests of evaporative emission control systems, and the emission levels associated with failure to pass one or both of these tests (EPA, 1993b). Diumal emission rates for fuel-injected, light-duty gasoline trucks are based on a combination of data for this vehicle class and light-duty gasoline vehicles, because few data are available for these emissions on throttle body-injection and port fuel-injection light-duty trucks (SAI, 1991). MOBILE contains no lower limit on RVP for diurnal emission rates. Unfortunately, there are no data on evaporative emissions for fuels with volatility levels less than 8.5 psi. Consequently, the accuracy of MOBILE diurnal rates for fuels with RVP below 8.5 is probably not good (SAI, 1991).

EMFAC's treatment of hot soak and diurnal emission rates does not allow determination of the relative contributions of individual technology types without analysis of the original data (SAI, 1991). For EMFAC, the differences between light-duty vehicles and trucks is attributed to the slower introduction of fuel injection systems into the light-duty truck fleet (SAI, 1991). EMFAC7F has revised and improved its evaporative methods and also added resting losses (evaporative emissions that occur because of permeation through such things as hoses and plastic fuel tanks) (CARB, 1993b).

\subsubsection{Correction Factors}

Although both models use the same data base in developing temperature correction factors, different assumptions as to the distribution of technology types in the fleets lead to differences between the models. The two models disagree strongly at both ends of the temperature scale, specifically for $\mathrm{CO}$ and $\mathrm{HC}$. The temperature correction factors for the exhaust processes were updated for EMFAC7F.

When examining the speed correction factors, the differences between the way the two models handle high speeds are apparent. When interpreting the slope of the curves of EMFAC's high-speed corrections, caution should be exercised, as there is a $600 \%$ increase in CO emissions over a range of $20 \mathrm{mph}$ (SAI, 1991). This could be caused by a confusion of the effects of acceleration and high-speed vehicle operation in the test cycle used in the high-speed studies (Cicero-Fernandez and Long, 1993). These two effects must be treated separately. MOBILE5 speed correction factors have been updated for 1981 and later model year light-duty vehicles and light-duty trucks over the mid and high ranges of average speed, e.g. 19.6-65 mi/h, (Guensler et al., 1993; EPA, 1992; CARB, 1992a; 1992c). CARB is further refining the 
speed correction factors, and this has recently become an area of increased research. Of particular concern is the significant increase in emissions for $\mathrm{CO}$ and $\mathrm{HCs}$ at high speed.

\subsection{Application of EMFAC and MOBILE for Alternative Fuels}

The general procedure for developing an emissions inventory for AFVs is similar to that used for gasoline vehicles, but many of the correction factors to the base emissions rates, which have been developed from very large data bases for gasoline vehicles, are unavailable for AFVs. To accurately determine emission factors for vehicles powered by alternative fuels using EMFAC or MOBILE, the following input data would be required:

- Zero mile rate for vehicles powered by alternative fuels (per vehicle class and technology group)

- The corresponding deterioration rates per vehicle class and technology group

- Cumulative mileage per vehicle class and technology group

- The corresponding penetration rates to predict the vehicle fleet

- Correction factors (such as speed correction factors) to adjust the FTP-based base rates for alternative fuels to non-FTP conditions.

Although some information is available for the first item, data for the remaining items are extremely limited. Thus, simplistic assumptions must be used in developing emissions factors for AFVs.

To a large extent, many of the correction factors developed for gasoline vehicles will have to be used to model AFVs. Deterioration rates for AFVs, for example, have shown a high degree of variability, and thus can not be assumed to be different than those of gasoline vehicles (Colorado Department of Health, 1993; AFDC, 1994; Cox et al., 1994; Urban Consortium Energy Task Force, 1994). Several ongoing programs may contribute to the development of appropriate correction factors for AFVs. The AMFA and Cleanfleet programs are both collecting data from in-use AFV OEMs, which could eventually lead to the development of separate deterioration factors for AFVs (Battelle Memorial Institute, 1994; Kelly, 1994). From our perspective, this would be the preferred procedure. AQIRP is currently conducting tests over a high speed/high acceleration driving schedule, which may likewise help in the development of speed correction factors for AFVs (Gorse, 1994). Such data can be incorporated into the modeling process as they become available in large enough quantities.

Eventually, other components will have to be integrated into the models to account for the impact of socalled full cycle emissions. These include not only the emissions from the vehicle itself, but also emissions resulting from activities such as production, conversion, transportation and marketing of the fuels used to operate the vehicle. These additional emissions have recently been examined by several groups (Darrow, 1994; Bull, et al.). Darrow concluded that when considering full fuel cycle emissions, vehicles fueled by alternative fuels could provide full cycle emissions similar to those of electric vehicles.

The assumptions built into MOBILE5a about the Inspection and Maintenance (I/M) programs' effectiveness may also need modification, as they were developed for gasoline vehicles. EPA believes that $\mathrm{I} / \mathrm{M}$ programs for vehicles operating on alternative fuels will be more stringent. This is primarily the result of the inadequacy of the current $\mathrm{I} / \mathrm{M}$ testing equipment. The current $\mathrm{I} / \mathrm{M}$ testing program is also 
inadequate for dealing with AFVs. I/M programs (as they are currently planned) do not distinguish methane from other $\mathrm{HC}$ emissions, for example. Consequently, a CNG vehicle with predominantly methane HC emissions might easily pass NMOG certification, but still fail the THC test in an $/ / M$ program. This situation could be even more problematic considering that $\mathrm{I} / \mathrm{M}$ test equipment is calibrated for propane gas and tends to read higher methane emissions than actually exist. Currently planned I/M programs also do not account for the ozone reactivity of the THC emissions. This could, in effect, result in more stringent certification standards for $\mathrm{AFVs}^{5}$. EPA is planning on examining whether differences in NMOG and NMHC might warrant different $\mathrm{I} / \mathrm{M}$ credits in the modeling of some or all AFVs. EPA is also studying how to incorporate the effectively more stringent requirements for CNG vehicles into emissions inventory models (EPA, 1993a).

Regarding fleets of AFVs, EPA has two other concerns. First, fleet vehicles capable of operating on gasoline and an alternative fuel (i.e., FFVs) may tend to operate on gasoline alone after leaving the fleet service. Second, the resale market for fleet vehicles that can operate on gasoline is expected to be similar to the current resale market for gasoline fleet vehicles. However, the resale for dedicated alternative fuel fleet vehicles will be more of a problem until a broad alternative fuel infrastructure is in place (EPA, 1993a).

Given the complexity of the parameterization in the modeling process and limitations of the data available on AFVs, we recommend that the initial development of a mobile source emission inventory for AFVs be based solely on differences in the mass emission rates of AFVs. Differences in emissions should be accounted for in determining both exhaust and evaporative emissions, as well as emissions associated with refueling. AFVs can be incorporated into the current models by assuming that the AFVs are a separate vehicle class that has a given penetration rate. In particular, the low-emission vehicle/clean fuel regulations adopted by CARB in September 1990 established four progressively more stringent vehicle categories as described in Section 2. Alternatively, a fuel correction factor can be added to the BER equations, but more information on the emission characteristics of AFVs are needed to establish realistic fuel correction factors for each vehicle category and fuel type.

The benefits of Phase 1 gasoline were added to the EMFAC program when it was updated from version $7 E$ to version $7 E P$. Further improvements in EMFAC were made as the program was updated from version 7ESCF2 to version 7F (the latest as of this writing) to incorporate the benefits of Phase 2 gasoline and oxygenates. This is accomplished mainly by using the fuel correction factor to the BER equation in the form of an input data file.

Some limited characteristics of AFVs have also been added to MOBILE. In the earlier MOBILE4.1 version, the effects of oxygenates on exhaust $\mathrm{CO}$ emissions were included. In MOBILE5 and MOBILE5a, the effects of reformulated gasoline and oxygenated fuels on exhaust and evaporative HC emissions were incorporated based on estimates of exhaust reductions and RVP changes that would result from the use of Federal Phase 2 reformulated gasoline (EPA, 1993b). Based on limited emission measurements, it was determined that use of Federal Phase 2 reformulated gasoline would result in a $20 \%$ reduction in exhaust emissions and have an RVP of 7.5. A more recent analysis of emission data

5 This is because the $\mathrm{HC}$ as measured in the $\mathrm{I} / \mathrm{M}$ program may be greater than the NMOG measured during vehicle certification, even if methane emissions are accounted for. 
indicates that the exhaust reductions for Federal Phase 2 reformulated gasoline may be less than assumed in MOBILE5a, but the expected RVP could also be lower (EPA, 1993a). Thus, the exhaust benefit may be smaller, but the evaporative emission reduction would be greater. The current estimate of the effect of California reformulated gasoline is a $29 \%$ exhaust reduction and an RVP of 6.9. More recent EPA data indicate, however, that exhaust reductions for California reformulated gasoline may be closer to $22 \%$ (EPA, 1993a). MOBILE5 and MOBILE5a also include the ability to model the effects of participation in the California LEV program.

The effects of methanol vehicles on the emissions inventory have been investigated by SAI, as part of AQIRP, and CMU (Russell et al., 1989; AQIRP, 1992a). For the CMU study, the contribution of methanol vehicles to the emissions inventory was derived by considering methanol fuel, catalyst-equipped vehicles as a separate group within each vehicle class in the EMFAC program (Russell et al., 1989). A simpler approach was used in the SAI modeling study (AQIRP, 1993a). In the latter case, emissions factors were developed by multiplying the projected mass emission rate from MOBILE and EMFAC for the entire light-duty fleet by a ratio of the mass emissions rate from the methanol vehicles tested to the mass emissions rate for the gasoline vehicles tested. A similar technique using the mass emission rate for vehicles at different certification levels could also be applicable for all alternative fuels.

Modeling studies done by SAI and CMU included measures to accommodate refueling emissions for alternative fuels. The principle considerations for refueling emissions are differences in vapor pressure between different fuels and differences between volumetric fuel economy or the mileage per gallon of different fuels. In the SAI model, these differences were accounted for by using multiplicative factors (AQIRP, 1993a). One multiplicative factor was used to account for the differences in the volumetric fuel economy or the mileage per gallon. This was accounted for by multiplying the storage and refueling emissions predicted for gasoline by the M0 to M85 ratio of volumetric fuel economies. The other was used to account for the differences in the vapor density between methanol and gasoline fuels. This was simply represented by the ratio of the M85 to M0 vapor densities.

Some similar considerations were used by the researchers at CMU (Russell et al., 1989). Methanol emissions were used to replace the gasoline refueling emissions, accounting for vapor pressure differences, increased consumption of methanol due to a lower energy content, and whether the emissions are due to spillage or vapor displacement. For emissions caused by vapor displacement from an originally fixed volume, such as an underground tank or gas tank during refueling, the different vapor pressures and evaporative composition of methanol, gasoline and methanol-gasoline mixtures were accounted for. Vapor displacement calculations for methanol account for the RVP, the relative molecular weights and the base emissions of gasoline as follows:

Mass of Methanol =

(Mass of Gasoline) x (mole. wt. Methanol/mole. wt. Gasoline) x (RVP Methanol/RVP Gasoline)

The vapor displacement calculation for M85 was somewhat more involved and used solution theory and Raoult's Law. This formulation is discussed in greater detail in (Russell et al., 1989).

CMU calculated evaporative emissions by using the distribution of the hot soak and diumal emissions from the base-case inventories and available EMFAC reports (Russell et al., 1989). These mass emission rates were corrected for vapor pressure differences. The approach used by SAI (AQIRP, 1993a) to model evaporative emissions was similar to their procedure for developing exhaust mass emission rates in that 
emissions changes were expressed as ratio of the methanol fleet-average emission rate to the industryaverage gasoline fleet-average emission rate. Similar procedures using the data base discussed in Section 2.7 would be appropriate for generating inventories of evaporative emissions from alcohol fuel vehicles. For NGVs, we recommend the evaporative emission rate be set to zero. 


\subsection{Governing Processes and Air Quality Models}

\subsection{Introduction}

A model that can be used to estimate the air quality effect of alternative fuels such as methanol, must account for the complex processes that determine the fate of emissions of VOCs and $\mathrm{NO}_{\mathrm{x}}$ resulting from the use of fuels. These emissions, the precursors of ozone, are transported away from their sources by wind flows, which vary in both space and time. During transport, the chemical species are mixed vertically by atmospheric turbulence and by updrafts in clouds. The emitted species undergo a host of reactions, both in the gas and the aqueous phases, which lead to the formation of secondary pollutants such as ozone and nitrate. These primary and secondary species are scavenged from the atmosphere by removal at the ground and by incorporation into rain.

This section provides a critical review of the formulation and application of air quality models that can be used to estimate ozone concentrations on urban and regional scales. This review will pay attention to the applicability of these models for the examination of the air quality effects of substituting currently used fuels, such as gasoline, with alternatives, as discussed in the previous sections.

We begin with a description of the treatment of the governing processes in air quality models. We then discuss how these processes are incorporated into the framework of the mass conservation equation, which forms the basis of all air quality models. The final section examines the performance of currently available air quality models in explaining observations of chemical species relevant to photochemistry.

\subsection{Approaches to Air Quality Modeling}

A credible model must include the governing processes in some manner, although the appropriate level of detail required in the description of the processes is never clear. The model must also account for the nature of the environmental system that governs the fate of atmospheric pollutants. The environmental system differs from other systems whose examination also require computer resources. Computer simulation provides the best results when applied to systems with two characteristics: a) they can be divided into subsystems whose internal workings can be ignored in modeling the system as a whole, and b) the interactions between the subsystems are governed by well-established laws. Modeling such systems reduces to computing the complex consequences of simple, well-established laws operating on a large number of subsystems. For example, flow past complex shapes represents the solution of wellestablished partial differential equations governed by the boundary conditions imposed by the shape. The numerical solution represents the fluid continuum by a large number of fluid elements that are described by their thermodynamic properties and center-of-mass velocities. The computer generates the complex consequences of the interactions between these fluid elements.

The environmental system does not have the two features described in the previous paragraph. The details of the subsystems or governing processes cannot be ignored. Furthermore, there are large gaps in our understanding of the processes as well as the interactions between them. In view of these characteristics of environmental systems, there are several possible approaches to modeling air quality. They generally fall into three categories, although the distinction between them is not clear. The first approach involves using what is referred to as a comprehensive model. Such a model incorporates the 
relevant processes in as much detail as possible, with the objective of developing a numerical surrogate of the real system. It thus potentially provides the most realistic assessment of what might happen in an actual airshed, and how emissions changes might affect air quality as a function of time and space. Because the environmental system is complex, the comprehensive model is necessarily complex; it requires relatively large computational resources.

In view of the ready availability of computer resources, the comprehensive approach appears to be attractive. In practice, it suffers from several disadvantages. The first is that because of uncertainties in the process formulations, the predictions of the model cannot be considered reliable until they have evaluated extensively against observations. This evaluation requires large data sets to run the model and to compare with model estimates. These data sets are always incomplete, which means that the results of an evaluation are never conclusive as to the validity of the model. Furthermore, process formulations always require empirical modifications to decrease discrepancies between model estimates and observations. Such empirical adjustments decrease the value of the a priori scientific content of the comprehensive model.

One way of alleviating the problems associated with model complexity is to simplify the treatment of selected processes. This approach is represented by different versions of the Empirical Kinetic Modeling Approach (EKMA) model (Dodge, 1977). In this model, the atmosphere is represented as a single wellmixed box into which pollutants are emitted and undergo their chemical transformations. Such models incorporate major simplifications to transport and mixing phenomena, and cannot represent any actual air pollution episode in great detail. However, they can incorporate dynamic injection of pollutants, timevarying light intensities, temperatures, humidities, and time-varying changes in the mixing height with entrainment of pollutants from aloft as the inversion height increases during the day. Thus, they can represent a wide range of conditions that can affect rates of chemical transformations, and thus affect predictions of effects of emissions changes on ozone formation. Such models also have the advantage that their use requires significantly less computer resources and data input and analysis efforts, and that more realistic representations of the chemical transformations can be used than are practical in the more comprehensive three-dimensional models. Therefore, an appropriate set of box or EKMA model scenarios might be useful for assessing effects of emissions changes in a wide variety of conditions.

The third approach to air quality modeling, referred to as semi-empirical, acknowledges the uncertainties in the process formulations and the data sets required to run the model. In this, no attempt is made to include all the details in the processes, which are parameterized to the simplest form possible. Their simplicity allows the parameterizations to be adjusted to minimize the deviations between model estimates and observations. This process assumes the forced correspondence with observations ensures that the parameterization is realistic. Thus, the a priori scientific basis of the processes, incorporated into the comprehensive model, is exchanged for a description of observations that can be better than that provided by a comprehensive model. The semi-empirical model is designed to have a simple structure, and thus requires much less computational resources than a comprehensive model. This allows for the type of numerical experimentation that would be difficult with the computationally demanding comprehensive model. Semi-empirical models have been used extensively in acidic deposition studies (see Venkatram et al., 1990), but they have rarely been used for ozone estimates. Although such models are potentially highly useful for screening purposes, they will not be discussed further here. 
In the following sections, we discuss the parameterization of processes used in the current generation of air quality models.

\subsection{Parameterization of Processes in Models}

The processes considered in most air quality models are:

- Emissions

- Transport

- $\quad$ Mixing

- Scavenging-wet and dry removal

- Chemistry

The representation of chemistry is discussed in detail in Section 5. Before describing the rest of the processes, we introduce some terminology. Existing air quality models can be classified as urban and regional models on the basis of their spatial and temporal scales of applicability. Urban models apply to scales of the order of tens of kilometers, and temporal scales of the order of hours. Regional models apply to spatial scales of the order of hundreds of kilometers, and time scales of the order of days.

Urban models incorporate parameterizations for transport, mixing, and dry deposition. Wet deposition and cloud processes are neglected because they play a minor role during ozone episodes over urban space and time scales. However, these processes are typically included in regional models. In the following sections, we briefly discuss the role of each of these processes.

\subsubsection{Emissions}

Air quality models require, as inputs, detailed emissions data for the specific region to be modeled. For ozone modeling, at a minimum, this requires spatially and temporally resolved emissions of $\mathrm{NO}_{\mathrm{x}}, \mathrm{CO}$, and NMOG, and should also include estimates of $\mathrm{SO}_{\mathbf{x}}$ and particulate matter emissions. The spatial resolution varies depending on the size of the region to be modeled. For urban applications, the spatial resolution is usually $5 \mathrm{~km}$ (Reynolds et al., 1979; McRae et al., 1982) Modeling studies on regional scales can use spatial resolutions of $50 \mathrm{~km}$ or larger (Venkatram et al., 1988; Chang et al., 1987). The temporal resolution of the emissions data is usually hourly. For some pollutants, such as particulate matter, where ambient data and emission source measurements are integrated over larger time scales, a diurnal profile of relative emission rates is used to estimate hourly emission rates. Emission estimates are needed for on-road and off-road mobile sources, area and point stationary sources, and biogenic sources. In addition, to properly evaluate the relative differences of the various alternative fuels, fully speciated NMOG emission rates are needed, although lumping of the various species into chemical classes is required for use with almost all of the chemical mechanisms currently used in air quality models. The development of emission inventories for gasoline and AFVs was discussed in Section 3. The details of the chemical mechanism will be discussed in Section 5. Finally, the emission inventory should coincide with the time period to be modeled, which is usually during the period of highest ozone concentrations in a given year. 
Each state air pollution agency is required to develop an emissions inventory that can be used for modeling demonstration of attainment of the ozone standard as part of the State Implementation Plan (SIP). In fact, the need for accurate emissions estimates has taken on a new level of significance as a result of U.S. and California Clean Air Act legislation. The 1990 amendments to the U.S. Clean Air Act requires states to track emissions reductions to show reasonable further progress toward attainment of all of the U.S. air quality standards. The California Clean Air Act of 1988 requires air pollution control districts in nonattainment areas of California air quality standards to achieve annual reductions in emissions of 5\%. The implementation of the Regional Clean Air Incentives Market (RECLAIM) within the South Coast Air Quality Management District, where emission reductions can be traded on the open market, puts new demands on the development of an accurate emission inventory for Southern California for mobile and stationary sources.

\subsubsection{Transport}

Transport refers to the movement of pollutants by the three-dimensional wind field in the atmosphere. This wind field can be derived in one of three ways:

- Diagnostic analysis of observed winds

- Prediction through dynamic meteorological models

- Combination of observations with meteorological predictions.

In the first method, winds measured at stations are interpolated to grid points. These interpolated winds are then adjusted to ensure they are consistent with the mass conservation equation for air (Goodin et al., 1980). The adjustment can sometimes include empirical corrections for complex terrain effects such as upslope/downslope flows and flow acceleration around hills (Yocke, 1981). Because the interpolation/adjustment procedure is arbitrary, it can lead to: a) the final winds deviating substantially from the observations, and/or b) creation of unrealistically large vertical velocities in response to horizontal wind adjustments. These effects can be avoided by allowing the final wind field to retain a degree of mass inconsistency. However, by doing so, we can introduce errors in the concentrations estimated from the one form of the mass conservation equation. Because diagnostic analysis is anchored to observations, and requires small computational resources, it is popular. Clearly, the usefulness of this technique depends on the density of the wind stations making observations; these will be necessarily sparse at heights above the ground.

The wind field can be obtained from prognostic wind field models that incorporate mass, momentum, and energy balances (Pielke, 1984). Here, the three-dimensional wind field is computed as a function of time after it has been initialized. While prognostic models attempt to incorporate the relevant physical process, they suffer from two disadvantages. First, they are very demanding from a computational viewpoint. Second, because of inevitable errors in the model inputs and formulations, model estimates of wind fields can deviate substantially from observations. These deviations can be a problem when the wind field is being used in an exercise to evaluate the estimates from an air quality model with corresponding observations. Adjustment of model inputs/formulations to obtain agreement between model estimates and observations can be a time consuming process. Predictions from a dynamic meteorological model are most useful when they are used as surrogates for real fields in simulations designed to examine the effect of emission control scenarios. 
There are essentially two ways of combining wind observations with estimates from meteorological models. One is to treat the model estimates as pseudo observations to construct the interpolated wind field; this introduces some physics into the interpolation procedure. The mass conservation equation is then used to smooth the interpolated wind field (Casmassi et al., 1990). A second method of combining wind observations with model estimates is sometimes referred to as four-dimensional data assimilation. One popular version of the technique, called Newtonian nudging (Seaman, 1990), injects observed information into the momentum conservation equation through a term that nudges the model prediction towards the interpolated observed field. This term, which is added to the dynamic terms, is the difference between the observed and predicted wind fields divided by an empirical time constant. We see immediately that nudging is most effective when the difference between the predicted and observed wind field is small. Otherwise, the nudging term can overwhelm the dynamic terms, and the procedure reduces to elaborate interpolation. Because Newtonian nudging is most useful when it is least needed, its usefulness as a data assimilation technique is questionable.

Wind field models also generate information on parameters that describe the atmospheric boundary layer. These parameters can be used to describe horizontal and vertical mixing, which are treated in the next section.

\subsubsection{Mixing}

Mixing refers to vertical or horizontal transport by fluid motions that are not included in the wind field. This unresolved component typically refers to small-scale fluid motion, or turbulence, within the atmospheric boundary layer. During transport, chemical species are usually confined within the atmospheric boundary layer, whose depth varies from $1000 \mathrm{~m}$ during the day to about $100 \mathrm{~m}$ during the night. Atmospheric turbulence levels in the daytime boundary layer, or mixed layer, are maintained by the upward heat flux from the ground heated by solar radiation. These levels are an order of magnitude higher than those in the nighttime boundary layer, which is maintained by wind shear. The dynamics of the atmospheric boundary are governed by the energy balance at the ground, which is sensitive to land use. Because the specification of land use is an uncertain exercise, air quality models rely on observations of the boundary layer as much as possible.

Turbulent transport is usually modeled as a gradient-driven process in which mass transfer occurs down the gradient of the mixing ratio of the relevant species, where the ratio of the mass transfer rate to the gradient is referred to as the eddy diffusivity. The eddy diffusivity is taken to be a function of the turbulence properties of the atmosphere. This model of turbulent transport is only a crude approximation to the actual process. In spite of this, it is used in almost all the available grid models because it produces the intuitively appealing result that vertical mixing increases with the turbulence levels in the atmospheric boundary layer. At urban space and time scales, the details of the specification of the eddy diffusivity become unimportant because high ozone concentrations occur during the daytime when the mixing ratio (not concentration) is well mixed through the height of the boundary layer. If the mixed height is known, it is only necessary to choose an eddy diffusivity that is large enough to achieve mixing through the mixed layer depth over a time scale of minutes.

The treatment of vertical mixing is important when modeling transport and chemistry over regional scales. In this case, the details of mixing during the night are important because of multiday transport. Errors in the specification of vertical mixing will lead to the incorrect vertical placement of pollutants. 
Because wind shears are typically large during the night, these errors will, in turn, result in ozone precursors being transported to the wrong locations.

In most problems, the parameterization of horizontal turbulent transport has little effect on concentration estimates because transport by the mean wind is much larger than unresolved turbulent transport. This contention is less valid under low-wind speed, stagnation conditions.

\subsubsection{Scavenging}

Pollutants are scavenged from the atmosphere through processes referred to as dry and wet deposition. Dry deposition occurs when chemical species are transferred to the ground and then removed by chemical, physical, or biological processes at the air-ground interface. Wet deposition refers to the incorporation of chemical species into cloud or rain water, followed by removal from the atmosphere by the rain. In discussing wet deposition, it is necessary to describe the parameterization of cloud processes.

We begin with a discussion of dry deposition, which is incorporated in most urban scale ozone models.

\subsubsection{Dry Deposition}

The dry deposition flux of a species at a given height is usually expressed as the product of the concentration at that height and the dry deposition velocity. The electrical resistance analog is often used to parameterize the dry deposition velocity. In this model, the concentration (voltage) at the reference height drives the flux of species (current) to the sink at the receptor through three resistances in series. The first resistance is provided by the atmosphere in transporting material from the reference height to the top of the quasilaminar layer that forms on the receptor surface. The second resistance corresponds to the quasilaminar deposition layer. The final resistance is that to uptake of the species at the receptor surface. The dry deposition velocity is the inverse of the sum of these three resistances.

Because these resistances are in series, the largest resistance controls the value of the deposition velocity. The formulations for the atmospheric resistance, which is a function of surface layer turbulence, are relatively well established. There is also consensus on the parameterization of the deposition layer resistance, which is a function of the molecular diffusivity of the depositing species.

The surface resistance is a complicated function of the physical, chemical, and biological characteristics. Current calculations of this resistance rely on semi-empirical formulations that are still highly uncertain for most photochemical species. For species such as $\mathrm{H}_{2} \mathrm{O}_{2}$ and $\mathrm{HNO}_{3}$, this resistance is essentially zero, and the more established atmospheric and deposition layer resistances control the dry deposition velocity. A large number of experimental programs (Hicks et al., 1990) have narrowed the uncertainty in the surface resistances of ozone and $\mathrm{NO}_{2}$. However, we have almost no data on the surface resistances of the HC species; we can only make estimates at this time. This uncertainty is likely to be important for transport over regional scales when dry deposition can be an important factor in determining boundary layer concentrations. The effects of precursor emission control are highly dependent on the $\mathrm{VOC} / \mathrm{NO}_{\mathrm{x}}$ concentration ratio; dry deposition will affect this ratio on regional scales. 


\subsubsection{Wet Deposition}

The parameterization of wet deposition requires consideration of processes within clouds. Wet deposition is not an important removal mechanism over urban scales because high ozone episodes are not usually associated with rain. However, fair weather clouds can transport pollutants vertically out of the boundary layer; this process is sometimes referred to as cloud venting (Chang et al., 1989). This suggests that parameterization of clouds as vertical transport mechanisms might be warranted even in urban models.

Wet deposition and cloud processes can become important over regional scales. Particles and soluble gases are incorporated into cloud or rain water, and subsequently removed during rain events. Some chemical species such as $\mathrm{SO}_{2}$ participate in chemical reactions within clouds. The transfer of material from the atmosphere into cloud water depends on cloud processes, which can be extremely complicated. The parameterization of these clouds should include at a minimum: a) the formation of cloud water, b) mixing within and outside clouds, c) aqueous phase chemistry, d) removal of cloud water by rain, and e) incorporation of chemical species into rain below the cloud. These mechanisms are qualitatively different in the two classes of clouds: a) convective clouds triggered by upward motion in unstable air, and b) stratiform clouds formed in stable air by large-scale upward motion along fronts. As mentioned earlier, only the regional scale ozone models include cloud parameterizations.

The parameterization of clouds in regional scale ozone models is fraught with uncertainty for two reasons. First, the current understanding of cloud physics is very incomplete. Second, little research has been conducted into converting even this incomplete understanding into parameterizations suitable for incorporation into comprehensive air quality models.

The next section describes the framework used to tie the governing process together.

\subsection{The Governing Equation and Numerical Solution}

The mass conservation equation for the concentration, $C$, for each species involved in photochemistry forms the basis of all comprehensive air quality models,

$$
\frac{\partial C}{\partial t}+\frac{\partial\left(u_{i} C\right)}{\partial x_{i}}=\frac{\partial}{\partial x_{i}}\left(\rho_{a} K_{i} \frac{\partial q}{\partial x_{i}}\right)+S+R
$$

In Equation (4.1), $K$ is the eddy diffusivity, $S$ is a source (emissions) term, $R$ is a transformation/removal (chemistry) term, $\rho_{a}$ is the density of air, and $u_{i}$ represents the mean velocities in the three co-ordinate directions $i=x, y, z$. The mixing ratio, $q$, is defined by

$$
q=\frac{C}{\rho_{a}}
$$

where the concentration, $C$, is expressed in mass/volume units. Equation (4.1) is referred to as the flux form of the conservation equation because the left hand side is expressed in terms of the mass flux, $u_{i} C$.

The second term on the lefthand side of the equation represents transport by the mean wind specified by $u_{i}$. The first term on the righthand side of the equation is the turbulent diffusion term, which accounts for transport by winds not resolved by the model. 
The mass conservation equation has to be written in such a form that the mixing ratio $q$ is conserved when the only governing processes are transport and turbulent diffusion. This property of $q$, which can be readily derived (Venkatram, 1993), is physically obvious if we notice that $q$ is a ratio of two concentrations, and thus a ratio of two masses in a control volume. Transport alone cannot change this ratio. Thus, the turbulent gradient transport equation has to be formulated in terms of the mixing ratio rather than the concentration to ensure a constant mixing ratio in a well-mixed boundary layer. If the turbulent transport is incorrectly written in terms of concentration, as it is in some popular air quality models, the estimated concentration of ozone will be consistently underpredicted by about $10 \%$ in a $2-\mathrm{km}$ deep boundary layer.

The flux form of the mass conservation equation [Equation (4.1)] does not ensure the conservation of $q$ along a trajectory. However, this property can be ensured by recasting Equation (4.1) in the advective form (See Venkatram, 1993),

$$
\frac{\partial q}{\partial t}+u_{i} \frac{\partial q}{\partial x_{i}}=\frac{1}{\rho_{a}} \frac{\partial}{\partial x_{i}}\left(\rho_{a} K_{i} \frac{\partial q}{\partial x_{i}}\right)+\frac{(S+R)}{\rho_{a}} .
$$

The numerical solution of the transport component of the mass conservation equation can introduce errors that can overwhelm physical effects. These errors can be reduced by proper design of the numerical scheme. However, proper design cannot alleviate errors caused by lack of mass consistency in the wind field used to transport chemical species. This mass inconsistency is inevitable when the wind field is derived through interpolation of observed winds. The effect of wind field errors can be minimized by using the advective form of the mass conservation equation [Equation (4.3)] rather than the flux form [Equation (4.1)]; this is because the advective form does not explicitly include the divergence of the wind field. Note that none of the popular regional or urban grid models use Equation (4.3).

A grid system in space and time is used to translate the governing mass conservation equation into a set of coupled algebraic equations, in which the unknowns are the concentrations corresponding to each grid box. The number of equations is equal to the number of grid points covering the region of interest. Because these equations need to be solved for each time step, the total number of equations representing a problem is equal to the number of grid points multiplied by the number of time steps needed to cover the time period of simulation. If we think of grid points as observation stations, it is easy to see that our ability to describe the system of interest improves with the number of grid points and how often we sample the system. The grid spacing used in the model is referred to as resolution. The number of grid points and the time step used in solving a problem are generally limited by the computer resources required to solve the large number of coupled algebraic equations.

A fixed grid system used in most air quality models is sometimes called an Eulerian grid system. Grid points can also move with the flow, in which case the system is referred to as Lagrangian. Several air quality models use a Lagrangian system because it allows the user to confine attention to a small set of grid points, and thus reduce computational time. This set of grid points is attached to something called a parcel of air, which is then moved along a trajectory. The definition of the air parcel, and the computation of its trajectory, are highly subjective exercises. Because the air parcel is treated as a single entity that moves along a trajectory, it is not possible to account for the effects of velocity variations within the parcel itself. This means that important effects, such as subsidence or descending vertical motion and those related to the variation of horizontal velocity with height, cannot be readily accounted for in a 
Lagrangian model. On the other hand, the Eulerian model readily accounts for spatial variations in the velocity field by placing grid points or observational stations throughout the region of interest; the information at these grid points includes the variation in the velocity fields. This more accurate description of the system is bought with increased computational resources.

The box or EKMA models are the simplest (and perhaps the most important) examples of Lagrangian models. They represent the air parcel as a single cell (or air parcel), with no horizontal mixing or transport of pollutants. Thus, transport is represented by movement of the air parcel itself. However, such models can provide a simple representation of vertical mixing. This is done by allowing the parcel to have a variable top (mixing height) that can increase with time during the simulation to simulate the effect of the increase of the mixed layer during the day. The pollutants aloft (above the mixed layer) are then mixed, or entrained, into the parcel as the height of the mixed layer raises. In standard EKMA models, the compositions of the pollutants aloft must be specified as inputs. A refinement to this, used for example in some scenarios discussed by Carter and Atkinson (1989), is to use a second cell to separately simulate the reactions of the pollutants aloft left over from the previous day. This provides a somewhat more realistic representation of multi-day effects than is possible with standard EKMA models, though it is still highly approximate compared to the representation in Eulerian or Lagrangian models with multiple vertical cells.

\subsection{Survey of Existing Models}

The effects of fuel substitution on ozone peak concentrations are currently estimated to be relatively small (a reduction of about $15 \%$ ), and highly variable depending on the existing $\mathrm{VOC} / \mathrm{NO}_{\mathrm{x}}$ ratio (Russell et al., 1990). This estimate may change if the contribution of mobile sources increases, as discussed in Section 3. An examination of such effects places special demands on the air quality model, the most important of which is the ability to simulate many emission and meteorological scenarios. This is necessary to separate the effects of emission changes on air quality from those of other confounding processes such as meteorology and scavenging. In addition, the model must be deemed reliable by having undergone extensive testing with observations.

\subsubsection{Comprehensive Models}

Current comprehensive models use similar parameterizations for the governing processes. However, there are some differences, which might have significant effects on their predictive ability. These are highlighted in Table 4.1.

We see that the urban scale models, UAM and the California Institute of Technology model (CIT), limit the extent of their vertical domains to about $2 \mathrm{~km}$ because they are designed to focus on transport within the atmospheric boundary layer. These models do not incorporate clouds, which can extend to heights of $10 \mathrm{~km}$. This limitation implies that urban scale models cannot be readily extended to regional scales at which cloud transport and chemistry become important. On the other hand, the regional scale models have 10-15 layers extending to heights varying from 6 to $10 \mathrm{~km}$, a domain designed to accommodate cloud processes. Although they have been applied primarily to horizontal scales ranging from $18 \mathrm{~km}$ to $120 \mathrm{~km}$, nothing in the formulation of these models restricts their application to regional scales. They can be readily applied to smaller horizontal scales without any modifications. 
Urban and regional scale models use variants of the following chemical mechanisms: a) the Carbon Bond IV (CB4) mechanism developed by SAI, b) previous generations of the mechanisms developed at the Statewide Air Pollution Research Center (SAPRC) at UC Riverside, or c) the Regional Acid Deposition Model (RADM) mechanism developed at the State University of New York (SUNY). The CB4 mechanism is used in the Regional Oxidant Model (ROM) and UAM, versions of SAPRC are incorporated in the Acid Deposition and Oxidant Model (ADOM), the Sulfur Transport Eulerian Model (STEM-II), and CIT; and the RADM mechanism is used in RADM. These are discussed in Section 5.

Except ADOM and ROM, existing comprehensive models use the flux form of the mass conservation equation. This makes them susceptible to errors in the wind fields, which are inevitable when the winds are derived through data interpolation or diagnostic wind field models.

\subsubsection{Lagrangian Models}

Although the use of Eulerian models is favored in the U.S., Europeans rely primarily on Lagrangian models for urban and regional scales. (See, for example, Eliassen and Hov, 1987) Their experience indicates no clear evidence to support the use of grid models over simpler Lagrangian models. The reason for this could be that the problems associated with numerical methods in grid models could counteract the advantages gained in including more realistic meteorology; Lagrangian models do not suffer from the numerical dispersion of grid models.

As discussed above, the most important examples of Lagrangian models in the U.S. are EKMA or box models. The actual application of EKMA to estimating emission control required to bring a specific area into compliance consists of the following steps [National Research Council (NRC), 1991]. The model is run for various combinations of $\mathrm{VOC}$ and $\mathrm{NO}_{\mathrm{X}}$ initial concentrations and $\mathrm{VOC}$ and $\mathrm{NO}_{\mathrm{X}}$ emission injection scenarios along a hypothetical trajectory. The results from these runs are converted into maximum ozone concentration isopleths as a function of initial VOC and $\mathrm{NO}_{\mathrm{X}}$ concentrations (see Figure 4.1). In this plot, the loci of constant $\mathrm{VOC} / \mathrm{NO}_{\mathrm{x}}$ ratios are straight lines passing through the origin. Then one of these lines corresponds to the measured $\mathrm{VOC} / \mathrm{NO}_{\mathrm{X}}$ measured in the early morning in the upwind area of interest. The intersection of this line with the maximum measured ozone concentration specifies the current state of the area. With this information we can choose the path to the National Ambient Air Quality Standards (NAAQS) ozone isopleth in terms of VOC and $\mathrm{NO}_{\mathrm{X}}$ reductions.

The EKMA results are sensitive to the specification of the initial $\mathrm{VOC} / \mathrm{NO}_{\mathrm{X}}$ ratio and the emission injection history. Because these inputs are uncertain, EKMA is considered to be inadequate for developing control strategies for particular areas. However, in principle, it can use spatially and temporally varying emissions and meteorology along a calculated trajectory.

Because of the practical limitations of the EKMA model, the use of three-dimensional grid models is considered more scientifically acceptable, and use of the EKMA approach is no longer recommended by the EPA (NRC, 1991). However, models based on EKMA airshed scenarios have been adopted to calculate VOC reactivity scales, as discussed in detail in Section 6. EKMA-type models are well suited for VOC reactivity assessment because VOC reactivity is primarily a chemical effect. EKMA models can use much more detailed chemical mechanisms than is practical for Eulerian models. 
Table 4.1. Comparison of Currently Used Air Quality Models

\begin{tabular}{|c|c|c|c|c|c|c|}
\hline \multirow{2}{*}{$\begin{array}{l}\text { Name-Abbreviation } \\
\text { Major Reference }\end{array}$} & \multirow{2}{*}{$\begin{array}{l}\text { Vertical Domain- } \\
\text { Horizontal Scale }\end{array}$} & \multicolumn{3}{|c|}{ Treatment of Processes } & \multirow{2}{*}{$\begin{array}{l}\text { Construction of } \\
\text { Winds }\end{array}$} & \multirow{2}{*}{$\begin{array}{c}\text { Form of Mass } \\
\text { Conservation } \\
\text { Equation }\end{array}$} \\
\hline & & Chemistry & Vertical Transport & Cloud Processes & & \\
\hline $\begin{array}{l}\text { CMU and CIT Model } \\
\text { Carnegie Mellon University and } \\
\text { California Institute of Technology } \\
\text { McRae et al., } 1982\end{array}$ & $\begin{array}{l}\text { - } 1.5 \mathrm{~km} \\
\text { - Urban scale }\end{array}$ & $\begin{array}{l}\text { - SAPRC gas phase chemistry } \\
\text { - No aqueous phase chemistry }\end{array}$ & $\begin{array}{l}\text { - Turbulent Diffusion } \\
\text { (Does not conserve } \\
\text { mixing ratio) } \\
\text { - No transport by clouds }\end{array}$ & - None & $\begin{array}{l}\text { - Data interpolation } \\
\text { with diagnostic wind } \\
\text { field model }\end{array}$ & - Flux Form \\
\hline $\begin{array}{l}\text { UAM } \\
\text { SAI } \\
\text { Reynolds et al., 1973,1979 }\end{array}$ & $\begin{array}{l}\text { - } 1.5 \mathrm{~km} \\
\text { - Urban scale }\end{array}$ & $\begin{array}{l}\text { Carbon Bond IV gas phase } \\
\text { chemistry } \\
\text { - No aqueous phase chemistry }\end{array}$ & $\begin{array}{l}\text { - Turbulent Diffusion } \\
\text { - No transport by clouds }\end{array}$ & - None & $\begin{array}{l}\text { Data interpolation } \\
\text { with diagnostic wind } \\
\text { field model }\end{array}$ & - Flux Form \\
\hline $\begin{array}{l}\text { RADM } \\
\text { State University of New York- } \\
\text { Albany. } \\
\text { Chang et al., } 1987\end{array}$ & $\begin{array}{l}-16 \mathrm{~km} \\
- \text { Urban and } \\
\text { Regional scale }\end{array}$ & $\begin{array}{l}\text { - RADM gas phase mechanism } \\
\text { - } 42 \text { equilibria and } 5 \text { reactions in } \\
\text { aqueous phase chemistry }\end{array}$ & $\begin{array}{l}\text { - Turbulent Diffusion } \\
\text { - Transport by cumulus } \\
\text { clouds }\end{array}$ & $\begin{array}{l}\text { - Chemistry and wet } \\
\text { removal in precipating } \\
\text { and non-precipitating } \\
\text { cumulus clouds }\end{array}$ & $\begin{array}{l}\text { Observations } \\
\text { assimilated into } \\
\text { predictions from } \\
\text { MM4 dynamic } \\
\text { mesoscale model }\end{array}$ & - Flux Form \\
\hline $\begin{array}{l}\text { ROM } \\
\text { EPA } \\
\text { Lamb } 1983\end{array}$ & $\begin{array}{l}-4 \mathrm{~km} \\
\text { - Urban and } \\
\text { Regional scale }\end{array}$ & $\begin{array}{l}\text { - Carbon Bond IV gas phase } \\
\text { chemistry } \\
\text { - No aqueous phase chemistry }\end{array}$ & $\begin{array}{l}\text { - Turbulent Diffusion } \\
\text { - Transport by cumulus } \\
\text { clouds }\end{array}$ & - None & $\begin{array}{l}\text { - Data interpolation } \\
\text { with diagnostic wind } \\
\text { field model }\end{array}$ & - Advective Form \\
\hline $\begin{array}{l}\text { STEM II } \\
\text { University of Kentucky } \\
\text { Carmichael et al., } 1986 \\
\end{array}$ & $\begin{array}{l}-6 \mathrm{~km} \\
\text { - Urban and } \\
\text { Regional scale }\end{array}$ & $\begin{array}{l}\text { - SAPRC mechanism } \\
\text { - } 26 \text { equilibria and } 30 \text { reactions in } \\
\text { aqueous phase chemistry }\end{array}$ & $\begin{array}{l}\text { - Turbulent Diffusion } \\
\text { - Transport by cumulus } \\
\text { clouds }\end{array}$ & $\begin{array}{l}\text { - Chemistry and wet } \\
\text { removal in precipating } \\
\text { and non-precipitating } \\
\text { cumulus clouds }\end{array}$ & $\begin{array}{l}\text { - Data interpolation } \\
\text { with diagnostic wind } \\
\text { field model }\end{array}$ & - Flux Form \\
\hline $\begin{array}{l}\text { ADOM } \\
\text { ENSR Consulting and } \\
\text { Engineering } \\
\text { Venkatram et al., } 1988\end{array}$ & $\begin{array}{l}-10 \mathrm{~km} \\
\cdot \text { Urban and } \\
\text { Regional scale }\end{array}$ & $\begin{array}{l}\text { - SAPRC mechanism } \\
\text { - } 14 \text { equilibria and } 5 \text { reactions in } \\
\text { aqueous phase chemistry }\end{array}$ & $\begin{array}{l}\text { - Turbulent Diffusion } \\
\text { - Transport by stratus } \\
\text { and cumulus clouds }\end{array}$ & $\begin{array}{l}\text { - Chemistry and wet } \\
\text { removal in precipating } \\
\text { and non-precipitating } \\
\text { stratus and cumulus } \\
\text { clouds }\end{array}$ & $\begin{array}{l}\text { Observations } \\
\text { assimilated into } \\
\text { predictions from } \\
\text { Canadian large scale } \\
\text { weather prediction } \\
\text { dynamic model }\end{array}$ & - Advective Form \\
\hline
\end{tabular}




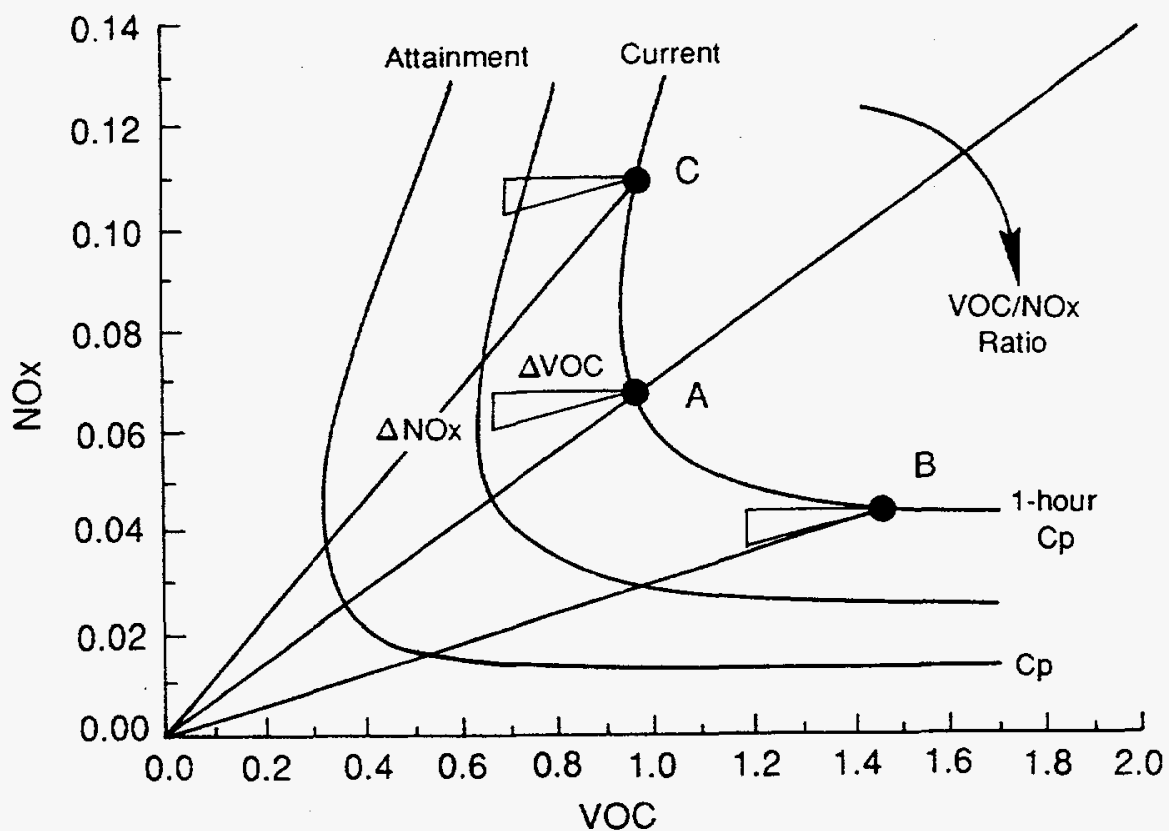

Figure 4.1. Ozone isopleth diagram for three cities (A, B, and C) that have the same peak 1-hour ozone concentrations $(\mathrm{Cp})$. The $\mathrm{VOC} / \mathrm{NO}_{\mathrm{x}}$ ratios differ: a low ratio (C), a high ratio (B), and a medium ratio (A). Isopleths $=$ lines of constant 1-hour peak ozone. (NRC, 1993)

\subsection{Model Performance}

Comprehensive air quality models have been extensively evaluated with observations over the past 15 years (Roth et al., 1989). In most cases, these evaluations have consisted of comparing estimated time series of hourly averaged ozone concentrations near the surface with corresponding observations. This type of evaluation has limited value. To see this, consider the simple picture in which the final concentration of ozone is determined by a mixture consisting of initial concentrations of VOC and $\mathrm{NO}_{\mathrm{x}}$ that is subject to photolysis in a box. We know that different combinations of the concentrations of the precursors, VOC and $\mathrm{NO}_{\mathrm{x}}$, can result in the same concentration of ozone. Furthermore, the ozone concentration resulting from initial concentrations of $\mathrm{VOC}$ and $\mathrm{NO}_{\mathrm{x}}$ depends on the time of exposure to photolysis, which corresponds to the travel time between precursor source area and the receptor. Thus, in a sense, the chemical state of the photochemical system is specified by at least three variables: the initial VOC and $\mathrm{NO}_{\mathrm{x}}$ concentrations, time of photolysis, or the final $\mathrm{VOC}, \mathrm{NO}_{\mathrm{x}}$, and ozone concentrations. Clearly, reasonable evaluation of the model requires comparison of model estimates of $\mathrm{VOC}$ and/or $\mathrm{NO}_{\mathrm{x}}$ concentrations with corresponding observations, in addition to comparison with ozone. Most evaluations performed to date deal only with ozone concentrations, primarily because of the lack of data on VOC and/or $\mathrm{NO}_{\mathbf{x}}$ concentrations; the lack of data does not change the fact that ozone only evaluations are incomplete.

Studies on model performance of urban scale models (Roth et al., 1989) conducted thus far indicate that the mean discrepancies between model estimates and measured zone concentrations are about $20 \%$ to 
$40 \%$ of the observations, when paired in space and time. The peak ozone concentrations are generally underestimated by about $15 \%$ (NRC, 1991).

The limited comparisons of model estimates with $\mathrm{NO}_{2}$ observations show that the model underestimates the observations by about $30 \%$. Very few comparisons have been made with VOC observations. A recent study (Harley et al., 1993) used VOC measurements made during the Southern California Air Quality Study (SCAQS) conducted in the Los Angeles basin in 1987. The results from the study show that the CIT model underestimates the VOC observations by about $35 \%$ (see Figure 4.2). This underestimate was consistent with that for the corresponding ozone estimates, which were underestimated by about $25 \%$; however, the peak ozone concentrations downwind of source areas were underestimated by more than $50 \%$ (Figure 4.3). Model estimates of $\mathrm{NO}_{2}$ were consistent with the observations only when the observations of $\mathrm{NO}_{2}$ were assumed to include other reactive nitrogen compounds. Even here, the model underestimated the peaks by $50 \%$ in the $\mathrm{NO}_{2}$-rich emission regions (Figure 4.2 ).

Most modelers believe that the ozone underprediction bias is related to the underestimation of VOC emissions from mobile sources, as discussed in Section 3. This theory was tested by Harley et al. (1993) by increasing the light-duty vehicle VOC emissions by a factor of 3 in a sensitivity study with the CIT model. As expected, the ozone and VOC concentrations increased. However, the peak ozone concentrations in Claremont and Rubidoux, the downwind areas, were still underpredicted by $30 \%$; and the VOC concentrations were still underpredicted by about $30 \%$ at these stations (Figure 4.3 ). These results suggest that underestimation of VOC emissions could be a contributor to the underprediction of ozone peaks, but it cannot be the only or possibly the primary cause.

These results suggest the need for a detailed study to examine the effect of numerical schemes on concentration estimates from grid models. There is good reason to believe that some of the ozone underprediction problems could be related to numerical errors rather than VOC emission underestimates. This is supported by results from the application of ADOM and RADM to regional scales (Barchet et al., 1991), where underestimation of VOC emissions is not a problem. Even here, ozone is underestimated by more than $20 \%$. The interesting observation is that the same chemistry that underestimates ozone concentrations in ADOM yields the observed ozone peaks when incorporated into a Lagrangian model, which presumably avoids the numerical dispersion of Eulerian models (Report of the External Review Panel of the EMEFS).

Schere and Wayland (1989) performed a detailed evaluation of the ROM regional model using data from five ozone episodes in the Northeast corridor during 1980. They found that the model performed best when ozone observations were around $60-100 \mathrm{ppb}$. The model underpredicted observed concentrations in the range $120-140 \mathrm{ppb}$ by about $30 \mathrm{ppb}$, and the observations above $160 \mathrm{ppb}$ by as much as $60 \mathrm{ppb}$. The observed ozone peaks went above $170 \mathrm{ppb}$, but the model estimates rarely exceeded $100 \mathrm{ppb}$. The model also overpredicted the minimum nighttime concentrations by about $20 \mathrm{ppb}$. Thus, the range of model estimates was smaller than that of the observations.

The experience with ROM is similar to the recently completed intercomparison of RADM and ADOM with the EMEFS data (Barchet et al., 1991). Both RADM and ADOM underpredicted the peak ozone concentrations by about $20 \mathrm{ppb}$ when the observed peaks were about $120 \mathrm{ppb}$ at the surface; the RADM overpredicted the minimum ozone concentrations during the night. 

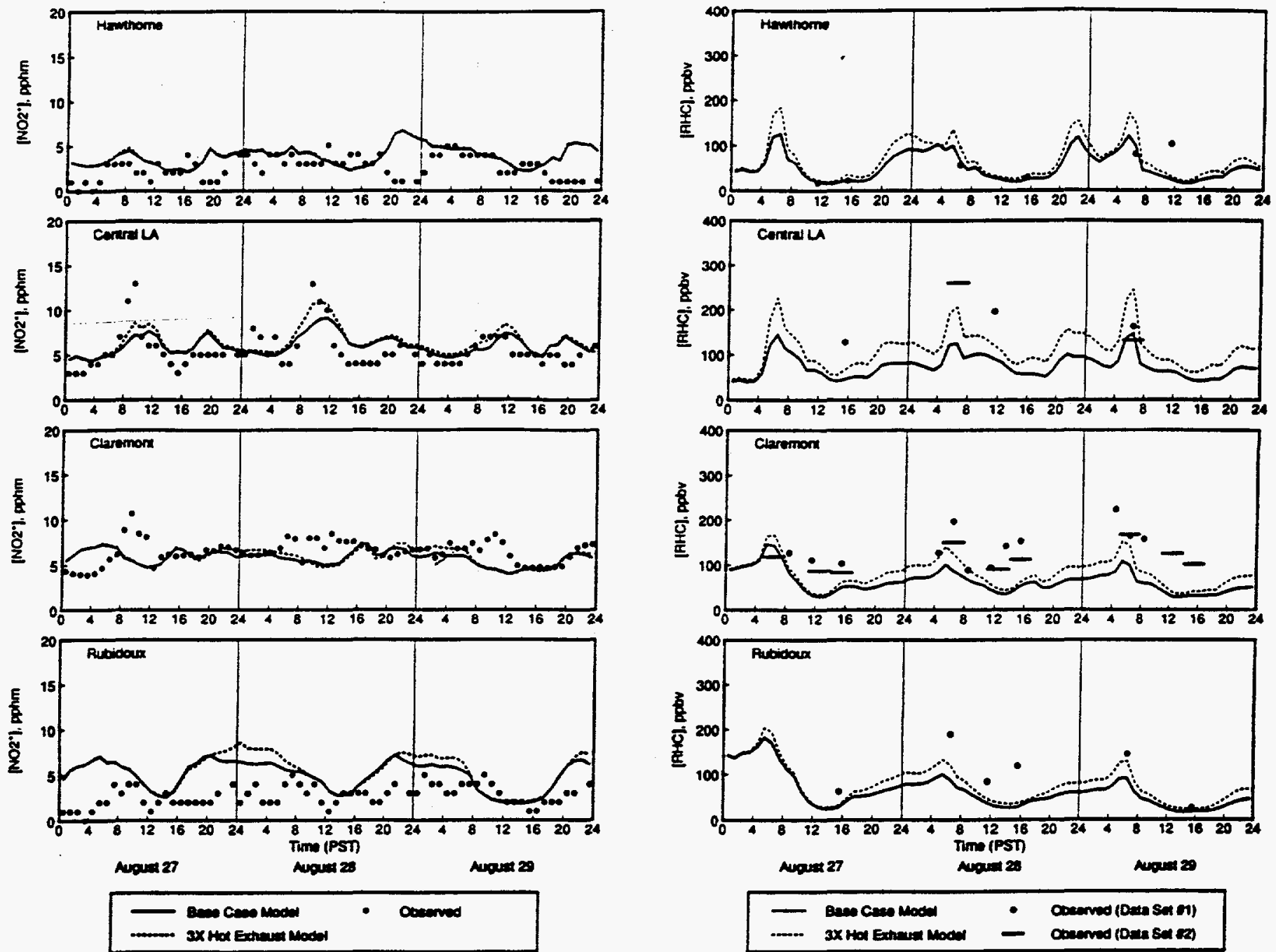

(a)

(b)

Figure 4.2. (a) Time series plots of observed $\mathrm{NO}_{2}$ concentrations (solid circles) and model predictions for the base case (solid line) and for the case of increased on-road vehicle hot exhaust emissions (dashed line); (b) Time series plots of observed reactive hydrocarbon concentrations (measurements from data set 1 plotted as solid circles; 3 -h average samples from data set 2 plotted as horizontal bars) and model predictions for the base case (solid line) and for the case of increased on-road vehicle hot exhaust emissions (dashed line). (Harley et al., 1993) 

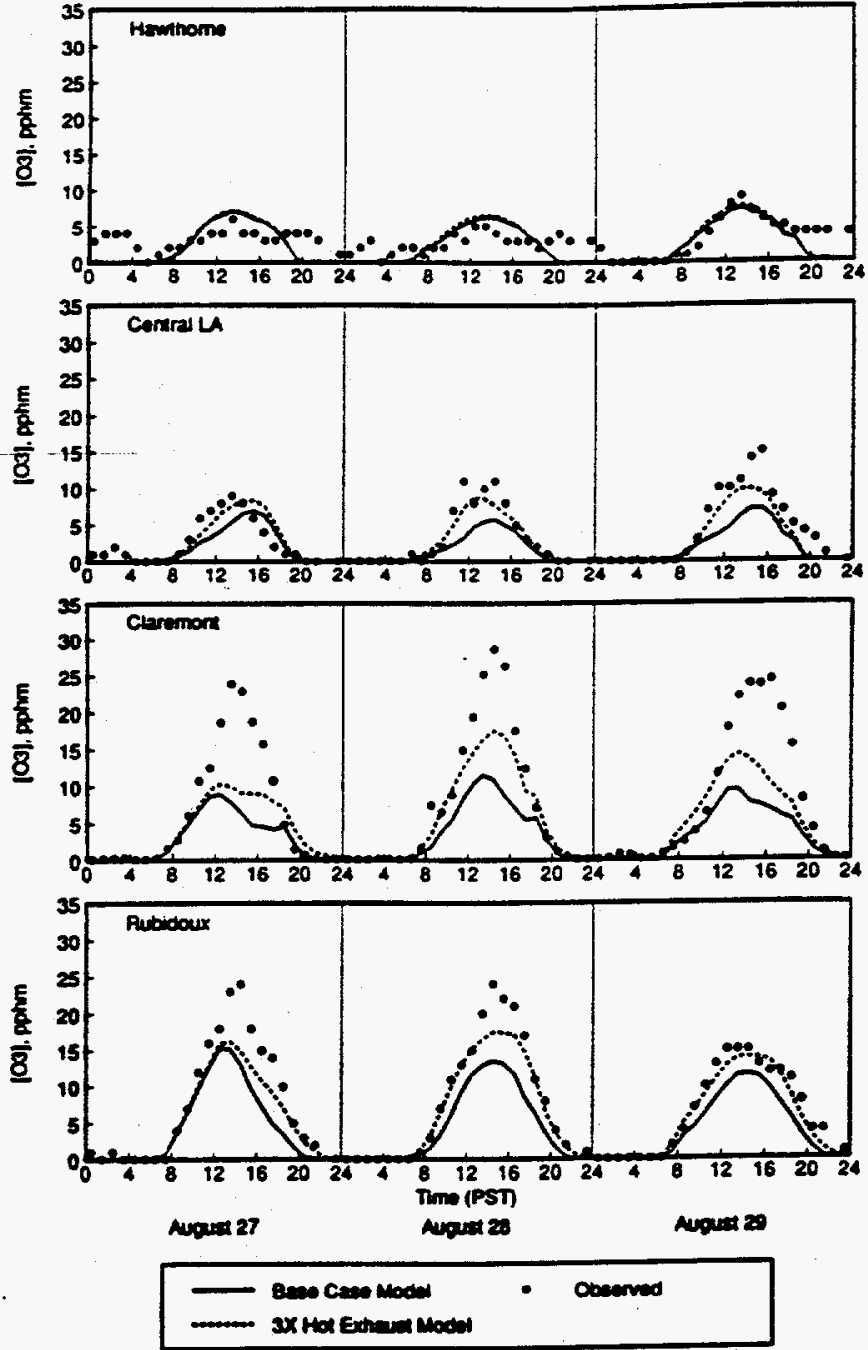

Figure 4.3. Time series plots of observed ozone concentrations (solid circles) and model predictions for the base case (solid line) and for the case of increased on-road vehicle hot exhaust emissions (dashed line). (Harley et al., 1993) 
Schere and Wayland (1989) also compared models estimates of $\mathrm{NO}_{\mathrm{X}}$ and VOC with available observations. They found that ROM underpredicted $\mathrm{NO}_{\mathrm{x}}$ concentrations by about a factor of 2 , and VOC concentrations by as much as a factor of 6 . It is possible that the underestimation of $\mathrm{NO}_{\mathrm{x}}$ and VOC emissions might be responsible for these model underestimates. However, correcting VOC emissions might have little effect on the ozone concentrations because regional $\mathrm{VOC} / \mathrm{NO}_{\mathrm{x}}$ ratios are usually high enough ( $>10)$ to make ozone relatively insensitive to VOC emission changes. Clearly, sensitivity studies with ROM are required to examine these issues.

The following picture arises from the model performance studies conducted with both urban and regional scale models:

- Models underpredict peak ozone concentrations by about $20 \%$

- Most studies are incomplete in that model estimates have not been compared with observations of VOC and $\mathrm{NO}_{\mathrm{X}}$ concentrations. The few studies that have done so indicate that grid models underpredict these precursor concentrations by significant factors.

- It is generally believed that the underprediction of ozone peaks is related to the underestimation of VOC emissions. However, a recent study (Harley et al., 1993) conducted to test this hypothesis shows that this cannot be the only cause of ozone underestimation. Clearly, VOC emission underestimation alone cannot explain the inability of regional scale models to estimate ozone peaks.

Currently available comprehensive models are plagued by the inability to treat processes at different scales. For example, we have not yet come up with a practical method for treating the chemistry and dispersion of plumes in a grid system whose grid spacing is generally much larger than the initial dimensions of the plume. The plume-in-grid modules used in some of the grid models represent the unsatisfactory grafting of a Lagrangian approach into an Eulerian system; this approach has not yielded any conclusive results.

Some current air quality models might be based on an incorrect mass conservation equation. The UAM expresses the equation in terms of the mixing ratio, $q$, but incorrectly uses the flux form on the lefthand side of the equation. The CIT model expresses the mass conservation equation in terms of $C$, but fails to express the turbulent dispersion term in terms of $q$. These effects of these errors on the solution might not be negligible, and need to be investigated.

In view of the current performance of comprehensive ozone models, it is not clear that they represent the only reliable tools for estimating the air quality effects of replacing conventional fuels with less reactive fuels, such as methanol. Until comprehensive grid models are improved, their results need to be supplemented with those from alternative approaches, such as EKMA, which compensate for their simple formulation by using measured values of $V O C / \mathrm{NO}_{\mathrm{x}}$ concentration ratios and the maximum ozone concentration as inputs. In the next section, we provide a critique of the use of ozone models in examining the effect of alternative fuels. 


\subsection{Representation of Chemical Processes}

The representation of the chemical processes is a critical component of the airshed models used to assess the effects of emissions on ozone. This is because ozone is not emitted directly, but is formed in the chemical transformations of the $\mathrm{VOC}$ and $\mathrm{NO}_{\mathrm{x}}$ species that are emitted. An appropriate representation of chemistry is particularly important when modeling the effects of alternative fuel use, because most of the fuel options being considered involve changing the chemical compositions (i.e., reactivity) of the VOC emissions. Because of this, the chemical basis of ozone formation and VOC reactivity, and the methods used to represent these processes in the current generation of airshed models, are discussed separately in this section.

\subsection{Chemical Basis of Ozone Formation}

Ozone and other photochemical oxidants are formed in the gas-phase chemical reactions of the emitted $\mathrm{NO}_{\mathrm{x}}$ and VOCs in sunlight. The only significant reaction forming ozone in the lower troposphere is the photolysis of $\mathrm{NO}_{2}$, which is reversed by the rapid reaction of $\mathrm{O}_{3}$ with $\mathrm{NO}$.

$$
\begin{gathered}
\mathrm{NO}_{2}+\mathrm{hv} \rightarrow \mathrm{O}\left({ }^{3} \mathrm{P}\right)+\mathrm{NO} \\
\mathrm{O}\left({ }^{3} \mathrm{P}\right)+\mathrm{O}_{2}+\mathrm{M} \rightarrow \mathrm{O}_{3}+\mathrm{M} \\
\mathrm{O}_{3}+\mathrm{NO} \rightarrow \mathrm{NO}_{2}+\mathrm{O}_{2} .
\end{gathered}
$$

This results in $\mathrm{O}_{3}$ being in a photostationary state dictated by the light intensity and the $\left[\mathrm{NO}_{2}\right] /[\mathrm{NO}]$ ratio. If reactive VOCs were not present, then $\mathrm{O}_{3}$ (and other oxidants) would not be formed in significant amounts. When VOCs are present, they react to form radicals, which either consume NO or convert NO to $\mathrm{NO}_{2}$, which, because of the photostationary state relationship, causes $\mathrm{O}_{3}$ to increase. Although many types of reactions are involved, the major processes responsible for $\mathrm{O}_{3}$ formation can be summarized as follows:

$$
\begin{gathered}
\mathrm{VOC}+\mathrm{OH} \rightarrow \mathrm{RO}_{2}+\text { products } \\
\mathrm{RO}_{2}+\mathrm{NO} \rightarrow \mathrm{NO}_{2}+\text { radicals } \\
\text { radicals } \rightarrow \mathrm{OH}+\text { products }
\end{gathered}
$$

where "products" can include oxygenated organics such as aldehydes, most of which also react to promote ozone formation. The rate of ozone increase caused by these processes is dependent on the amounts of VOCs present, the rate constants for the VOC's initial reactions, the number of radicals the VOC forms that oxidize NO or convert $\mathrm{NO}$ to $\mathrm{NO}_{2}$, and the level of $\mathrm{OH}$ radicals and other species with which the VOCs might react. Ozone production continues as long as sufficient $\mathrm{NO}_{\mathrm{x}}$ is present that reactions of peroxy radicals $\left(\mathrm{RO}_{2}\right)$ with $\mathrm{NO}_{\mathrm{x}}$ compete effectively with their reactions with other peroxy radicals.

Note that $\mathrm{OH}$ radicals are particularly important in affecting the $\mathrm{O}_{3}$ formation rate because reaction with $\mathrm{OH}$ is a major (and in many cases the only) process causing most VOCs to react. The $\mathrm{OH}$ radical levels are strongly influenced by the VOCs, with some causing enhanced $\mathrm{OH}$ levels (through photoinitiation reactions), and others causing radical inhibition. If the reactions of a VOC enhance radical levels, the higher radical levels would increase the rate of ozone formation from all the other reacting VOCs, while 
the opposite would occur if the VOC causes radical inhibition. For many VOCs, this is a more important factor determining the net effect of the VOC on ozone than the ozone formed directly from the VOC's reactions. Aromatics, formaldehyde, and internal alkenes are examples of VOCs that enhance radical levels, but high molecular weight alkanes are the most important examples of radical inhibitors.

Ozone formation stops once $\mathrm{NO}_{\mathrm{x}}$ is consumed. Because $\mathrm{NO}_{\mathrm{x}}$ is removed from the atmosphere more rapidly than VOCs (most VOCs form product VOCs, which also react), $\mathrm{NO}_{\mathrm{x}}$ ultimately limits $\mathrm{O}_{3}$ formation if sufficient time is available to react. If the $\mathrm{NO}_{\mathrm{X}}$ levels are sufficiently high that is not consumed before the end of the day, then the rate of the VOC's reactions and their effects on $\mathrm{OH}$ radicals determine the ozone impact of the VOCs. $\mathrm{NO}_{\mathbf{X}}$ inhibits $\mathrm{O}_{3}$ under high $\mathrm{NO}_{\mathbf{X}}$ conditions because reaction of $\mathrm{OH}$ with $\mathrm{NO}_{2}$ is an important radical terminating process. If, however, $\mathrm{NO}_{\mathbf{x}}$ is consumed before the end of the day, then $\mathrm{O}_{3}$ is $\mathrm{NO}_{\mathrm{x}}$-limited, and increasing $\mathrm{NO}_{\mathbf{x}}$ would cause increased $\mathrm{O}_{3}$ formation. Under such conditions, if a VOC's reactions caused $\mathrm{NO}_{\mathrm{x}}$ to be removed more rapidly than if the VOC were absent; such as, for example, by forming nitrogen-containing products such as peroxy acetyl nitrates (PANs) from aldehydes and nitrophenols from aromatics, this would have a negative effect on $\mathrm{O}_{3}$ yields. Thus, some VOCs that cause enhanced $\mathrm{O}_{3}$ levels under high $\mathrm{NO}_{\mathrm{x}}$ conditions actually cause peak ozone levels to decrease when $\mathrm{NO}_{\mathrm{x}}$ is sufficiently low. Toluene and other aromatics are examples of such compounds.

\subsection{Chemical Mechanisms}

The chemical mechanism is the portion of the airshed model used to represent the gas-phase processes by which the emitted species cause formation of ozone and other secondary pollutants. The mechanism must be able to take all these factors into account if it is to credibly predict the effects of VOC or $\mathrm{NO}_{\mathrm{X}}$ emissions changes on formation of ozone or other oxidants. Several hundred types of organic compounds have been identified in speciated emissions inventories, and all have differing reaction rates, amounts of NO oxidation caused by the radicals they form, effects on $\mathrm{OH}$ radical and $\mathrm{NO}_{\mathrm{x}}$ levels, and reactivities of their products. Current laboratory and chamber data are available to develop and test the mechanisms for only a subset of these, and there are major gaps in our understanding of important details of the atmospheric reactions of all but the simplest VOCs. For this reason, even some of the most extensively studied VOCs are represented in airshed models using parameterized mechanisms that are adjusted to fit environmental chamber data. For the other VOCs, their reactions are either derived by analogy with mechanisms for compounds that have been studied, or they are represented as if they reacted the same way as the other compound.

Nevertheless, the rate constants for at least the initial atmospheric reactions of almost all important VOCs have been measured or can be estimated with a reasonable level of confidence (Atkinson, 1987, 1990, 1994 and references therein). Mechanistic data and environmental chamber results are available for enough representative compounds to allow parameterized mechanisms to be developed to represent reactions of more than 100 types of VOCs (Carter, 1990). Such a mechanism has been incorporated in a Lagrangian model and used to estimate the ozone reactivities of most VOCs measured from vehicle emissions (Carter and Atkinson, 1989; Carter, 1991, 1993, 1994a). This mechanism still uses a highly simplified representation of the subsequent reactions of these species, designed mainly to represent the overall photooxidation and ozone formation processes. Lagrangian models can potentially incorporate much more complex mechanisms than this (e.g., NCAR, 1987), but given the current state of knowledge 
of atmospheric reactions of VOCs, any additional complexity would be largely speculation which would not necessarily improve the model's predictive capability.

Eulerian models are very computationally intensive, and most of the computer time is taken up in processing the chemistry. Because of this, such models must have highly condensed chemical mechanisms. For example, the CB4 mechanism in the UAM model (the most widely used model in regulatory applications), uses only 11 model species to represent the hundreds of types of VOCs emitted, and the Lurmann, Carter, and Coyner (LCC) mechanism (Lurmann et al., 1987) in the CMU model (used in a number of alternative fuel assessments and other research applications [e.g., Russell et al., 1989, 1990; McNair et al., 1992, 1994]), is similar in its level of detail, though it uses somewhat different condensation approaches. Such mechanisms were developed and optimized to simulate current ambient mixtures, and were not designed for use in evaluating scenarios where the emissions speciation may change significantly. In particular, they cannot take advantage of the full chemical information contained in speciated emissions data and our current best estimates for the chemical reactions of all individual species involved. Some "fixes" have been applied to the Carbon Bond mechanism for use in alternative fuel assessment by adding explicit reactions for methanol, ethanol, and MTBE, but these are only a few of the compounds that need to be taken into account when assessing alternative fuel use.

Even if it were practical to incorporate detailed explicit mechanisms in airshed models, such models would not necessarily give even approximate predictions of the effects of alternative fuel use. This is because there are major gaps in our understanding of many important details of the atmospheric photooxidation reactions of all but the simplest VOCs. Thus, most reactions in existing explicit mechanisms reflect estimates or speculation. We know that VOCs can react in the atmosphere by reacting with $\mathrm{OH}$ radicals and in some cases by reacting with $\mathrm{O}_{3}, \mathrm{NO}_{3}, \mathrm{O}\left({ }^{3} \mathrm{P}\right)$ and direct photolysis. For most VOCs the rate constants which might be significant for these primary processes have been measured or can be estimated based on data for similar compounds (Atkinson, 1987, 1990, 1994). However, the subsequent reactions are much less well characterized, and the rate constants have been measured for only the simplest analogues for the major types of radicals believed to be formed. There are major uncertainties in the reactions involved and even the products formed in many of the important photooxidation routes. The photooxidation reactions of the aromatics are perhaps the most uncertain, as only a fraction of the reacting carbon has been quantitatively identified for even the most well-studied molecule (toluene), and qualitative studies show that many products are formed for which detailed reaction mechanisms have not been formulated (Dumdei and O'Brein, 1984; Shepson et al., 1984). Modeling of smog chamber experiments indicates that these uncertain processes and unidentified products must be extremely important in affecting the aromatics' reactivity. The reactions of alkenes with ozone proceed via a highly complex mechanism, which remains highly uncertain despite much study (Atkinson, 1990, 1994), and modeling indicates they are also important in affecting alkene reactivity. Even the higher alkanes have significant uncertainties, as the major types of products believed to be formed based on theoretical considerations (Carter and Atkinson, 1985) have not been identified experimentally.

Because of this, before any chemical mechanism-whether detailed or condensed-is incorporated in an airshed model, it must be demonstrated to predict at least the major features of the $\mathrm{VOC}-\mathrm{NO}_{\mathrm{X}}$-air photooxidation process. This can be tested by conducting environmental chamber experiments, where the chemical processes of interest are occurring under controlled and well-characterized conditions and then by determining whether the results are consistent with the predictions of the mechanism. Irradiations of 
single VOCs in the presence of $\mathrm{NO}_{\mathrm{x}}$ in air test the mechanisms for the individual compounds; $\mathrm{NO}_{\mathrm{x}}$-air irradiations of more complex mixtures test the performance of the model as a whole (Gery et al., 1987; Carter and Lurmann, 1990, 1991; Jeffries et al., 1992); and experiments where the effect of adding single VOCs to irradiations of $\mathrm{NO}_{\mathrm{x}}$ and complex mixtures test model predictions of the VOC's incremental reactivity (Carter and Atkinson, 1987; Carter et al., 1993). Evaluation of chemical mechanisms with chamber data is complicated by uncertainties in chamber effects (Carter et al., 1982; Carter and Lurmann, 1990, 1991; Jeffries et al., 1992), and separate characterization experiments are needed to evaluate models for these effects, which are used when evaluating the mechanism of interest (Carter and Lurmann, 1990, 1991; Jeffries et al., 1992). Although this introduces uncertainties in such evaluations, the uncertainties in evaluating chemical mechanisms using chamber data are far less than the uncertainties in attempting to evaluate mechanisms using the full airshed model and ambient air data. At least with chamber experiments, the amounts of input pollutants are accurately known, and there are no uncertainties regarding dilution or transport that need to be dealt with.

Current chamber data are available to test the mechanisms for only a subset of the many types of VOCs emitted into the atmosphere. For the other species, reactions are either derived by analogy with mechanisms for compounds that have been studied, or they are represented in the model as if they reacted in the same way as some other species. The latter is referred to as "lumping," where a single species is used in the model to represent an entire class of compounds assumed to react in the same way, or a group of model species is used to represent various aspects of the reactions of various chemical compounds. The various lumping approaches, and the approximations and inaccuracies they introduce, vary depending on the mechanisms, as discussed below.

The chemical mechanisms currently in use, which have been evaluated against chamber data, include the CB4 mechanism (Gery et al., 1988), the LCC mechanism (Carter et al., 1986a; Lurmann et al., 1987), the RADM-2 mechanism (Stockwell et al., 1990; Carter and Lurmann, 1990), and the SAPRC-90 mechanism (Carter, 1990). In addition, the Harwell mechanism (Derwent and Hov, 1979) is being used in a number of European modeling studies (e.g., Derwent and Hough, 1988; Derwent and Jenkin, 1991; AnderssonSkold et al., 1992), though it is not being considered for alternative fuel evaluations in the U.S. because it has not been evaluated against chamber data, and is not formulated in a way currently compatible with Eulerian airshed model software. With the possible exception of the Harwell mechanism, none of these mechanisms attempts to explicitly represent all chemical reactions and species of significance. Instead, they all use various approximations and "lumping" procedures to reduce their size and make them more computationally tractable. The major features of these various mechanisms are briefly summarized below.

\subsubsection{Carbon Bond IV (CB4)}

The CB4 mechanism is documented by Gery et al. (1988). This is incorporated in the UAM, the only model officially approved by EPA for attainment demonstration modeling. The UAM is also being used in the modeling for AQIRP (1991e, 1992a; Pollack et al., 1993). This is a highly compact mechanism whose implementation has been optimized for computational efficiency. This compactness is achieved in part through use of the "Carbon Bond" lumping procedure, where model species are used to represent parts of molecules that are assumed to react independently. Unfortunately, in reality different parts of real molecules do not react independently, and various generations of the Carbon Bond mechanisms have had to abandon different aspects of the Carbon Bond approximations as more chamber data became available 
to demonstrate their problems (Gery et al., 1988 and references therein). The Carbon Bond approximations remaining in CB4 primarily concern the use of a single model species (PAR for "paraffin") to represent all alkane carbons and carbons in other reactive molecules not represented by other groups, and the use of product species to represent the rapidly reacting internal double bonds. Other approximations in this model are similar to those used in the other mechanism; i.e., a single aldehyde species is used for all higher aldehydes, a single "TOLU" ("toluene") species is used for all monoalkylbenzenes, a single species is used to represent terminal alkenes, etc.

Despite its approximations, the mechanism performed fairly well in simulating the chamber experiments used in its evaluation (Gery et al., 1988), which included runs with representative compounds used to derive mechanisms of the lumped model species (e.g., ethylene, propene, toluene, m-xylene, formaldehyde, and acetaldehyde), as well as runs with complex VOC mixtures representative of ambient conditions.

In view of its ability to simulate experiments designed to represent current ambient mixtures, this mechanism is probably as well suited as any for use in airshed models where the speciation of the emissions is not significantly different from that assumed when the mechanism was developed. It may be better than most for some applications because of its superior computational efficiency. However, its relatively high degree of chemical approximation makes it much less suited for the assessments of alliterative fuel use, which involve major changes to the ambient speciation compared to that assumed when it was developed, and introduction of species that the model was not designed to represent. The latter problem has been addressed to some extent by explicitly adding methanol, ethanol, and MTBE as separate species in the mechanism. However, the CB4 mechanism still cannot represent effects of changes in alkane speciation, and its failure to explicitly incorporate initial reactions of internal alkenes can be expected to introduce inaccuracies in assessments of situations where emissions of these compounds may change significantly. The mechanism does not distinguish between the xylenes and the more reactive organics such as the trimethylbenzenes or the naphthalenes.

The CB4 mechanism has recently been updated for the Phase 2 AQIRP modeling by refining the methanol rate constant to reflect current data and by making its representation of low $\mathrm{NO}_{\mathbf{x}}$ radical-radical reactions somewhat less approximate than previously (Yarwood, private communication, 1994; Carter, 1994b). However, other than the introduction of the oxygenated species listed above, it has not been expanded to represent changes in emissions speciation in any greater detail than when it was originally developed.

The CB4 mechanism has some differences in its representation of aromatic photooxidations compared to the other mechanisms currently in use. These differences represent different approaches the developers used when adjusting the mechanisms to fit aromatics chamber data, and not necessarily differences in condensation approaches. Differences in prediction of aromatic reactivity between models using CB4 and those using other mechanisms may thus reflect effects of current uncertainties in our knowledge of atmospheric chemistry. However, their agreement would not necessarily mean there is no uncertainty, as CB4 makes the same assumptions as other mechanisms about other uncertainties in these mechanisms. 


\subsubsection{Lurmann, Carter and Coyner (LCC)}

LCC actually refers to two mechanisms, both developed by Lurmann et al. (1987) as condensations of a more detailed mechanism developed earlier by Carter et al. (1986a). The most condensed version is used in the CIT model by Russell and co-workers in a number of assessments of alternative fuel use and VOC reactivity evaluations (McNair et al., 1992, 1994; Russell et al., 1989, 1990). The less condensed version was developed for use in single-cell models such as EKMA. It has been used by Chang and co-workers in evaluations of methanol fuels using EKMA models (e.g., Chang et al., 1989; Chang and Rudy, 1990). The less condensed version of LCC has also been referred to as the "SAPRC/ERT" mechanism.

The detailed mechanism used as the starting point in the development of the LCC mechanisms (which can be referred to as SAPRC-86 because it was developed at SAPRC) has semi-explicit representations of approximately 20 representative alkanes, alkenes and aromatics, and $\sim 15$ species used for their oxygenated products. The SAPRC-86 mechanism was evaluated extensively against chamber data (Carter et al., 1986a), using procedures similar to those employed subsequently for the RADM (Carter and Lurmann, 1990) and SAPRC-90 (Carter and Lurmann, 1991) mechanisms. Lurmann et al. (1987) adapted this for use in the then-current generation of airshed models by producing several condensed versions with reduced numbers of model species to represent the VOCs and their products. The condensed mechanisms were evaluated by comparing their predictions with those of the detailed SAPRC86 using primarily simulations of ambient mixtures.

In the most condensed form, which is implemented in the CIT model, seven species are used for the HCs and methanol and approximately seven for the oxygenated products. For example, all alkanes are represented by a single species, all higher alkenes other than ethene are represented by another species, and two species were used to represent the various aromatics. Since this version of LCC has approximately the same number of organic species as CB4, it suffers the same problem-the lack of the chemical detail required to evaluate fuel options where emissions are significantly different from those assumed when it was developed. It is also the oldest of the mechanisms discussed here, and thus the most out of date. It is expected that Russell and co-workers will be updating the mechanism in the CIT model in the near future (Russell, private communication, 1994).

The less condensed version of LCC is slightly more detailed in that it uses two lumped species to represent alkanes (C4-C5 and $\mathrm{C} 6+$ ) and a separate species to represent terminal alkenes. As such, it would be expected to be somewhat better suited for representing speciation changes. However, it still has considerably less chemical detail than available in emissions inventories. It has approximately the same level of detail in terms of numbers of species used to represent emitted VOCs and their products as the RADM-II mechanism, discussed below.

Because of a documentation error (Lurmann et al., 1987), some versions of the LCC contain an incorrect implementation of the reactions of the "MEK" (methyl ethyl ketone) model species, used to represent most alkane photooxidation products, are much too reactive. This error causes the model to predict somewhat higher reactivities for alkanes than intended by the mechanism developers. This error was incorporated in versions of the CIT model used in various assessments of methanol fuel substitutions (e.g., Russell et al., 1989, 1990; McNair et al., 1992) and in the initial evaluations of the Carter (1993, 1994a) reactivity scales. It has subsequently been corrected (McNair et al., 1994). 


\subsubsection{RADM-II}

The RADM-II chemical mechanism was developed for use in regional acid deposition modeling by Stockwell et al. (1990), and was evaluated against chamber data by Carter and Lurmann (1990). It has a much more detailed representation of the peroxy + peroxy radical reactions-which become important under low $\mathrm{NO}_{\mathrm{x}}$ conditions - than the other current mechanisms. This makes it perhaps more suitable than the others for calculating peroxide formation, if the assumptions concerning the rate constants for these reactions are approximately correct. This is important in acid deposition models, but has essentially no effect on predictions of ozone formation (Carter and Lurmann, 1990). Other than this, the RADM-II mechanism is very similar to the version of the LCC mechanism used in EKMA models, except that it is somewhat more up-to-date, and it explicitly represents ethane and propane, as is appropriate for multi-day regional modeling. The aromatics mechanism is essentially the same as that used in the LCC and later SAPRC mechanisms, being based on the recommendations of Carter and Lurmann (1990).

The RADM model has not been used to (our knowledge) in evaluations of alternative fuel use; thus, this mechanism does not explicitly represent the oxygenated fuel components. However, because of greater chemical detail, the RADM-II mechanism is probably more suitable for evaluating alternative fuel use than CB4 or the CIT version of LCC, and it is to preferred to the EKMA version of LCC because it is slightly more up-to-date.

\subsubsection{Harwell Mechanism}

The chemical mechanism incorporated in the Harwell photochemical trajectory model is extensively used in Europe (e.g., Derwent and Jenkin, 1991; Andersson-Skold et al. 1992), and is based on the work of Derwent and Hov (1979). By design it is potentially suitable for assessing alternative fuel use, as it has separate representations of approximately 75 VOC species, though these do not include MTBE or other important components of some alternative fuels. Reactions for these species would have to be added, because the mechanism is designed to represent all reactants explicitly. Because of its large size, this mechanism cannot be incorporated into the current generation of three-dimensional models, and existing EKMA model software used in the U.S. for fuel reactivity evaluations would have to be significantly modified before it can be used. However, its most serious drawback is that it has not been evaluated against chamber data, and an examination of its details indicate omissions that probably would result in poor model performance when such an evaluation is performed. Until such an evaluation has been carried out and the omissions addressed, this mechanism will not be suitable for evaluation of alternative fuel use.

\subsubsection{SAPRC-90}

The SAPRC-90 mechanism is documented by Carter (1990) and was used in the calculation of the MIR scale (Carter, 1993, 1994a) which is now widely used for estimating alternative fuel emissions reactivity (e.g., CARB, 1991b, 1993c; AQIRP, 1993c). It is an updated and expanded version of the SAPRC-86 mechanism that was used to develop LCC mechanisms, and incorporates rate constant and product yield assignments for almost 120 separate VOCs or types of VOCs, including most - though not all —of the components of alternative fuel emissions. The different VOCs are represented using a variable parameter methodology, which allows the modeler to choose whether to represent a species explicitly, or whether to lump it with other species and use its parameters-together with those for the other species being lumped with it-to derive the most appropriate set of parameters for the model species. For the reactivity 
calculations, the VOC whose reactivity is being assessed is represented explicitly, and the other VOCs are lumped together using approximately the same level of detail as the species in the RADM-II or the EKMA version of LCC. However, because the parameters of the lumped species are optimized based on the mixture they represent, the full chemical detail in the emissions input can still be incorporated in the model without significantly increasing its size or computational burden.

The SAPRC-90 mechanism was evaluated by simulating the results of a variety of chamber experiments, and could simulate maximum ozone concentrations and rates of NO oxidation to within $\pm 30 \%$ for approximately two-thirds of the experiments (Carter and Lurmann, 1991). Thus, this is the only mechanism that is sufficiently detailed for reactivity assessments and that has been evaluated against chamber data. However, at the time it was developed, the chamber data were sufficient to test its ability to simulate the reactions of only $\sim 20$ representative VOCs, and it has not been updated to incorporate the results of an extensive series of experiments carried out in our laboratories designed explicitly to test reactivity predictions (Carter et al., 1993; unpublished results from this laboratory). Indeed, Carter et al. (1993) found that this mechanism significantly underpredicted the reactivities of alkenes (this being improved significantly with updates based on recent laboratory results) and also tended to underpredict the reactivities of most of the aromatics. Interestingly, Jeffries et al. (1992) found the opposite problem with this mechanism, in that it tended to significantly overpredict ozone formation in new University of North Carolina (UNC) experiments carried out to compare reactivities of alternative fuel surrogates, though it performed significantly better in experiments not containing aromatics (Jeffries et al., 1992). He also found that the Carbon Bond IV mechanism had the same problem. But these results are not consistent with our modeling of SAPRC and older UNC experiments with either mechanisms.

Although more detailed than others in its representation of the overall reactions of the various individual VOCs, SAPRC-90 uses approximately the same number of species as RADM-II or the EKMA version of LCC to represent the reactive organic products. It does use separate species to represent acetaldehyde and the higher $\left(\mathrm{C}_{3+}\right)$ aldehydes, which allows for a separation of PAN and the higher PAN analogues, and allows the use of acetaldehyde data for model evaluation studies. Nevertheless, this mechanism is still significantly condensed in terms of representation of reactive products, because a wide variety of product species can actually be formed. Nevertheless, such a condensation may not be inappropriate because only relatively few organic oxidation products have been identified, and the mechanisms for most would be largely speculative. Any greater level of detail in this regard would add to the complexity of the mechanism without necessarily improving its accuracy.

The SAPRC-90 mechanism has been critiqued in detail by Gery (1991), the principal developer of the CB4 mechanism. He concluded that the SAPRC-90 is more suitable for reactivity assessments than the other available mechanisms, but that it is out of date in some important respects and has a number of other areas where improvements are needed. One of its major problems is that it does not use the currently accepted rate kinetic parameters for PAN formation and formaldehyde photolysis, because making this update degraded the mechanism's performance against the chamber data base available at the time. (Recent results from our laboratories indicate that this may be caused in part by problems with the chamber characterization model.) (Carter et al., 1994b) He also had concerns about the parameterization of uncertain aromatic processes used in this, and most other, mechanisms. This mechanism is currently being updated to incorporate the new kinetic data, a re-evaluation of the past chamber data and chamber models (Carter et al., 1994b), and the extensive data base of new environmental chamber experiments concerning VOC reactivity. 
The SAPRC-90 mechanism has been used primarily by Carter and Atkinson (1989) and Carter (1991, 1993, 1994a) in reactivity assessment calculations using the EKMA model formulation. It has been adopted for use in the UAM by Lurmann et al. (1991), but it has not been widely used because the SAPRC/UAM model takes significantly longer to complete simulations than the standard version with CB4. Preliminary calculations on Los Angeles scenario simulations have shown only minor differences in UAM predictions using the two mechanisms (Lurmann 1993), but to our knowledge the SAPRC/UAM model has not been used to assess the effects of alternative fuel use or to evaluate the SAPRC-90 calculations using the EKMA model formulation.

Regardless of the chemical detail in the model, it should be recognized that current mechanisms have significant uncertainties, and the reactivity predictions of using any chemical mechanism are uncertain unless it is evaluated experimentally. For that reason an experimental program is under way to address this need for data to evaluate the reactivity predictions of current detailed and condensed mechanisms. These new data suggest potentially significant problems with the current mechanisms that have not yet been addressed (Carter et al., 1993, 1994a, 1994b; Jeffries and Sexton, 1993; unpublished results from this laboratory). 


\subsection{Fuel and Compound Reactivity Assessment}

\subsection{Quantification of Reactivity}

VOCs can differ significantly in their effects on ozone formation or other air quality impacts. Because a major result of alternative fuel use will be a change in the chemical composition of VOC emissions, these differences in air quality impacts, or "reactivities," must be taken into account when assessing the environmental impact of alternative fuels. The various approaches for doing this are discussed in this section.

VOC reactivity is generally used to refer to the tendency of the VOC to promote ozone formation. However, ozone formation is not the only way VOCs can adversely affect air quality. Some VOCs, such as benzene and 1,3-butadiene are toxic, and thus can have a direct impact on air quality. Assessments of alternative fuels in terms of toxic VOCs can come directly from the speciated emissions measurements, and is not generally considered a reactivity issue. VOCs can also affect air quality by reacting to form toxic organic oxidation products such as formaldehyde and PAN, by promoting secondary organic aerosol formation, and by promoting the rates of other oxidation processes, such as the conversions of NO to $\mathrm{NO}_{2}, \mathrm{NO}_{2}$ to nitrate, and $\mathrm{SO}_{2}$ to sulfate. These aspects of reactivity should be considered in a comprehensive assessment. However, most of these factors are correlated to ozone reactivity, and if the assessments of the ozone reactivity effects of a fuel are incorrect, it would not be reasonable to expect these other reactivity effects to be correctly predicted. Thus an ozone reactivity assessment is a necessary-though not sufficient-component to any comprehensive evaluation of the atmospheric impacts of alternative fuel use. For that reason, most of the discussion below will focus on assessment of ozone reactivity. Reactivities with respect to other impacts can be derived in an analogous manner from the experimental or modeling studies, in a manner analogous to those discussed below for ozone.

There are a number of ways to quantify VOC reactivities. Early reactivity scales have been based on amounts of ozone formed when the VOC is irradiated in the presence of $\mathrm{NO}_{\mathrm{x}}$ in environmental chambers (e.g., Wilson and Doyle, 1970; Altshuller and Bufalini, 1971; Laity et al., 1973). However, individual VOCs are not emitted in the absence of other reactive organics, so such experiments do not represent atmospheric conditions. Furthermore, chamber effects such as unknown radical sources (Carter et al., 1982), affect the results of such experiments (Bufalini et al., 1977; Joshi et al., 1982; Carter et al., 1982; Carter and Lurmann, 1990, 1991; Jeffries et al., 1993), particularly if the compound reacts slowly or has radical sinks in its mechanism (Carter et al., 1986a; Carter and Lurmann, 1990, 1991). Therefore, single organic- $\mathrm{NO}_{\mathrm{X}}$-air experiments do not reliably quantify reactivity.

An alternative measure that has been proposed is the $\mathrm{OH}$ radical rate constant for the VOC (e.g., Darnall et al., 1976; CARB, 1989; Chameides et al., 1992). Although not strictly a measure of ozone formation, for most compounds reaction with $\mathrm{OH}$ is the main process that initiates the VOC's ozone forming reactions. This approach has the significant advantage that it is universal and that $\mathrm{OH}$ rate constants are known or can be estimated for essentially all VOCs of relevance to alternative fuel use (Atkinson, 1987, 1989, 1990). However, it does not account for the significant differences in VOC reaction mechanisms (e.g., see Gery et al. 1988; Carter, 1990; Atkinson, 1990, 1994), which can affect how much ozone is formed once the VOC reacts (Carter and Atkinson, 1989; Carter, 1991, 1993, 1994a; Carter et al. 1993). It has been shown to correlate poorly with other measures of ozone formation potential (Carter, 1991), which are discussed below. 
The most direct measure of ozone reactivity of a VOC is the change in ozone caused by changing the emissions of the VOC in an air pollution episode. This is referred to as the incremental reactivity of the VOC in the episode. This takes into account the effects of all aspects of the organic's reaction mechanism and the effects of the environment where the VOC is emitted. Model calculations (Dodge, 1977; Chang and Rudy, 1990; Carter, 1991; 1994a) and environmental chamber experiments (Carter et al., 1994a) have shown that environmental conditions can significantly affect incremental reactivities, both in a relative and in an absolute sense. This is discussed in more detail below.

The incremental reactivity of a VOC under ambient conditions cannot be measured directly-other than by changing emissions and then observing the resulting changes of air quality for enough years to factor out effects of meteorological variability-but can be estimated either by computer model calculations or by suitable designed environmental chamber experiments. Both types of estimation approaches have their limitations. In the case of model calculations, uncertainties and approximations in the model for airshed conditions, in the model formulation (discussed in Section 4) and in the chemical mechanism (discussed in Section 5), cause uncertainties in the predicted ozone impacts. The impacts of these uncertainties on model predictions need to be understood before the results of such calculations can be used for decision making. In the case of experiments, one does not necessarily know whether the conditions of the experiment are a sufficiently close approximation to ambient conditions that the results have general applicability. The only way to assess this is by modeling, which has its own set of uncertainties.

Before discussing the various modeling and experimental approaches for assessing reactivity in more detail, it is useful to first give a description of the chemical basis of ozone reactivity. An understanding of this is necessary to understanding the processes and factors that need to be represented in any model simulation of reactivity effects. It is also necessary to understanding the problems of extrapolating environmental chamber results to ambient conditions. This will be followed by a discussion of the chemical mechanisms currently being used in the modeling assessments of reactivity.

\subsection{Chemical Basis of Reactivity}

The chemical processes by which VOCs promote $\mathrm{O}_{3}$ formation were discussed in Section 5 . As indicated there, the aspects of a VOC's reaction mechanism that determine its effect on ozone (i.e., its incremental reactivity) are its reaction rate, the number of NO oxidations caused by the intermediates in its oxidation, the VOC's effect on $\mathrm{OH}$ radical levels, the VOC's effect on the $\mathrm{NO}_{\mathrm{x}}$ consumption rate, and the reactivities of the VOC's major oxidation products. The VOC's reaction rate is of major importance, as it determines how much of the VOC will react to promote ozone formation during the episode. The other factors are important in determining how much the VOC affects ozone once it reacts. This can vary widely for different types of VOCs and for different types of environmental conditions. Under high $\mathrm{NO}_{\mathrm{x}}$ conditions the effect of the VOC on OH radical levels is extremely important, as this is the major factor in determining how rapidly almost all VOCs react to form ozone. As $\mathrm{NO}_{\mathrm{x}}$ levels are reduced and ozone levels become limited by $\mathrm{NO}_{\mathrm{x}}$ availability, the effect of the VOC on $\mathrm{NO}_{\mathrm{X}}$ removal rates becomes an increasingly important factor, causing some VOCs with high $\mathrm{NO}_{\mathrm{x}}$ sinks in their mechanisms, such as aromatics, to actually inhibit ozone levels. Thus, the relative importance of different aspects of a VOC's mechanism can depend significantly on the $\mathrm{NO}_{\mathrm{X}}$ levels.

Because of this, $\mathrm{NO}_{\mathrm{x}}$ conditions are a major factor affecting a VOC's reactivity, both in an absolute sense, and relative to other VOCs. However, other environmental conditions will also affect reactivity, by 
affecting how rapidly $\mathrm{NO}_{\mathrm{x}}$ is removed, by affecting overall radical levels and thus how rapidly $\mathrm{NO}_{\mathrm{x}}$ and VOCs react, and by affecting other factors determining the efficiency of ozone formation. This results in variations of ozone impacts of a VOC among different airshed conditions, even those with similar $\mathrm{NO}_{\mathrm{x}}$ levels. It also results in different ozone impacts of VOCs in environmental chamber experiments compared to the ambient atmosphere. The relative importance of these factors has been investigated to some extent, though probably not comprehensively. This will be discussed further below.

\subsection{Assessments of Factors Affecting Reactivity}

Available assessments of general factors affecting reactivity include modeling studies of incremental reactivities and their variations for different VOCs and different environments; and detailed analyses of processes responsible for ozone formation from VOCs, and their relative importance. Examples and relevant results of each of these are summarized below.

Dodge (1984) showed that the calculated change in ozone caused by adding a given amount of a VOC to the other reactive organic gas (ROG) inputs in EKMA model simulations varied widely among different VOCs at low ROG/NO $O_{X}$ ratios, but were lower and less variable under high $R O G / N O_{X}$ conditions. The $\mathrm{OH}$ radical rate constant was found to perform poorly in predicting reactivities of compounds more reactive than ethylene.

Factors affecting incremental reactivity were studied in more detail by Carter and Atkinson (1989), who used an early version of the SAPRC-90 mechanism to calculate incremental reactivity (defined as the change in ozone formation caused by adding a small amount of a VOC to a scenario, divided by the amount added) as a function of ROG/NO $\mathrm{NO}_{\mathbf{x}}$ for several types of single-cell model scenarios. The results showed that the incremental reactivities depended on environmental conditions and on the nature of the reaction mechanism. The latter includes not only how fast the VOC reacts, but also the tendency of the VOC to enhance or inhibit radical levels, the tendency of the VOC to remove $\mathrm{NO}_{\mathrm{x}}$ from the system, and the reactivity of the VOC's major products. Aromatics, which have strong $\mathrm{NO}_{\mathrm{x}}$ sinks and radical sources in their mechanisms, were found to have relatively high reactivities under low ROG/NO their reactivities became negative when the $\mathrm{ROG} / \mathrm{NO}_{\mathrm{x}}$ ratio became sufficiently high. The $\mathrm{ROG} / \mathrm{NO}_{\mathrm{x}}$ ratio was the most important environmental factor affecting reactivity, but different reactivities (both absolute and relative) are also obtained between scenarios representing chamber experiments, and 1- or 2day ambient episodes, and scenarios where a highly simplified mixture is used to represent ambient VOCs-as might be the case in environmental chamber experiments. Incremental reactivities measured in chamber experiments should therefore not be used to assess atmospheric reactivities without the benefit of model calculations to take into account the differences between chamber and airshed conditions. (This latter point is discussed further below.)

In conjunction with the development of general reactivity scales, Carter $(1993,1994 a)$ conducted a number of sensitivity calculations on the effect of varying environmental conditions on incremental reactivity in single-cell 1-day EKMA-type scenarios. As with other studies, the most important factor affecting relative reactivities was found to be $\mathrm{NO}_{\mathrm{X}}$ conditions, though there was still some variability in relative reactivities among different EKMA scenarios even after $\mathrm{NO}_{\mathrm{X}}$ inputs in the scenarios were adjusted to yield consistent conditions of $\mathrm{NO}_{\mathrm{X}}$ availability. 
Jeffries and Crouse (1991) and Bowman and Seinfeld (1994) looked at the factors affecting reactivity from the perspective of the chemical reactions actually responsible for ozone formation. The result was that the relative contribution of VOCs to the reactions directly responsible for ozone can be quite different than the relative incremental reactivities of those VOCs. This is because many VOCs have high (or negative) incremental reactivities - not because of the ozone formed by their own reactions, but because their reactions affect how much ozone is formed from other VOCs. For example, if the reactions of a VOC significantly affects radical levels, it will affect how much $\mathrm{O}_{3}$ is formed from the reactions of other VOCs, and for many VOCs this indirect effect on reactivity makes a larger contribution to its incremental reactivity than the ozone directly formed by the VOC's reactions (Bowman and Seinfeld, 1994). This has also been shown from an analysis of the results of incremental reactivity experiments carried out under maximum reactivity conditions (Carter et al., 1993). Jeffries (1993) argues that this has implications that must be understood when assessing alternative fuel use. However, although such analyses provide interesting and useful data that aid our understanding of the chemistry of ozone formation and the evaluation of chemical mechanisms, we believe that beyond that they have relatively little direct relevance to assessing the effects of alternative fuel use. The decision maker is concerned not with the details of what causes ozone formation but with the actual change in ozone caused by the substitution or emissions change being considered. This is measured by incremental reactivities or by scenario-specific analyses such as those discussed below.

\subsection{Development of General Reactivity Scales}

A general scale ranking of the reactivities of VOCs would clearly be useful in assessing and comparing multiple fuel options, especially if reactivities of the mixtures can be obtained by linear summation of components' reactivities. While scenario-specific assessments (discussed below) provide the best estimate of effects of any particular substitution, they are of limited use for screening many options, and may not necessarily be superior to a more general scale when estimating relative ozone impacts for a wide variety of conditions. Because of this, $\mathrm{CARB}$ initially proposed using the $\mathrm{OH}$ rate constant as a means for assessing multiple options on an ozone impact basis. This scale has a number of limitations (discussed above), and Lowi and Carter (1990) argued that a scale based on incremental reactivities would provide a much more comprehensive indication of the effect of a VOC on actual ozone formation. However, because incremental reactivities depend on environmental conditions, no incremental reactivity scale will correctly predict relative ozone impacts under all conditions; even if there were no uncertainties in the models, the chemical mechanism, and the airshed conditions.

Most of the recent work on developing general reactivity scales applicable to alternative fuel assessment has been carried out by Carter $(1991,1993,1994 a)$, who developed a number of scales based on incremental reactivities in Lagrangian (EKMA) model simulations. These scales, and available information concerning their sensitivities to scenario conditions and chemical mechanisms, are discussed below. The only other reactivity scales based on model calculations of ozone sensitivities to individual species are the photochemical ozone creation potential (POCP) scales calculated by Derwent and coworkers and other researchers in Europe (e.g., Derwent and Jenkin, 1991; Andersson-Skold et al., 1992). Most other work on general reactivity scales carried out thus far has consisted of evaluating the Carter scales using other types of airshed models, rather developing alternatives to them. 


\subsubsection{Carter Reactivity Scales}

Carter (Weir et al., 1988; Carter, 1989; Lowi and Carter, 1990) proposed basing a general reactivity scale on the highest incremental reactivities the VOCs attain, and the resulting scale was designated the MIR scale. CARB concluded that this was a superior method to the $\mathrm{OH}$ scale for assessing reactivity, and proposed that it be used as a basis for deriving RAFs in California's Clean Fuels-Low Emissions Vehicle regulations (CARB 1991). An updated version of this scale was eventually incorporated in that regulation (CARB, 1993c), and the MIR scale is also widely used as a means for comparing reactivities of vehicle emissions (e.g., AQIRP, 1993b).

The initial version of the MIR scale was based on the highest incremental reactivities of the VOCs in any scenario (Weir et al., 1988; Carter, 198; Lowi and Carter 1990). This was subsequently modified to be based on the average of the incremental reactivities in a set of scenarios where the $\mathrm{NO}_{\mathrm{x}}$ inputs were adjusted to give the highest incremental reactivities in each (Carter, 1991, 1993; 1994a). The first MIR scale using the latter approach employed a set of single-day EKMA scenarios employed previously in studies by Whitten (1988), and Gery et al. (1987). The most recent scale, which is the version used in the current CARB regulation (CARB, 1993c), was based on the 39 EKMA scenarios developed to represent conditions of ozone non-attainment areas throughout the U.S. (Baugaus, 1990), with various modifications to the input data based on consultations with the CARB staff and others (Carter, 1993). The scales were calculated using the SAPRC-90 chemical mechanism, which, as discussed previously, has been designed specifically for reactivity assessment calculations. The various versions of the MIR scales differed in the magnitudes of the incremental reactivities, but except for specific VOCs where mechanism updates were implemented, the differences in relative reactivities were minor, especially for the various alternative fuel exhaust mixtures.

In addition to MIR, Carter (1993, 1994a) developed a total of 17 other reactivity scales, based on six approaches for dealing with the dependence of reactivity on environmental conditions, and on three methods for quantifying ozone impacts. These are summarized in Table 6.1. Examples of incremental reactivities for selected individual compounds and alternative fuel exhaust mixtures, relative to incremental reactivities of a the standard exhaust ${ }^{6}$, are shown on Figure 6.1. The representative scales shown are MIR, MOIR, and base-case average ratio scale based on the peak ozone concentration and on integrated $\mathrm{O}_{3}$ over the California standard of $0.09 \mathrm{ppm}$. For most VOCs, the MIR scale gives a better correspondence to the base-case scale based on integrated $\mathrm{O}_{3}$, but the MOIR scale gives a somewhat better correspondence to the base-case scale based on peak $\mathrm{O}_{3}$. The error bars show the standard deviations of the averages for the relative incremental reactivities in the individual scenarios used to derive the scales. The error bars for the MIR and MOIR scale show how relative reactivities vary with other scenario conditions in scenarios with the same levels of $\mathrm{NO}_{\mathrm{x}}$ availability, while the error bars for the base-case scales show the extent to which relative reactivities based on peak ozone and on integrated ozone vary in scenarios with variable $\mathrm{NO}_{\mathrm{x}}$ levels. These variations give an indication of the uncertainties

6 The compositions of the alternative fuel (M85, E85, LPG, and CNG) and the standard (RFA) exhaust mixtures were based on TLEV certification data and were provided by the CARB (1991). The RFA exhaust mixture is used as the reference because this is the standard for calculating RAFs in the CARB's "Low-Emission Vehicle and Clean Fuels" regulations (CARB 1990, 1991, 1993). 
Table 6.1. Summary of Major Characteristics of Reactivity Scales derived by Carter (1993, 1994a).

\begin{tabular}{|c|c|c|c|c|}
\hline Scale & Type of Scenarios used & $\begin{array}{l}\text { Derivation of scale from } \\
\text { individual scenario } \\
\text { reactivities }\end{array}$ & $\begin{array}{l}\text { Ozone } \\
\text { quantific- } \\
\text { ation }\end{array}$ & $\begin{array}{l}\text { Reflects effect } \\
\text { of VOC on: }\end{array}$ \\
\hline $\begin{array}{l}\text { Maximum } \\
\text { Incremental } \\
\text { Reactivity (MIR) }\end{array}$ & $\begin{array}{l}\text { Low } \mathrm{ROG} / \mathrm{NO}_{\mathrm{x}} \text { conditions } \\
\text { where } \mathrm{O}_{3} \text { is most sensitive } \\
\text { to VOC changes }\end{array}$ & $\begin{array}{l}\text { Averages of incremental } \\
\text { reactivities in the MIR sce- } \\
\text { narios }\end{array}$ & $\begin{array}{l}\text { Maximum } \\
\text { ozone }\end{array}$ & $\begin{array}{l}\text { ozone } \\
\text { formation rates }\end{array}$ \\
\hline $\begin{array}{l}\text { Maximum Ozone } \\
\text { Incremental } \\
\text { Reactivity (MOIR) }\end{array}$ & $\begin{array}{l}\text { Moderate } \mathrm{ROG} / \mathrm{NO}_{\mathrm{x}} \\
\text { conditions where highest } \\
\mathrm{O}_{3} \text { yields are formed }\end{array}$ & $\begin{array}{l}\text { Averages of incremental } \\
\text { reactivities in the MOIR } \\
\text { scenarios }\end{array}$ & $\begin{array}{l}\text { Maximum } \\
\text { ozone }\end{array}$ & $\begin{array}{l}\text { ultimate ozone } \\
\text { yield }\end{array}$ \\
\hline $\begin{array}{l}\text { Equal Benefit } \\
\text { Incremental } \\
\text { Reactivity (EBIR) }\end{array}$ & $\begin{array}{l}\text { Higher } \mathrm{ROG} / \mathrm{NO}_{\mathrm{X}} \text { condi- } \\
\text { tions where VOC and } \mathrm{NO}_{\mathrm{x}} \\
\text { control are equally effective } \\
\text { in reducing } \mathrm{O}_{3}\end{array}$ & $\begin{array}{l}\text { Averages of incremental } \\
\text { reactivities in the EBIR } \\
\text { scenarios }\end{array}$ & $\begin{array}{l}\text { Maximum } \\
\text { ozone }\end{array}$ & $\begin{array}{l}\text { ultimate ozone } \\
\text { yield }\end{array}$ \\
\hline $\begin{array}{l}\text { Base-Case Average } \\
\text { Ratio }-\mathrm{O}_{3} \text { Yield }\end{array}$ & $\begin{array}{l}\text { Base case conditions } \\
-\mathrm{ROG} / \mathrm{NO}_{\mathrm{X}} \text { conditions are } \\
\text { as observed for the indi- } \\
\text { vidual scenarios }\end{array}$ & $\begin{array}{l}\text { Averages of incremental } \\
\text { reactivities in the base case } \\
\text { scenarios }\end{array}$ & $\begin{array}{l}\text { Maximum } \\
\text { ozone }\end{array}$ & $\begin{array}{l}\text { ultimate ozone } \\
\text { yield }\end{array}$ \\
\hline $\begin{array}{l}\text { Base-Case Least } \\
\text { Squares Error - } \\
\mathrm{O}_{3} \text { yield }\end{array}$ & Base-Case & $\begin{array}{l}\text { Minimizes the sum of } \\
\text { squares change in ozone } \\
\text { which would occur if a } \\
\text { "null test" substitution were } \\
\text { made in all the scenarios } \\
\text { based on the scale [a] }\end{array}$ & $\begin{array}{l}\text { Maximum } \\
\text { ozone }\end{array}$ & $\begin{array}{l}\text { depends on the } \\
\text { variability of } \\
\text { scenario condi- } \\
\text { tions [b] }\end{array}$ \\
\hline $\begin{array}{l}\text { Base-Case Average } \\
\text { Ratio - Integrated } \\
\mathrm{O}_{3}\end{array}$ & Base-Case & $\begin{array}{l}\text { Averages of incremental } \\
\text { reactivities in the base case } \\
\text { scenarios }\end{array}$ & $\begin{array}{l}\text { Integrated } \\
\text { ozone }\end{array}$ & $\begin{array}{l}\text { ultimate ozone } \\
\text { yield }\end{array}$ \\
\hline $\begin{array}{l}\text { Base-Case Least } \\
\text { Squares Error - } \\
\text { Integrated } \mathrm{O}_{3}\end{array}$ & Base-Case & $\begin{array}{l}\text { Same as base case least } \\
\text { squares error }-\mathrm{O}_{3} \text { yield. }\end{array}$ & $\begin{array}{l}\text { Integrated } \\
\text { ozone }\end{array}$ & $\begin{array}{l}\text { ultimate ozone } \\
\text { yield }\end{array}$ \\
\hline
\end{tabular}

[a] A "null test" substitution based on a reactivity scale consists of substituting VOC emissions such that the scale predicts there would be no change in ozone. Two types of least squares error scales were derived - one based on substitution of the individual VOCs for the base ROG mixture, and one on substituting the base ROG for the VOCs. The scales are similar except for VOCs with variable incremental reactivities distributed around zero.

[b] Depends on effect on $\mathrm{O}_{3}$ formation rate if scenarios are highly varied in $\mathrm{ROG} / \mathrm{NO}_{\mathrm{x}}$ conditions as in the Whitten (1988) and Gery et al. (1987) scenarios used by Carter (1991), but depends more on effect on ultimate $\mathrm{O}_{3}$ yield if the ROG/NO $\mathrm{x}$ conditions are more narrowly distributed, as with the EPA scenarios (Baugaus, 1990) used in the most recent reactivity scale derivation (Carter, 1993, 1994).

[c] Two such scales were developed, one based on integrated $\mathrm{O}_{3}$, and one on integrated $\mathrm{O}_{3}$ over the California standard of $0.09 \mathrm{ppm}$. The scales were similar. 


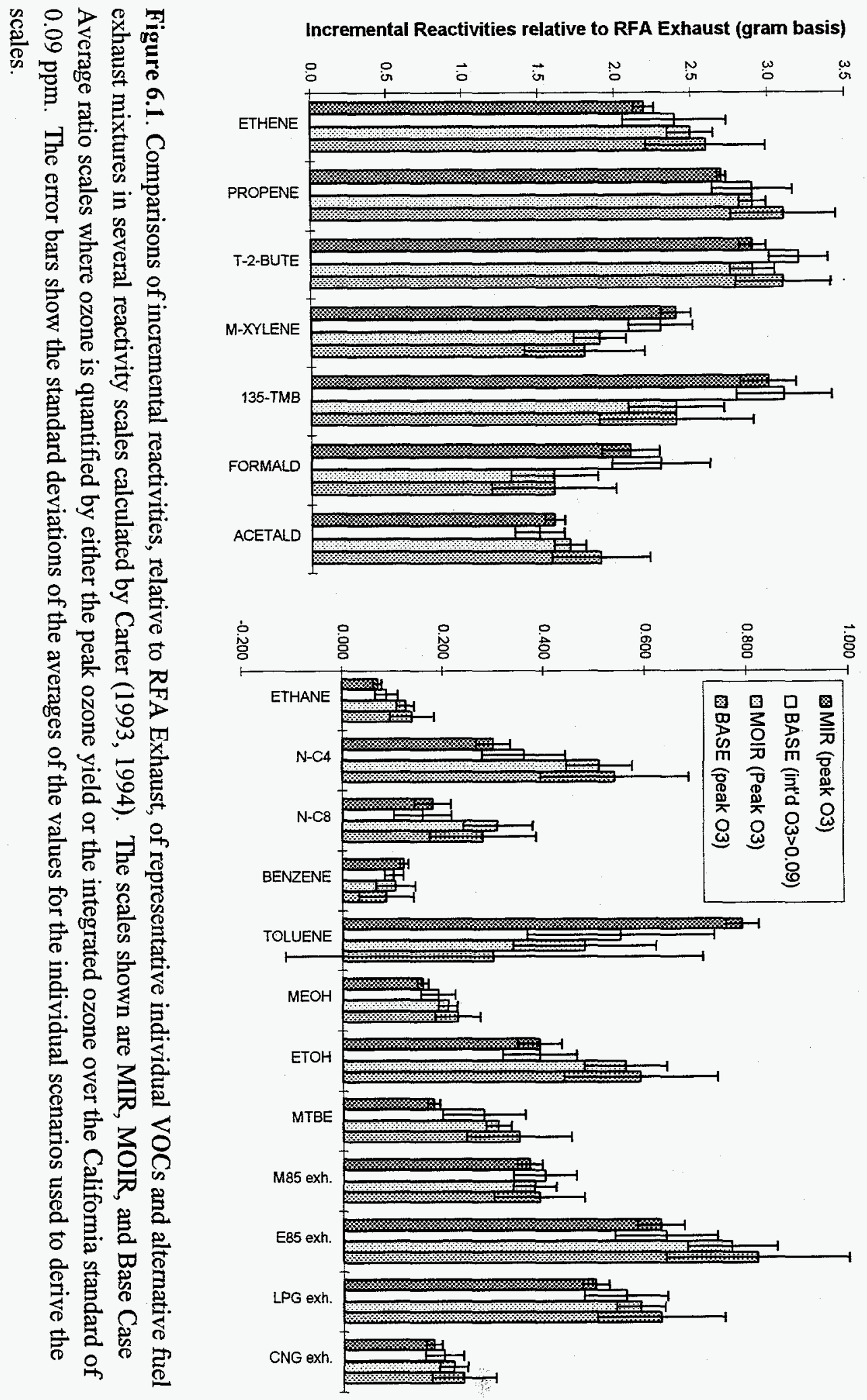


in the various types of reactivity scales caused by variability in scenario conditions. The base-case relative reactivities are much less variable when they are based on integrated $\mathrm{O}_{3}$ over the standard than when based on peak $\mathrm{O}_{3}$ yields. This means that reactivities based on integrated ozone can be quantified with much lower levels of uncertainty because of variabilities in reactivities with scenario conditions.

Although there were 18 different scales, to a large extent the choice boils down to the use of a scale which, like MIR, reflects primarily the effect of the VOC on ozone formation rates. Such a scale (e.g., MOIR, EBIR, or the base-case average ratio ozone yield scales) is more sensitive to the effect of the VOC on ultimate $\mathrm{O}_{3}$ yields in $\mathrm{NO}_{\mathrm{x}}$-limited conditions, or scales based on integrated $\mathrm{O}_{3}$, which tend to be sensitive to both factors. Scales sensitive to effects of VOCs on ozone formation rates tend to give higher relative reactivities for aromatics, and lower relative reactivities for alkanes, than those based on ultimate $\mathrm{O}_{3}$ yields in $\mathrm{NO}_{\mathrm{x}}$-limited conditions.

Carter (1991, 1993, 1994a) and CARB (1991b) have argued that the MIR scale is appropriate for applications requiring use of a single scale because it is designed to be most accurate for conditions that are most sensitive to VOC controls. The MIR scale may be less accurate than others in predicting $\mathrm{O}_{3}$ effects under lower $\mathrm{NO}_{\mathrm{x}}$ conditions. However, because of the lower sensitivity of $\mathrm{O}_{3}$ to VOC under those conditions, the practical impact of those inaccuracies is less than would be the case for the conditions where the scale is designed to apply. It was also found to correlate well to scales based on integrated $\mathrm{O}_{3}$ yields, even in lower $\mathrm{NO}_{\mathrm{x}}$ scenarios. Nevertheless, the MOIR scale is attractive because it is more representative of the "worst case" ozone formation conditions in various airsheds, and also because it tends to be more conservative in predicting substitution benefits for most alternative fuels. The MIR scale tends to predict larger reactivity benefits for slowly reacting compounds than may be appropriate, because the higher $\mathrm{NO}_{\mathrm{X}}$ levels of MIR scenarios cause suppressed radical levels, which decrease the amount that slower reacting compounds react in the scenarios.

For applications requiring a single scale, an alternative approach that may have the best features of both the MIR and MOIR would be to use a scale based on integrated ozone under base-case or maximum ozone conditions. This has the advantage of the MIR scale in that it performs well in predicting reactivity effects under high $\mathrm{NO}_{\mathrm{x}}$ conditions that are most sensitive to VOCs (because it correlates reasonably well to MIR for most VOCs), while also being based on conditions of scenarios that are more representative of worst case $\mathrm{O}_{3}$ pollution episodes. It is also somewhat less likely to be biased toward overpredicting reactivity benefits of slowly reacting compounds than may be the case for MIR. Furthermore, in the context of Eulearian model simulations, where ozone impacts vary with both time and space, integrated ozone throughout the full air basin and time period of the episode is arguably a more robust measure of the exposure of the environment to ozone than just the peak ozone concentration, which might be highly localized in time and place. Indeed, integrated ozone over the standard has been the ozone impact used when the MIR and MOIR reactivity scales were evaluated in Eulearian model simulations (e.g., McNair et al., 1994). 


\subsubsection{Effect of Chemical Mechanism on Reactivity Scales}

The MIR and other scales listed in Table 6.1 were all developed using the SAPRC-90 mechanism. As discussed above, this is probably the most appropriate of current mechanisms for developing a general scale because of the number of different types of VOCs it can represent. The RADM-II and LCC employ assumptions similar to SAPRC-90 concerning uncertain portions of the aromatics and other mechanisms, and would be expected to give similar reactivities for species which the condensed mechanisms are designed to represent. However, this may not be the case for the CB4 mechanism, which employs differing assumptions concerning some of the uncertainties in the aromatics mechanisms, and uses different methods for treating alkane and alkene reactions. Figure 6.2 compares SAPRC-90 MIR and MOIR reactivities of selected species, relative to those of the standard exhaust mixture, with those calculated using an updated version of the CB4 mechanism being used in Phase 2 of AQIRP (Yarwood, private communication, 1994; Carter, 1994b). Other than the mechanism, the scenarios and the calculation methodology are the same (Carter, 1994b).

Despite the differences in the mechanisms and level of chemical detail, the CB4 and SAPRC-90 relative incremental reactivities are remarkably close for the representative alternative fuel exhaust mixtures, and for most of the selected species shown. The most conspicuous difference is toluene, for which the developers of the CB4 added a speculative reaction so model simulations could accurately predict the relatively low maximum ozone yields in some toluene- $\mathrm{NO}_{\mathrm{X}}$ outdoor chamber experiments (Gery et al., 1988). This reaction is not included in the SAPRC-90 mechanism, nor is it in the CB4 mechanism for xylenes. This causes somewhat lower MIR reactivities for toluene and causes toluene to be negatively reactive at the lower $\mathrm{NO}_{\mathrm{x}}$ levels where maximum ozone formation occurs. (The SAPRC-90 mechanism also predicts that toluene becomes negatively reactive at low $\mathrm{NO}_{\mathrm{x}}$ levels, but the $\mathrm{NO}_{\mathrm{x}}$ levels must be much lower than is the case with CB4). In the case of xylenes, where the CB4 lacks this speculative reaction, the MIR and MOIR relative reactivities agree quite well. The somewhat higher CB4 formaldehyde reactivity is believed to be primarily caused by a greater sensitivity of the CB4 mechanism to radical input processes, rather than by differences in the formaldehyde mechanism itself.

Some of the differences shown on Figure 6.2 can be attributed to condensation approximations incorporated in the Carbon Bond mechanism. The CB4 uses a "xylene" species to represent all higher aromatics, which causes the mechanism to underpredict the reactivity of trialkylbenzenes compared to SAPRC-90, which represents trialkylbenzenes separately. The higher reactivity predicted for n-octane and other high molecular weight alkanes is caused by the use of a single species to represent all alkanes, which does not take into account the increasing importance of radical inhibition processes as the size of the alkane molecule increases (Carter and Atkinson, 1985; Atkinson, 1990).

Despite the differences, the mechanisms agree quite well in predictions of relative reactivities of M85 and CNG exhausts. This could be to some extent caused by reactivity differences for some species in the mixture being canceled out by opposing differences in others. The CB4 mechanism predicts higher reactivities for E85 in the MOIR scale and for LPG in both scales, for reasons that have not yet been examined in detail. These differences, however, are no larger than the differences between different reactivity scales calculated using the same mechanism. 

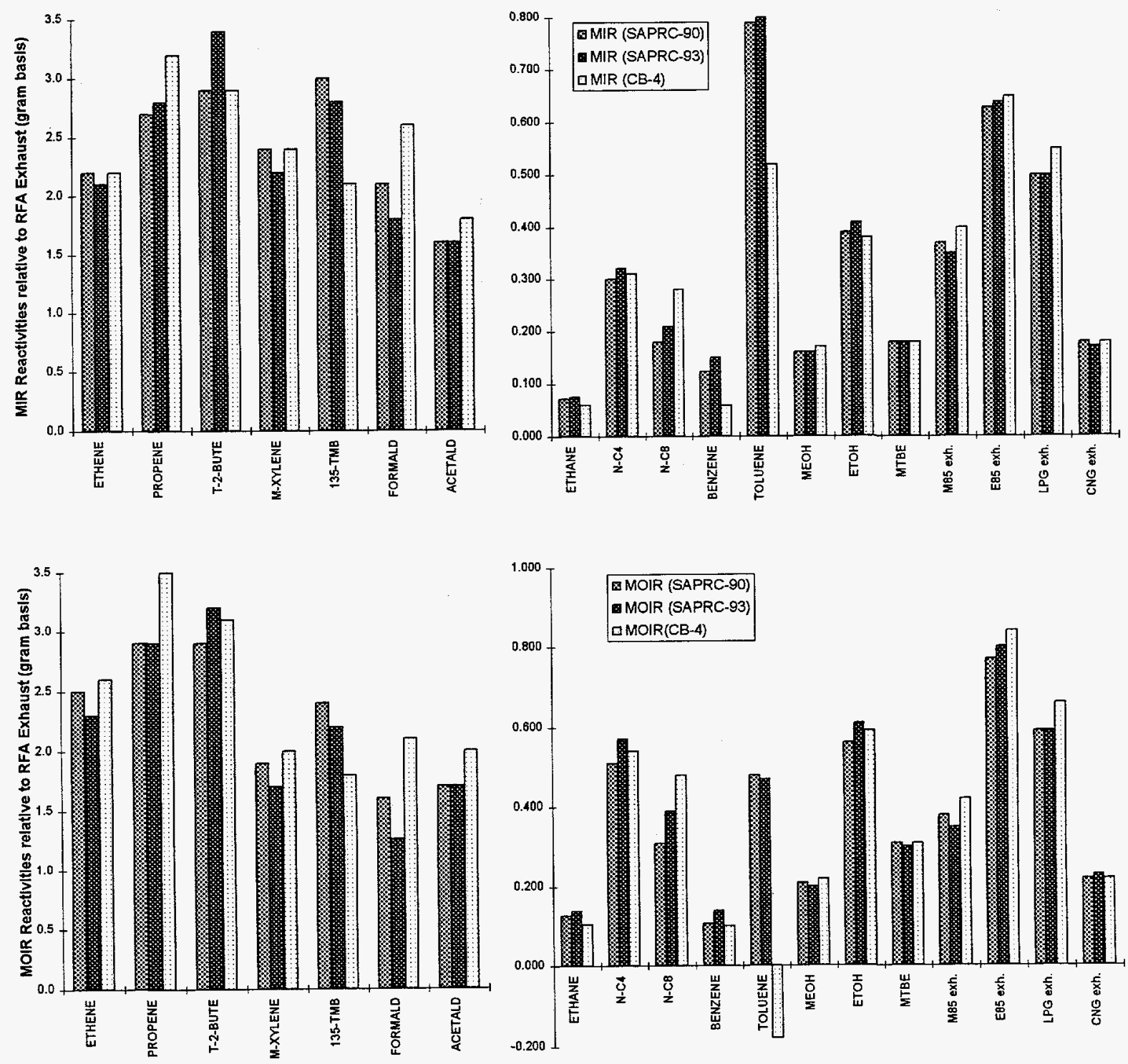

Figure 6.2. Comparison of MIR and MOIR incremental reactivities, relative to RFA exhaust, of representative individual VOCs and alternative fuel exhausts, calculated using theSAPRC-90, the preliminary updated SAPRC (SAPRC-93), and the Carbon Bond IV chemical mechanisms. 
Despite the different condensation approaches and assumptions involved in uncertain parts of the aromatics mechanisms, in many respects the CB4 and SAPRC-90 mechanisms are more alike than different. They were developed around the same time, are based primarily on the same data base of laboratory studies and literature evaluations (Atkinson, 1994 and references therein), and were evaluated (and adjusted) using largely the same set of environmental chamber experiments. Their assumptions concerning most of the uncertainties in the aromatics mechanisms are similar. Therefore, the fact that the two mechanisms give similar reactivity predictions for many species and exhaust mixtures does not necessarily mean they are correct.

Since the CB4 and SAPRC-90 mechanisms were developed, there have been significant changes in our understanding of alkene + ozone reactions, new data on aromatics mechanisms, new laboratory data concerning a number of potentially significant reactions, and a large data base of new environmental chamber experiments designed explicitly to test VOC reactivity scales (Carter et al., 1993; Jeffries and Sexton, 1993; Carter et al., 1994a). Because of this, SAPRC is under contract with CARB to develop an updated mechanism for calculating VOC reactivity scales (Carter, 1993). Although this update is far from complete, a preliminary version was used by Carter et al. (1993) to compare how well the model could simulate results of maximum incremental reactivity experiments. Figure 6.2 shows a comparison of MIR and MOIR (relative to the standard exhaust) calculated with the preliminary updated mechanism, designated SAPRC-93, with those calculated using SAPRC-90 and CB4. Except for the internal alkenes, where a significant change was made in the reaction with ozone, the changes in reactivity predictions are relatively minor. However, the aromatics portion of the mechanism has not yet been modified, and other updates to the mechanism are anticipated.

\subsubsection{Photochemical Ozone Creation Potential (POCP) Reactivity Scales}

An alternative set of reactivity scales was developed by Derwent and Jenkin (1991) and Andersson-Skold et al. (1992) using the Derwent and Hov (1979) chemical mechanism and a two-layer Lagrangian model representing various multi-day trajectories across Europe. The reactivities, called POCPs are calculated from the change in mid-afternoon ozone for each day in the trajectory resulting from removing the test VOC from the emissions, divided by the integrated emissions of the test VOC up to the time of the ozone observation. The tabulated values are given relative to the POCP for ethylene. The Derwent and Hov (1979) mechanism is chemically detailed and intended to be explicit, but has not been evaluated against chamber data, and probably does not adequately represent the large $\mathrm{NO}_{\mathrm{X}}$ sink processes in the aromatic photoxidations that give them low or negative reactivities under low $\mathrm{NO}_{\mathrm{x}}$ conditions. Unfortunately, evaluation of the mechanism against chamber data or comparison with other mechanisms in incremental reactivity or substitution calculations is difficult because its formulation is not well suited to the types of modeling software used in the U.S. Software incompatibilities also make the scenarios difficult to compare with those used in other studies. Most of the POCP scenarios probably represent low $\mathrm{NO}_{\mathrm{X}}$ conditions.

Figure 6.3 shows a comparison of POCP reactivities calculated by Derwent and Jenkin (1991) and reactivities relative to ethylene calculated using the SAPRC-90 MIR and MOIR scales. The error bars on the POCP values show the standard deviations of the averages of daily values for two, 5-day trajectories over Europe. It can be seen that for some VOCs the results agree within the range of variabilities, and for others the disagreement is significant. While some of the differences might be caused by differences in 


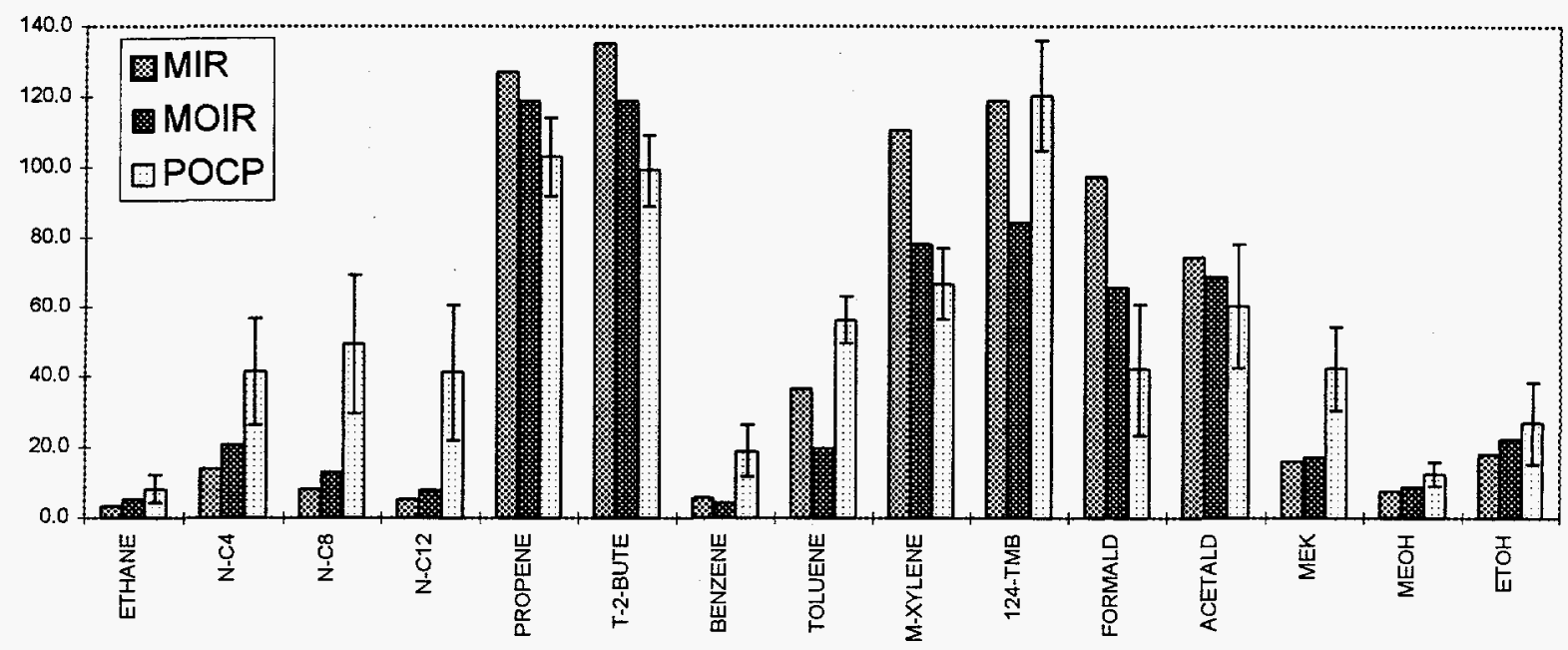

Figure 6.3. Comparison of MIR and MOIR incremental reactivities, relative to ethene, with average POCP reactivities calculated by Derwent and Jenkin (1991). The error bars in the POCP values are standard deviations of the averages.

the scenario conditions, we believe that the major disagreements are caused primarily by mechanism differences. The high POCP reactivities for the higher alkanes can be attributed to the Harwell mechanism assuming lower radical inhibition processes in the alkane photo-oxidations than do other mechanisms, and also that it assumes much higher photolysis rates for the ketones that represent the major alkane photooxidation products. The low formaldehyde reactivity is probably caused by a lower sensitivity of the POCP calculations to radical input from formaldehyde photolysis. This is expected because of the relatively large amounts of ketones in the emissions inventory used in the Derwent and Jenkin (1991) scenarios, combined with the very high photolysis rates assumed for them in the Harwell mechanism. Formaldehyde has a much higher incremental reactivity in the scenarios used by Carter $(1993,1994 a)$ because radical input from other species, such as ketones, is relatively much less important.

Although the scenarios and approach for evaluating reactivity may be appropriate for assessing alternative fuel impacts under some conditions, we do not recommend that the current POCP results be used until the mechanism differences are assessed. As discussed in Section 5.2.4, the Harwell mechanism has not been evaluated against chamber data, and we believe it needs to be updated based on these and other laboratory results before it is used as a basis for making policy decisions.

\subsection{Model Evaluations of Reactivity Scales}

One concern about incremental reactivity scales is that they are designed to measure the effect of small VOC emissions changes, and may not give good estimates of air quality impacts of large emissions changes that might occur with widespread penetration of an alternative fuel. Chang and Rudy (1990) showed that relative reactivities can be different when larger extents of substitution are considered, especially if the compositions of the mixtures being substituted are substantially different. The extent of difference depended on how relative reactivity for the substitution scenarios is defined. Similar results 
are obtained in our calculations, which are shown in Table 6.2. This gives relative reactivities of M85, E85, LPG, and CNG exhausts relative to RFA exhaust as a function of fuel substitution. The speciated profiles used here were similar, but not identical, to those given in Tables 2.6-2.10. Relative reactivity for an $n \%$ substitution is defined as: (alternative fuel substitution ozone - null substituted ozone)/(RFA substituted ozone-null substituted ozone), where: "substituted ozone" is the ozone formed in a calculation with $\mathrm{n} \%$ of the base case emissions substituted for either the alternative fuel, the RFA exhaust or (for "null substituted") nothing. (This definition of relative reactivity for large substitutions is consistent with the usage of many modeling studies. It converges to the ratio of incremental reactivities for small substitutions.) Calculations were carried out for maximum ozone and maximum reactivity $\mathrm{NO}_{\mathrm{x}}$ conditions. The results show that the differences can be minor (less than $12 \%$ ) for substitutions of $20 \%$ or less, or for substitutions of up to $50 \%$ for M85 or E85, but that the relative reactivity of CNG is changes by $\pm 30 \%$ for $50 \%$ substitutions, with the relative reactivity decreasing with extent of substitution for maximum reactivity $\mathrm{NO}_{\mathrm{x}}$ conditions (e.g., lower $\mathrm{ROG} / \mathrm{NO}_{\mathrm{x}}$ ratios), and changing in the opposite direction for lower $\mathrm{NO}_{\mathrm{x}}$, maximum ozone conditions.

Of greater concern is the fact that all of the Carter reactivity scales (Carter and Atkinson, 1989; Carter 1991, 1993, 1994a) are based on the EKMA (Lagrangian) model simulations of single day pollution episodes. As discussed in Section 4, this model lacks the physical detail that can be represented in Eulearian models, and does not represent multi-day pollution effects. For that reason, it is important that the Carter $(1993,1994 a)$ scales be evaluated using other types of models, and using multi-day simulations. For such comparisons to be useful, the model simulations must use similar chemical mechanisms and an emissions processing procedure consistent with the method used to derive the relative reactivities in the scale. This has been a limitation of most of the studies carried out to date.

Table 6.2. Effect of extent of substitution on relative reactivity compared to incremental reactivity ratios

\begin{tabular}{|c|c|c|c|c|c|c|c|c|c|c|}
\hline \multirow{2}{*}{$\begin{array}{l}\text { Mixture } \\
\text { Subst. }\end{array}$} & \multirow{2}{*}{$\begin{array}{c}0 \% \text { Sub } \\
\text { (IR ratio) }\end{array}$} & \multicolumn{3}{|c|}{$5 \%$ Substitution } & \multicolumn{3}{|c|}{$20 \%$ Substitution } & \multicolumn{3}{|c|}{$50 \%$ Substitution } \\
\hline & & Max 03 & $\mathbf{R R}$ & Diff. & Max 03 & $\mathbf{R R}$ & Diff. & Max 03 & $\mathbf{R R}$ & Diff. \\
\hline \multicolumn{11}{|c|}{ Maximum Reactivity Scenario } \\
\hline$\overline{\text { Null }}$ & & 0.155 & & & 0.126 & & & 0.079 & & \\
\hline RFA & 1.00 & 0.166 & 1.00 & $0 \%$ & 0.168 & 1.00 & $0 \%$ & 0.171 & 1.00 & $0 \%$ \\
\hline M85 & 0.73 & 0.163 & 0.72 & $-1 \%$ & 0.155 & 0.71 & $-3 \%$ & 0.139 & 0.65 & $-11 \%$ \\
\hline LPG & 0.53 & 0.161 & 0.54 & $1 \%$ & 0.148 & 0.52 & $-2 \%$ & 0.122 & 0.47 & $-12 \%$ \\
\hline CNG & 0.19 & 0.157 & 0.19 & $-3 \%$ & 0.133 & 0.17 & $-8 \%$ & 0.091 & 0.14 & $-27 \%$ \\
\hline E85 & 0.93 & 0.165 & 0.93 & $0 \%$ & 0.164 & 0.91 & $-2 \%$ & 0.159 & 0.88 & $-6 \%$ \\
\hline \multicolumn{11}{|c|}{ one Scenario } \\
\hline Null & & 0.203 & & & 0.189 & & & 0.139 & & \\
\hline RFA & 1.00 & 0.207 & 1.00 & $0 \%$ & 0.208 & 1.00 & $0 \%$ & 0.208 & 1.00 & $0 \%$ \\
\hline M85 & 0.75 & 0.206 & 0.76 & $1 \%$ & 0.203 & 0.78 & $4 \%$ & 0.197 & 0.84 & $12 \%$ \\
\hline LPG & 0.63 & 0.206 & 0.63 & $1 \%$ & 0.201 & 0.67 & $6 \%$ & 0.190 & 0.73 & $17 \%$ \\
\hline $\mathrm{CNG}$ & 0.24 & 0.204 & 0.24 & $2 \%$ & 0.194 & 0.27 & $11 \%$ & 0.161 & 0.32 & $32 \%$ \\
\hline E85 & 1.15 & 0.208 & 1.15 & $0 \%$ & 0.210 & 1.12 & $-3 \%$ & 0.212 & 1.06 & $-8 \%$ \\
\hline
\end{tabular}

$\mathrm{RR}=[\mathrm{O} 3(\mathrm{mix})-\mathrm{O} 3($ null) $] /[\mathrm{O} 3(\mathrm{RFA})-\mathrm{O} 3($ null) $]$

Diff. $=$ Difference in substition $R R$ relative to IR ratio.

$=[($ Substit. RR $-($ Atmos. IR ratio) $] /$ (Atmos. IR Ratio) 
The most direct and illustrative approach for using Eulerian models to evaluate reactivity scales is to use such a model to calculate a scale, and see how it differs from those derived using EKMA models. Unfortunately, to our knowledge only one such study has been carried out to date. McNair et al. (1992) used the CIT model with the LCC mechanism to calculate the effects of changes in emissions of the LCC model species on various measures of ozone formation in a 3-day Los Angeles pollution episode. The results showed that the MIR reactivities did not perform well in predicting peak ozone sensitivities for the LCC model species, but they performed reasonably well in predicting effects of model species on integrated ozone exposures over the air quality standard. The MOIR scale did not perform as well as MIR in predicting either the impacts on peak ozone or on ozone exposures over the standard.

The comparisons of McNair et al. (1992) are complicated somewhat by differences between the LCC and the SAPRC-90 mechanisms, with some lumped LCC model species not corresponding to single compounds in the MIR scale. In addition, the version of the LCC mechanism initially used had the erroneous MEK mechanism, which caused the CIT model to predict a $\sim 60 \%$ higher reactivity for alkanes compared to MIR. Subsequent calculations with this error corrected yielded a much closer agreement for alkane reactivities, and the correspondence was within $30 \%$ for all model species (CARB, 1992). The correspondence between the MIR scale and the CIT ozone exposure predictions is remarkably good considering the difference in the mechanisms, model, and the ozone impact quantification employed.

Several Eulerian model evaluations have been carried out using the "null test" approach. This is primarily a test of the use of reactivity scales to derive RAFs to place the emissions from different alternative fuels on an equal ozone impact basis. This involves conducting model simulations where the standard vehicle emissions are substituted by the alternative fuel emissions in a ratio which, according to the RAF, has equal ozone impact. The extent to which the ozone changes in the two simulations indicates the extent to which the scale successfully predicts the relative ozone impacts of the two fuels in the particular scenario.

The results of the initial null test calculations are inconclusive. Russell (1990) found that the MIR scale performed well in null tests of ozone exposure impacts in CIT model simulations of CNG and M85 substitutions in a Los Angeles episode. Smylie et al. (1990) used the UAM with the CB4 mechanism to simulate null tests in a different Los Angeles episode, and found that MIR null test substitutions of M85 or CNG caused ozone to increase by up to $30 \%$. An extension of this study for AQIRP presented at the 1991 Reactivity Conference (Croes et al., 1992) showed that UAM simulations of MIR null test substitutions of a reformulated gasoline with lower aromatics and higher alkenes also resulted in increased ozone. However, in all cases, the chemical mechanisms employed was different than that used to calculate the RAFs. In addition, the UAM simulations are probably not fair null tests because the procedures used when processing exhaust emissions for the UAM model were different than those assumed when the MIR RAFs were calculated (see Smylie et al., 1990).

The most recent and comprehensive null test study is described by McNair et al. (1994). They used the CMU Eulerian airshed model with the corrected LCC mechanism to calculate the effects of MIR null test substitutions involving M85, LPG, and CNG in four Los Angeles scenarios. The scenarios involved two meteorological conditions and 1987 and 2010 emissions inventories. The differences in the chemical mechanism were insignificant in this study because the RAFs for the exhausts under consideration were unchanged when derived using the MIR scale calculated using the same version of the LCC mechanism as used in the null tests. Unlike the UAM studies referenced above, the exhaust emissions data were 
processed in the same way for the model calculations as used to calculate the RAFs. Consistent with the incremental reactivity studies with the same model (McNair et al., 1992; CARB, 1992d) they found that the MIR null test caused changes in peak ozone of $30 \%$ or more in some cases, but gave changes in ozone impacts measured by grid-hours, ppm-grid-hours, or person-ppm-grid-hours above the standard, which were usually less than $10 \%$ and all less than $15 \%$. The MIR null test substitutions for M85 and LPG caused a slight increase in ozone formation in most cases, and as a result CARB made a 10\% upward adjustment in the M85 RAF for use in the CARB regulation (CARB, 1991). However, given the significant differences in the model formulations, the null tests showed that the MIR scale performed remarkably well in predicting relative ozone exposure impacts.

The results of the McNair et al. (1994) study is consistent with the results of Carter (1993, 1994a), who showed that the MIR scale corresponds reasonably well to base-case reactivity scales based on integrated ozone or integrated ozone over the standard. The differences observed in the CIT model calculations are well within the variability of the Carter $(1993,1994 \mathrm{a})$ base-case integrated $\mathrm{O}_{3}>0.09$ scales compared to MIR (see Figure 6.1). Note that the base-case integrated ozone scale predicts a slightly higher RAF for M85 and LPG, which would result in a slightly better agreement with the null test results of McNair et al., (1994).

\subsection{Environmental Chamber Assessments}

An alternative method of assessing fuel and compound reactivity is to conduct environmental chamber experiments. Chamber studies have the advantage that in principle they remove the problem of chemical mechanism uncertainty, and might provide information on forming secondary product species that may not be represented (or represented well) in the current mechanisms. However, chamber studies have a number of limitations, the principal one being the applicability of conditions simulated in the chamber to the conditions in the ambient atmosphere. This includes, but is not limited to, the issues of chamber effects, use of simpler chemical mixtures to represent the full distribution of reactive ambient emissions, generally higher than ambient reactant concentrations, and the need to choose between use of artificial light sources (for indoor chamber experiments) or coping with difficulties in controlling and reproducing experimental conditions (for outdoor chamber runs).

There are basically two objectives for conducting an environmental chamber study in the context of assessing reactivity: directly measuring reactivity effects that will be used to draw conclusions about ambient reactivity, or evaluating the ability of chemical mechanisms to predict reactivity effects. These will be referred to as "direct reactivity assessments" and "mechanism evaluation experiments," respectively. The distinction between these two quite different objectives must considered when designing an experimental program, as the most appropriate type of experiment, the requirements for success, and the interpretation of results, are quite different.

\subsubsection{Direct Reactivity Assessment Experiments}

The main concern with direct reactivity assessment experiments is their applicability to simulate ambient conditions. This may not be a serious problem if only qualitative results are required, but the alternative fuel assessment programs have now progressed to the point where quantitative information is needed. A properly conducted chamber study can yield quantitative information about the relative reactivities of the compound or mixtures being studied under the conditions of the experiment, but the applicability of this 
information to atmospheric reactivity will be qualitative at best unless the relationship between chamber reactivity and atmospheric reactivity is understood.

Modeling is a potentially useful means of evaluating how well certain types of experiments might correspond to atmospheric reactivity. Table 6.3 shows how well results of substitution experiments are predicted to correspond to ratios of incremental reactivities for similar $\mathrm{NO}_{\mathrm{X}}$ conditions. The experimental reactivities are defined relative to null substitution experiments, as is the case in the ambient air substitution simulations shown on Table 6.2. The results for $20 \%$ substitution and $100 \%$ substitution experiments are shown, where a $20 \%$ substitution consists of replacing $20 \%$ of the base case $\mathrm{ROG}^{7}$ with the mixture of interest, and a $100 \%$ substitution experiment consists simply of direct comparison of the

Table 6.3. Comparison of model simulations of experimental relative reactivities with ratios of atmospheric incremental reactivities for similar NOx conditions.

\begin{tabular}{|c|c|c|c|c|c|c|c|}
\hline \multirow{2}{*}{\begin{tabular}{|l} 
Mixture \\
Subst.
\end{tabular}} & \multirow{2}{*}{$\begin{array}{l}\text { Atmos. } \\
\text { IR ratio }\end{array}$} & \multicolumn{3}{|c|}{$20 \%$ Substitution } & \multicolumn{3}{|c|}{$100 \%$ Substitution } \\
\hline & & Max 03 & $\mathbf{R R}$ & Diff. & Max 03 & $\mathbf{R R}$ & Diff. \\
\hline \multicolumn{8}{|c|}{ Maximum Reactivity Experiment } \\
\hline Null & & 0.240 & & & - & & \\
\hline RFA & 1.00 & 0.355 & 1.00 & $0 \%$ & 0.398 & 1.00 & $0 \%$ \\
\hline M85 & 0.73 & 0.324 & 0.73 & $0 \%$ & 0.205 & 0.51 & $-30 \%$ \\
\hline LPG & 0.53 & 0.302 & 0.54 & $2 \%$ & 0.124 & 0.31 & $-41 \%$ \\
\hline $\mathrm{CNG}$ & 0.19 & 0.260 & 0.18 & $-7 \%$ & 0.018 & 0.05 & $-76 \%$ \\
\hline E85 & 0.93 & 0.338 & 0.85 & $-8 \%$ & 0.294 & 0.74 & $-21 \%$ \\
\hline \multicolumn{8}{|c|}{ Maximum Ozone Experiment } \\
\hline Null & & 0.626 & & & - & & \\
\hline RFA & 1.00 & 0.684 & 1.00 & $0 \%$ & 0.687 & 1.00 & $0 \%$ \\
\hline M85 & 0.75 & 0.693 & 1.17 & $56 \%$ & 0.750 & 1.09 & $45 \%$ \\
\hline LPG & 0.63 & 0.686 & 1.04 & $65 \%$ & 0.471 & 0.69 & $9 \%$ \\
\hline $\mathrm{CNG}$ & 0.24 & 0.650 & 0.41 & $71 \%$ & 0.051 & 0.07 & $-69 \%$ \\
\hline E85 & 1.15 & 0.692 & 1.16 & $0 \%$ & 0.686 & 1.00 & $-13 \%$ \\
\hline
\end{tabular}

$\mathrm{RR}=[\mathrm{O} 3(\mathrm{mix})-\mathrm{O} 3(\mathrm{nul1})] /[\mathrm{O} 3(\mathrm{RFA})-\mathrm{O} 3($ null) $]$

Diff. $=$ Difference in simulated experimental RR Relative to atmospheric IR ratio.

$=[($ Simulated Expt.RR) - (Atmos. IR ratio) $] /$ (Atmos. IR Ratio)

7 The "Base ROG Surrogate" is the mixture of reactive VOCs used in an experiment or model simulation to represent the reactive VOCs present in the atmosphere before the substitution or addition of the compound or mixture whose reactivity is being assessed. The term "surrogate" is used in the context of experimental studies because it is rarely practical to use the full mixture of VOCs actually present in the atmosphere, so simpler mixtures are employed. 
exhausts without any added base-case ROG. The $20 \%$ substitution simulations use the same base-case ambient ROG mixture as used in the ambient air simulations-the effects of using simpler base ROG surrogates in reactivity experiments is discussed later. The results show that under the relatively high $\mathrm{NO}_{\mathrm{X}}$ (low ROG/NO${ }_{\mathrm{X}}$ ) maximum reactivity ${ }^{8}$ conditions, the experimental $20 \%$ substitution reactivities correspond remarkably well to atmospheric reactivities under higher $\mathrm{NO}_{\mathrm{X}}$, maximum reactivity conditions, but that experimental reactivities under lower $\mathrm{NO}_{\mathrm{X}}$ (higher $\mathrm{ROG} / \mathrm{NO}_{\mathrm{X}}$ ) maximum ozone conditions do not correspond as well to atmospheric reactivities. This means that suitable experiments might indicate MIR reactivities, but they are less useful for estimating MOIRs.

The results shown in Table 6.3 also show that experiments using only the exhaust mixtures give poor predictions of atmospheric incremental reactivities. Thus, direct reactivity assessment experiments must include an ROG surrogate to represent the other reactive VOCs which are present in the atmosphere. Otherwise, the experiments would significantly overstate the reactivity differences among the various fuel options.

Model calculations have been carried out to assess the sensitivity of reactivity experiments to the level of detail of the base ROG surrogate employed in the experiments to represent ambient mixtures (Carter et al., 1994a). The results indicate that the ROG surrogate must at least represent the ambient mixture to the same level of detail used in model simulations with condensed mechanisms, but that beyond that, additional detail and complexity are insignificant. Use of an oversimplified mixture as the base ROG surrogate, particularly one that does not contain formaldehyde, may result in experiments that overestimate differences in reactivity, at least for certain species. However, this may make them more useful for mechanism evaluation, because the experiment is more sensitive to mechanism differences among the VOCs.

An additional issue in the context of alternative fuel use is the use of real exhausts as opposed to surrogate mixtures designed to represent exhaust. Experiments with real exhaust are of limited use for mechanism evaluation, because if the model performs poorly in simulating the results, it is uncertain whether the problem is caused by the chemical mechanism or by uncertainties in the exhaust speciation. On the other hand, such experiments provide the only means to assess exhaust reactivity without uncertainties concerning speciation analyses. Comparison of exhaust experiments with experiments using surrogates (designed to represent exhaust) provides the best means of evaluating whether we have succeeded in identifying all species that contribute to the exhaust's reactivity. To our knowledge, such a study has not been carried out.

However, the extreme difficulties in conducting such experiments well enough to provide useful data should not be understated. A significant complication is that exhaust contains large amounts of $\mathrm{NO}_{\mathrm{x}}$, making it difficult to control $\mathrm{ROG}$ and $\mathrm{NO}_{\mathrm{X}}$ independently. Because vehicle emissions are highly variable, conducting controlled experiments would be difficult. Exhaust also contains large amounts of water, which exacerbates surface effects, both in the sample line and in the chamber. The introduction of nitrous acid from the interaction of water with the $\mathrm{NO}_{\mathrm{x}}$ in the exhaust stream is a significant concern because nitrous acid is a powerful photoinitiator that is believed to play a major role in the "chamber radical source" artifact (Carter et al., 1982, 1986a; Carter and Lurmann, 1990, 1991). Analogous

8 Maximum reactivity conditions are conditions where VOCs have the greatest effect on ozone formation 
formation of nitrites is also a potential problem in the case of alcohol fuels. In some preliminary experiments with real exhaust, Jeffries et al. (1985) found that experiments with cryogenically trapped exhaust VOCs gave similar results as runs with comparable amounts of whole exhaust. This would allow for more controlled experiments with exhaust VOC mixtures. However, with such an approach there is always a concern about conversion or destruction of unidentified unstable and reactive exhaust components.

\subsubsection{Mechanism Evaluation Experiments}

The goal of mechanism evaluation experiments is to provide data needed to develop and test the chemical mechanisms in models. The need for such experiments was discussed above in Section 5. Models provide the only means of estimating reactivity impacts of emissions changes under ambient conditions, so this is probably the most important use of environmental chamber data. For mechanism evaluation, the critical requirements are not so much that the experiments simulate specific ambient situations, but that a) the experimental conditions are sufficiently well characterized for unambiguous modeling, and $b$ ) that the experimental data set, taken as a whole, can test all relevant aspects of the mechanism. The requirements for an environmental chamber data base for evaluating oxidant mechanisms are summarized by Jeffries et al. (1992). Although the effort involved in satisfying these requirements is considerable (requiring an understanding of the mechanism evaluation process and how to conduct chamber experiments), and the number of experiments required for comprehensive mechanism evaluation requires a multi-year effort, such experiments are far more useful in the long run than experiments designed to assess highly specific fuel options. Model simulations are much more flexible tools for assessing multiple fuel options under a variety of conditions. To have confidence in such simulations, we need to know that the model uses a fundamentally sound chemical mechanism that is backed by successful simulations of a sufficiently varied and well-characterized data base. The model is in effect being used to extrapolate from the conditions of the environmental chamber experiment to the conditions of the atmosphere.

Well-characterized experimental conditions are critical when using chamber data for evaluating mechanisms. If uncertainties in our understanding of run conditions can be used as an excuse for poor model performance, the experiment is useless for this purpose. Characterization of experimental conditions includes having an appropriate model for uncertain chamber effects, which must be taken into account when conducting model simulations of such experiments. This, in turn, requires special characterization experiments to evaluate (and usually adjust) what Jeffries et al. (1992) call the "ancillary mechanism." Characterization also includes knowing both the spectrum and intensity of the light source at all times during the experiment (a major problem with most outdoor runs), temperature, humidity, dilution, initial concentrations of all reactive species injected, and any other conditions needed to model the run. Because of these requirements, most experiments not carried out explicitly for mechanism evaluation turn out not to be useful for this purpose.

Well-characterized experiments simulating ambient conditions provide an essential test for the performance of the mechanism as a whole under realistic conditions. Such experiments need to be conducted under a variety of conditions to evaluate the performance of the mechanism for different environments. However, experiments that simulate ambient conditions are far from sufficient for mechanism evaluation. A mechanism cannot be relied on to give "the right answer for the right reason" if its component parts have not also been evaluated. This is particularly true for reactivity assessment, where the effects of varying the component parts (i.e., the individual VOCs) is of interest. Experiments 
with individual VOCs are essential for testing mechanisms for individual VOCs, particularly those whose mechanisms are highly uncertain. In some cases (as with aromatics) uncertain mechanisms to fit the data; thus, these experiments are essential to develop and evaluate the mechanisms. Unfortunately, single VOC experiments are almost useless for less reactive VOCs or for VOCs with radical sinks in their mechanisms, because the results are strongly dominated by chamber effects (e.g., see Carter et al., 1982, 1986a; Carter and Lurmann, 1990, 1991). Experiments with simple mixtures, or incremental reactivity experiments (discussed below) are required to evaluate mechanisms for such compounds.

Experiments with single VOCs do not provide a reliable test of a mechanism's ability to predict reactivity, because a major component of a VOC's reactivity is its effect on other VOCs' reactions (Carter et al., 1993; Jeffries and Crouse (1991); Bowman and Seinfeld (1994). On the other hand, experiments with realistic mixtures, by themselves, are not useful because they do not isolate the effects of any single VOC. Incremental reactivity experiments, where the effect of adding an individual VOC to a realistic or simplified surrogate ambient mixture is determined, can provide data to test the mechanism for an individual VOC in a chemically realistic environment. Experiments with both simple and complex ROG surrogates are useful in this regard. Experiments with simple surrogates provide a clearer test of the mechanism in that it is easier to investigate sources of problems when there are discrepancies, and our calculations have shown that the results can be more sensitive to differences among VOC's mechanisms than using more realistic mixtures (Carter et al., 1995a). Experiments with more realistic ROG surrogates are necessary to test the mechanism under more realistic conditions. Furthermore, as shown Table 5.3, model calculations indicate that experimentally measured reactivities under higher $\mathrm{NO}_{\mathrm{x}}$ maximum reactivity conditions can give reasonably good predictions of relative reactivities in the MIR scale. Thus, at least some types of reactivity experiments can provide useful data to assess direct reactivity and evaluate mechanisms.

\subsubsection{Examples of Relevant Chamber Studies}

Several studies have involved direct reactivity assessment experiments of methanol fuel substitutions. Pefley et al. (1984) showed that replacing $~ 33 \%$ of an "urban surrogate" mixture with $90 \%$ methanol + $10 \%$ formaldehyde caused reduced peak ozone levels in single-day experiments. These experiments, though qualitative in nature and not useful for mechanism evaluation, provided the first experimental confirmation of the potential benefits of alternative fuel use. Carter et al. (1986b) conducted an extensive series of multi-day indoor and outdoor chamber experiments to assess the effects of methanol and methanol + formaldehyde substitutions, and found that the benefits of methanol substitution decreased with increasing $\mathrm{ROG} / \mathrm{NO}_{\mathrm{x}}$ ratio, and with number of days of the experiment. The ROG surrogate employed did not contain formaldehyde, so the sensitivity of the results to formaldehyde may be greater than if a more realistic surrogate were employed. Efforts were made to characterize the runs well enough to evaluate the mechanism, though the light characterization for the outdoor runs is somewhat uncertain (Carter et al., 1986a). These experiments have been used in the evaluation of the SAPRC-86 (Carter et al., 1986a), RADM-II (Carter and Lurmann, 1990) and SAPRC-90 (Carter and Lurmann, 1991) mechanisms, which performed reasonably satisfactorily in simulating the effects of the methanol and methanol + formaldehyde substitutions.

More recently, Jeffries and Sexton (1993) conducted a series of UNC outdoor chamber experiments designed to study the effect of methanol fuel substitutions using highly realistic surrogate mixtures to represent industry average gasoline, M85, and the urban surrogate. Experiments were carried out at 
varying $\mathrm{ROG} / \mathrm{NO}_{\mathrm{X}}$ ratios, and with efforts to characterize the runs well enough for modeling. The results were qualitatively as expected based on previous experimental and modeling studies, but Jeffries and Sexton (1993) found that both the CB4 and a version of the SAPRC-90 mechanism simulated the results poorly. In particular, they consistently overpredicted ozone yields in the complex mixture experiments (though not in control runs), and predicted less benefit of methanol substitution than was observed. This modeling result is surprising in view of the performance of these mechanism in simulating SAPRC experiments and earlier UNC mixture runs (Carter and Lurmann, 1991; Gery et al., 1988), and needs to be confirmed. These data are not yet available for us to model.

Experimental studies of incremental reactivity have been or will be reported by Carter et al. (1993, 1995a) at SAPRC and CE-CERT and by Kelly et al. (1994) at the General Motors Research Laboratory (GMRL). These studies are ongoing at both laboratories. Although the SAPRC and GMRL studies had many similarities, the objectives were different. In the case of the SAPRC/CE-CERT studies, the objective is to provide data to test the ability of chemical mechanisms to predict reactivity. Carter et al. (1993) reported measurements of incremental reactivities of a wide variety of individual VOCs under high $\mathrm{NO}_{\mathbf{x}}$ "maximum reactivity" conditions using a simplified ROG surrogate. An indoor chamber with a blacklight light source was employed. The results were used in a preliminary evaluation of the SAPRC90 and the preliminary updated (SAPRC-93) mechanisms. The two mechanisms performed similarly except that the updated mechanism was significantly better for the internal alkenes. The updated mechanism could fit the data within the experimental uncertainty for approximately half the VOCs, and was consistent with the observed qualitative reactivity trends. The mechanisms tended to underpredict the incremental reactivities of the aromatics, which is opposite to what would be expected based on the Jeffries and Sexton (1993) modeling of the recent UNC experiments. In the more recent experiments, Carter et al. (1995a) measured incremental reactivities of representative VOCs under lower $\mathrm{NO}_{\mathrm{X}}$ conditions and with both a simpler and a more realistic ROG surrogate. The results were consistent with model predictions in terms of the $\mathrm{NO}_{\mathrm{x}}$ effects and also in that lower sensitivities to reactivity effects are observed when more complex ROG surrogates are employed. The model performed better in simulating reactivity measurements when using more complex rather than simpler ROG surrogates.

The objective of the Kelly et al. (1994) experiments was primarily to evaluate how well experimental incremental reactivities correlate with atmospheric reactivities. Incremental reactivities of several representative VOCs were measured as a function of amount of VOC added under approximately maximum reactivity conditions. A xenon arc light source (which gives a better approximation to the spectrum of sunlight than blacklights) and relatively small volume reaction bags were employed. Although the ROG surrogate did not contain formaldehyde, the results correlated reasonably well to atmospheric MIRs. The experiments were not intended for mechanism evaluation, though they may be useful for this if additional light characterization experiments are carried out. Light characterization experiments, and experiments with other VOCs, and temperature effects studies are planned (Kelly et al., 1994; Kelly, private communication, 1994).

Although the results of some of these new reactivity experiments have been used to test several existing mechanisms, updated mechanisms have not yet taken these data into account, except perhaps for a few individual VOCs (Carter, 1993). The apparent discrepancy in the modeling by Jeffries and Sexton (1993) and other work needs to be resolved. 
In addition to these studies, which are directly applicable to reactivity and alternative fuel assessments, a large data base of SAPRC and UNC experiments is useful for mechanism evaluation in general. This includes single compound runs, runs with simple mixtures, runs with ambient surrogates, runs with real and synthetic auto exhausts, and associated chamber characterization and control experiments. Under contract for EPA, chamber researchers at SAPRC, CE-CERT, and UNC have been compiling, evaluating, and in many cases correcting problems in this data base to develop a standard data base of chamber experiments for evaluating oxidant mechanisms (Jeffries et al., 1992; Carter et al., 1995b; Jeffries, unpublished results, 1994). A preliminary version of this data base for some earlier SAPRC experimenters is now available (Carter et al. 1995b), but the archived and corrected UNC experiments, and the more recent SAPRC experiments, including the large number of reactivity runs (Carter et al. 1993, 1995a), are not part of the available data base. The updated SAPRC data base should be available by the end of the year; the availability date for the UNC experiments is not known. This data base will be used in the update to the SAPRC mechanism, which is now under way under funding from CARB.

The present data base for mechanism evaluation, though extensive, has a number of critical gaps. Many important experiments are poorly characterized, and there are a number of inconsistencies between experiments carried out at different times and at different laboratories. For this reason, as part of its experimental reactivity studies in extending the work at SAPRC, CE-CERT is carrying out additional experiments of various types needed to fill the gaps and investigate or resolve the inconsistencies. The xenon arc light source recently acquired under NREL funding will provide an important component to this new data base (Carter et al., 1995c)

\subsection{Scenario-Specific Modeling Assessments}

A scenario-specific assessment is a model simulation whose objective is to estimate, as accurately as possible given the limitations of the available data and the type of model employed, the air quality impacts of some specific type of fuel substitution in a specific airshed scenario. A distinguishing characteristic of such studies is an attempt to make the emissions change being modeled a realistic representation of what might actually occur if the particular fuel were to become widely used. This type of study potentially provides the most accurate assessment given the limitations and uncertainties in the data and the model. (The types of models used, and their limitations, have been discussed in Section 4.) However, they provide relatively limited useful information about other fuel options, or about what might happen if the emissions from the fuels being considered were significantly different than the assumptions in the study. Thus, they are most useful for assessing fuel options that are in the advanced stages of being considered, and whose emissions are relatively well understood.

The various scenario-specific assessments on alternative fuel substitutions that have been carried out to date, the types of models they used, and representative results are listed in Table 6.4.

Most of these studies concerned the effects of methanol fuel substitution, and the effects of formaldehyde emissions in affecting methanol fuel exhaust reactivity. For example, methanol fuel substitutions have been studied with grid models (Russell et al., 1989; Russell, 1990) and Lagrangian models (Chang et al., 1989). The primary effect of methanol substitution is to reduce the reactivity of VOC emissions from automobiles. Consistent with the reactivity scale assessments, the use of methanol fuel was predicted to reduce ozone concentrations, with the magnitude of this reduction decreasing with increasing $\mathrm{VOC}_{\mathrm{NO}} \mathrm{x}$ concentration ratios, but with the benefit decreasing with increased formaldehyde emissions. For a $50 \%$ 
Table 6.4. Summary of Scenario-Specific Assessments of Reactivity Effects of Alternative Fuels.

\begin{tabular}{|c|c|}
\hline $\begin{array}{l}\text { Reference } \\
\text { Type of Model } \\
\text { Region Modeled } \\
\text { Fuel options } \\
\text { Results }\end{array}$ & $\begin{array}{l}\text { : Whitten and Hogo (1983) } \\
\text { :KKMA trajectory model applied for one day } \\
\text { : South Coast Air Basin (SoCAB) in California } \\
\text { : Methanol fuel vehicles. All gasoline vehicles substituted. } \\
\text { : Although changes in the emissions input were not treated in detail, different levels } \\
\text { of formaldehyde in the exhaust of methanol fuel vehicles were considered. The } \\
\text { predicted ambient ozone levels for } 1987 \text { were shown to decrease upon using } \\
\text { methanol (13 - } 31 \% \text { ), although they were extremely sensitive to the exhaust } \\
\text { formaldehyde content. }\end{array}$ \\
\hline $\begin{array}{l}\text { Reference } \\
\text { Type of Model } \\
\text { Region Modeled } \\
\text { Fuel options } \\
\text { Results }\end{array}$ & $\begin{array}{l}\text { O'Toole et al., (1983) } \\
\text { : CIT multilevel trajectory model applied for one day } \\
\text { : South Coast Air Basin (SoCAB) in California } \\
\text { : Methanol fuel vehicles. All gasoline vehicles substituted. } \\
\text { Studied the impact of methanol fuel utilization on air quality in the year } 2000 \text {. } \\
1974 \text { emission inventory scaled forward. Stationary source emissions not } \\
\text { changed. Several case studies (ROG and NO } \mathrm{X} \text { emission rates reduction) were } \\
\text { conducted and in all cases methanol was found to be effective at reducing peak } \\
\text { ozone levels }(14-20 \%) \text {. }\end{array}$ \\
\hline $\begin{array}{l}\text { Reference } \\
\text { Type of Model } \\
\text { Region Modeled } \\
\text { Fuel options } \\
\text { Results }\end{array}$ & $\begin{array}{l}\text { : Pefley et al. (1984) } \\
\text { : Box model applied for one day } \\
\text { : South Coast Air Basin (SoCAB) in California } \\
\text { Methanol fuel vehicles. All gasoline vehicles substituted. } \\
\text { : For the base year 1987, peak ozone concentrations reduced by } 18 \% \text {. }\end{array}$ \\
\hline $\begin{array}{l}\text { Reference } \\
\text { Type of Model } \\
\text { Region Modeled } \\
\text { Fuel options } \\
\text { Results }\end{array}$ & $\begin{array}{l}\text { : Nichols and Norbeck (1985) } \\
\text { EKMA trajectory model } \\
: 20 \text { cities } \\
\text { : Methanol fuel vehicles. All light-duty gasoline vehicles substituted. } \\
\text { : Ozone reduction sensitive to the ratio of } \mathrm{NMOG} \text { to } \mathrm{NO}_{\mathrm{X}} \text {. Ozone reduced by } 1- \\
36 \% \text { when methanol fuel vehicle exhaust was } 0 \% \text { formaldehyde, and by } 0-13 \% \\
\text { when methanol fuel vehicle exhaust was } 10 \% \text { formaldehyde. }\end{array}$ \\
\hline $\begin{array}{l}\text { Reference } \\
\text { Type of Model } \\
\text { Region Modeled } \\
\text { Fuel options } \\
\text { Results }\end{array}$ & $\begin{array}{l}\text { Whitten et al. (1986) } \\
\text { : Several trajectory models } \\
\text { : Philadelphia region } \\
\text { : Methanol fuel vehicles. All mobile sources converted. } \\
\text { : Calculations performed for the base year } 2000 \text {. Results were sensitive to the initial } \\
\text { and boundary conditions. Methanol substitution reduced peak ozone levels by } 7 \text { - } \\
10 \% \text {. }\end{array}$ \\
\hline $\begin{array}{l}\text { Reference } \\
\text { Type of Model } \\
\text { Region Modeled } \\
\text { Fuel options } \\
\text { Results }\end{array}$ & $\begin{array}{l}\text { : Chang et al., (1989) } \\
\text { : EKMA trajectory model } \\
: 20 \text { cities (in PA, OH, TX, MA etc.) } \\
: \text { Methanol fuel vehicles. All light-duty gasoline vehicles substituted. } \\
\text { Emission inventory for the year } 2000 \text { obtained from emissions model. For } \\
\text { different methanol fuel vehicle penetrations scenarios, potential impacts of } \\
\text { methanol use on ozone levels ranged from 1-5\%. }\end{array}$ \\
\hline
\end{tabular}


Atmospheric Process Evaluation of Mobile Source Emissions

Table 6.4. (cont.)

\begin{abstract}
Reference
Type of Model

Region Modeled

Fuel options

Results

: Russell et al., (1989)

: Three dimensional Eulerian grid based CIT airshed model

: South Coast Air Basin (SoCAB) in California

: Methanol fuel sources.

: Considered several emission scenarios. In a comparison of two such scenarios, one with full penetration of advanced technology methanol fuel vehicles into on-road advanced technology conventional fuel vehicles, and methanol conversion of offroad mobile sources (SCEN05), and the other with full penetration of advanced technology conventional fuel vehicles into on-road mobile sources (SCEN04), peak ozone levels decreased by $9 \%$ upon substitution. The effects of methanol fuel vehicles on concentrations of formaldehyde and PAN were also analyzed.

Reference

Type of Model

Region Modeled

Fuel options

Results

: Russell $(1989,1990)$; Russell et al., $(1989,1990)$

: Three-dimensional Eulerian grid based CIT airshed model

: South Coast Air Basin in California

: Methanol fuel sources

: Quantified the air quality impacts resulting from the use of methanol fuel within the SoCAB for the years 2000 and 2010 . The model was used to predict ambient concentrations of ozone, particulate matter, formaldehyde, nitric acid, benzene, methanol and peroxyacetyl nitrate. Major sources of uncertainty and their effects were also quantified. The episode of August 30 to September 1, 1982 in the Los Angeles basin was used as the basis for the study. The trajectory model calculations showed that conversion to methanol lowered ozone and PAN concentrations in the basin, although the extent of ozone reduction was highly dependent on the location within the basin. It was also found that ambient formaldehyde levels change very little when methanol use was simulated. The airshed calculations were first used to evaluate the air quality in the years 2000 and 2010 without alternative fuels and extraordinary emission control strategies. Results showed that the emission control strategies were effective in reducing ambient ozone levels in the year 2000 , but this was offset by 2010 due to increased economic activity during the period.
\end{abstract}

Reference

Type of Model

Region Modeled

Fuel options

Results
: AQIRP, (1991e, 1993a); Pollack et al., (1993)

: Three-dimensional Eulerian grid-based UAM model

: New York, Los Angeles, and Dallas-Fort Worth

: Reformulated Gasolines; Methanol/Gasoline Blends

: The AQIRP is investigating changes in aromatic, olefin, sulfur, oxygenate content and fuel vapor pressure of reformulated gasolines on air quality. Future year simulations (2005 for New York and Dallas, 2010 for Los Angeles) predict peak ozone concentrations to decrease by about $1 \%$ in Dallas to about $3 \%$ in Los Angeles. Research is still under way. Pollack et al. (1993) presented a methodology to study the impacts on air quality resulting from the use of reformulated gasoline and various other alternative fuels in the three metropolitan areas: New York, Los Angeles, and Dallas-Fort Worth. The methodology adopted was to first define the effects of various fuels on vehicle emissions, to estimate emissions in the future using vehicle emissions models, MOBILE4, EMFAC7E and BURDEN7D, and then using air quality models to predict ozone formation in the future. The air quality modeling was to be accomplished using a trajectory model as well as the Eulerian grid-based UAM. 
penetration of M85 vehicles, Russell (1990) found that the ozone reduction was about $15 \%$ in the $\mathrm{NO}_{\mathrm{X}^{-}}$ rich central basin of Los Angeles. However, the reduction of ozone concentrations was less than $10 \%$ in the downwind areas where the ozone peak actually occurred. This is to be expected because the peak ozone in these areas is controlled by the available $\mathrm{NO}_{\mathrm{x}}$; the slowing down of the photochemistry by methanol substitution is no longer important. This result is consistent with the sensitivity results presented by Harley et al. (1993), which show that increasing automobile VOC emissions by a factor of three has little effect on the peak ozone concentrations estimated at Claremont or Rubidoux. Results similar to Russell et al. (1990) were obtained by investigators using EKMA Lagrangian models (Chang and Rudy, 1989; Nichols and Norbeck, 1985). They found that ozone reductions amounted to less than 5\% for several emission scenarios associated with penetration of methanol fuel cars. Russell et al. (1989) also found that methanol substitution would reduce other pollutants such as particulate matter and toxic organics, such as benzene, which are the products of photochemistry.

AQIRP (Burns et al., 1991) is funding projects to examine the air quality impact of using reformulated gasolines. By changing the aromatic, olefinic, sulfur, and oxygenate content of gasolines, we can obtain reductions in VOC, $\mathrm{NO}_{\mathrm{x}}$, and $\mathrm{CO}$ emissions. Reformulation is also designed to reduce fuel vapor pressure to minimize evaporative emissions. Model results obtained thus far indicate that such changes in fuel composition are beneficial, but lead to relatively small decreases $(<5 \%)$ in peak ozone concentrations.

The main distinguishing feature of these and other scenario-specific assessments is the type of model used: some used three-dimensional Eulearian models such as UAM or the CIT model, while others used single-cell trajectory models such as EKMA. The major features of these different models were discussed in Section 4. The three-dimensional models provide potentially the most realistic assessment of what might happen in an actual airshed, and provide the only means of assessing how the impact of a substitution will vary with location and time in a particular airshed. However, as discussed, they have significant problems and may not be any more reliable in their reactivity predictions than the much simpler EKMA-type models. For example, the models may or may not provide reliable estimates of the spatial and temporal patterns of ozone if they underpredict the ozone precursors, $\mathrm{VOC}$ and $\mathrm{NO}_{\mathbf{X}}$, by large factors (see Section 6). Perhaps the most serious problem with reactivity assessments using these models is that usually only one pollution scenario is assessed, and only a few (if any) sensitivity studies are conducted in conjunction with these studies because of their expense and the difficulty in interpreting results.

As discussed in Section 4, the Lagrangian or EKMA models incorporate major simplifications to transport and mixing phenomena, and cannot represent any particular pollution episode with great detail. However, such models can represent a wide range of chemical conditions that may affect predictions of effects of ROG and $\mathrm{NO}_{\mathrm{x}}$ control on ozone formation. These chemical conditions are the same as those affecting VOC reactivity. Therefore, an appropriate set of EKMA-type scenarios should also be suitable for assessing effects of particular fuel substitutions under a wide range of conditions. The most useful of such studies examine a wide variety of scenarios, and thus one can obtain an indication of the range of impacts that might result for a particular substitution scenario under different environmental conditions.

Another potential advantage of trajectory models is that it is more practical to use more detailed chemical mechanisms when carrying out the assessment. The problem of chemical mechanism detail was 
discussed above. However, all the single-cell scenario-specific assessments listed in Table 5.4 employ condensed chemical mechanisms that are also suitable for use in grid models. Trajectory models with more comprehensive mechanisms have been used in development of reactivity scales, and would be appropriate for scenario-specific assessments as well.

An ideal type of scenario-specific assessment would be to conduct model calculations of the effects of the substitution under a variety of airshed conditions, including scenarios where critical model inputs are varied in their range of uncertainty. Use of Eulerian models for this purpose will require an advance of computer technology and software before it is practical. In the meantime, the physically simpler (and computationally more tractable) trajectory models provide the most useful means to assess how the effects of different substitutions vary with conditions, and to assess the sensitivities of model predictions to uncertainties in input data. 


\subsection{Recommendations for Future Research}

A comprehensive evaluation of the impact alternative fuels requires an accurate quantification of different factors ranging from mass emissions rates and species profiles from individual vehicles to large-scale emission inventories, and an accurate representation of these variables in complex regional air shed models. Unfortunately, each stage of the air quality modeling process contains a number of inherent errors. In this section, we summarize our recommendations for research needed to identify, reduce, and quantify uncertainty in the areas of emissions, chemistry, and modeling. In view of the limitations of the available emissions data and the air quality models, we feel the primary focus of short-term research should be on understanding the variability and uncertainty inherent in the modeling procedure as a whole. In fact, under the present conditions, knowledge of the answer's uncertainty is almost as important as the answer itself.

\subsection{Emissions}

To accurately determine the environmental impact of using alternative fuels, or for that matter any fuel, one must be able to generate an accurate emissions inventory of vehicles that use particular fuels. In Section 3 we provide a detailed overview of the methodology used in current emission models. Unfortunately, many studies have shown that under most on-road operating conditions actual vehicle emissions can differ dramatically from what is predicted by the current mobile emission models (CRCAPRAC, 1991, 1992, 1994; Fujita, et al., 1991). This discrepancy occurs for several reasons including: inadequate treatment of modern closed-loop emission control technology; inadequate representation of the active fleet; and poor mapping of emission data and vehicle operation when compared to present-day driving conditions. For alternative fuels the problem is even greater as the availability of emissions data for AFVs is limited. Clearly, the issues of inadequate emission inventory models and the scarcity of emissions testing data on AFVs must be addressed before an accurate assessment of alternative fuels can be made.

Of these problems, the most significant research need is apparently for an emissions testing procedure that can accurately portray real-world driving conditions. Several studies have shown that the current standard test, the FTP, does not accurately characterize today's driving behavior (Markey, 1993; Austin, et al., 1992; St. Denis and Winer, 1993; Carlock, 1992). The test was developed more than two decades ago and was designed to simulate average driving characteristics over a predetermined driving trace. At the time, however, the acceleration rates were reduced because the belt-driven dynamometer used then had a tendency to slip (Kelly and Groblicki, 1993). Thus, the driving sequence does not include off-cycle events common in today's traffic scenarios. In such high load situations, including high accelerations and/or driving on grades, a considerable percentage of actual in-use emissions can be produced. One study found, for example, that each second of driving with enrichment was equal to approximately 40 minutes of driving under stoichiometric conditions with respect to $\mathrm{CO}$ emissions (Kelly and Groblicki, 1993).

The methods used to collect and analyze data from the FTP test are also subject to considerable uncertainty. The FTP is divided into three segments that are collected in separate bags. The emissions from these segments are then used by the emissions models to statistically reconstruct the relationship between emission rates and average vehicle speeds. This procedure tends to smooth out the effects of accelerations and decelerations, however. The problem with this is that two vehicle trips having the same 
average speed, but different speed profiles (acceleration, deceleration, idle, etc.), can have a drastically different emissions output. This is particularly true for current closed-loop emission control systems where dynamic operations of the vehicle are important variables in predicting vehicle emissions (CRCAPRAC, 1991, 1992, 1994; St. Denis and Winer, 1993).

Similarly, there are shortcomings in the methods used to derive speed correction factors from transient tests that span a series of average speeds up to $65 \mathrm{mi} / \mathrm{h}$. In particular, actual emissions at a given speed will vary greatly depending on the engine load; e.g., during hard acceleration. Real-world conditions can also exceed the valid range of the test cycles; for example, real-world speeds often exceed the test cycle maximum of $65 \mathrm{mi} / \mathrm{h}$, and real-world accelerations commonly exceed the $3.3 \mathrm{mi} / \mathrm{h}$-s maximum in the FTP cycle.

Clearly, the above discussion underscores the need to investigate how emissions are affected during different modes of operation (acceleration, deceleration, idle, etc.). Dynamometer tests and instrumented vehicles are currently being used to study emissions during different operational modes. CARB has conducted several dynamometer tests to determine the effect of modal operations. In a nine-mode emissions analysis, a single hard acceleration (e.g., $6 \mathrm{mi} / \mathrm{h}$-s) could increase the total trip emissions for $\mathrm{CO}$ by a factor of 2 (Drachand, 1991). More recently, CARB has collected second-by-second emission data on 10 newer technology vehicles using four driving cycles (Cicero-Fernadez and Long, 1993). CO and $\mathrm{HC}$ emissions are greatly affected by different acceleration modes. EPA has also conducted dynamometer tests on 28 modern vehicles as part of the FTP revision project (Markey, 1993). The results of these tests are still being analyzed.

Several studies have attempted to better characterize in-use driving behavior by obtaining real-time, insitu emissions measurements (St. Denis et al., 1994). Instrumented vehicle projects evaluate on-road vehicle performance by collecting real-time vehicle operation parameters while simultaneously measuring second-by-second emission data. With data from these instrumented vehicles, we can examine the direct relationships between vehicle operation and emission output. Several researchers are currently involved with instrumented vehicle projects including groups at GM (Kelly and Groblicki, 1993), Ford (Jesion et al., 1994), the Denver Research Institute in collaboration with Ford (Lesco, 1994), CE-CERT, Sierra Research with CARB sponsorship and the Georgia Institute of Technology (Rodgers et al., 1994).

To supplement the data collected from dynamometer testing and instrumented vehicles, remote sensing devices can be used. The advantage of remote sensing devices is that they can collect emissions from a large number of vehicles under a variety of traffic conditions (Lawson et al., 1990; Stephens and Cadle, 1991; Bishop et al., 1993). Remote sensing data can thus be used to supplement and calibrate the emission data collected from dynamometer testing and instrumented vehicles. Such feedback is essential for correcting vehicle fleet emission estimates that are based on a limited subset of actual vehicles on the road.

Consideration must be also given to vehicle emissions other than those from tailpipe in the development of an inventory. This would include emissions from such sources as evaporation and refueling, as well as those from fuel production, conversion, and transportation (Darrow, 1994; Bull et al.). So-called full fuel cycle emissions will become increasingly more significant as vehicular emissions achieve lower and lower values and as different fuels become more widely used. Similarly, electric vehicles (which have zero tailpipe emissions) can have significant fuel cycle emissions and must be evaluated in this context. 
More specific to alternative fuels is the need to increase the current emissions data base for in-use current technology production vehicles. Several ongoing programs, e.g., AMFA and CleanFleet, could address this issue. Such programs must continue and additional programs initiated if the true impact of alternative fuels is to be accurately accessed. Initial results from both programs are just becoming available. In particular, the CleanFleet program has just released the low mileage emissions numbers for its fleet vehicles (Battelle Memorial Institute, 1994). Two additional emissions reports are expected to be released from the CleanFleet program, one shortly and the other in February 1995. The results of phase 1 of the AMFA program are also available through the AFDC, although a final report on this phase is not due until later in the year (Kelly, 1994). Clearly, the successes and failures of these programs will provide guidelines for future projects in this area.

The mere development of emissions data bases, species profiles, and emissions inventories is not sufficient. The uncertainty in these numbers must be quantified and included with the data sets in a form that can be used as an input in modeling analysis. For any missing data, knowledgeable guesses of the minimum and maximum mass and compositional ranges should be made along with a "best guess." Compositional ranges should also include maximum and minimum percentages of various classes of compounds. We have provided a set of emissions species profiles for the various alternative fuels in Tables 2.6-2.10 with an assessment of the validity of these estimates. More information of this type is needed.

\subsection{Chemistry}

The gas-phase chemical processes by which vehicle emissions promote ozone formation are complex and have significant uncertainties. In the long term, the most profitable method to reduce or quantify these uncertainties is to continue basic laboratory studies of the relevant elementary processes. A discussion of the specific areas of needed research in this regard is beyond the scope of this document, but priorities include improving our understanding of aromatic photooxidations and identifying the products formed, improved data on absorption cross sections and quantum yields of photolyzing species, improving our understanding of ozone-alkene reactions, identifying products formed from high molecular weight alkanes and alkenes, and obtaining better information on the effects of temperature on VOC oxidation mechanisms. While such long-term research may not yield immediate answers needed in the short term, it will yield the greatest benefit to our understanding of the impacts of vehicular and other emissions in the long run.

In the more immediate term, the priorities for atmospheric chemistry research concern improving the quality and comprehensiveness of the mechanism evaluation data base, improving the level of chemical detail that can be represented in comprehensive models, and improving our ability to quantify the effects of chemical mechanism uncertainty on airshed model results. Research in many of these areas is currently under way and should be continued. However, there are other areas where we feel that new research programs are needed.

For example, at our laboratories we have been carrying out a multi-year program to obtain environmental chamber data to test ozone reactivities of representative VOCs under a variety of atmospheric conditions. Similar work is being carried out at the GMRL (e.g., Kelly et al. 1994) and at the UNC (e.g., Jeffries et al., 1992). Two major areas of environmental chamber research not currently funded to an adequate extent but that we feel are essential are: a) determining the effects of temperature on VOC reactivity, and 
b) improving the quality of the chamber data base for low $\mathrm{NO}_{\mathrm{x}}$ conditions. The evidence is that the current generation of chemical mechanisms perform poorly in simulating ozone formation under low temperature conditions (Carter et al., 1994b; Gery et al, 1988), and this may be one of the reasons for some of the discrepancies between modeling chamber data from our laboratories and modeling recent results from the UNC (Jeffries et al., 1992; Carter et al., 1994b). Because of chamber effects and limitations in the types of analytical instrumentation generally used in chamber research, the present environmental chamber data base is not adequate for testing mechanisms for low $\mathrm{NO}_{\mathbf{x}}$ conditions. We are aware of no significant research program aimed at addressing this deficiency, even though in terms of area, most of the U.S. can be characterized as being under low $\mathrm{NO}_{\mathrm{x}}$ conditions.

The SAPRC-90 mechanism and its updated versions (which we are developing under CARB funding) represent a significant improvement in ability to represent chemical detail over the condensed mechanisms currently used in comprehensive models. Lurmann et al., (1991) developed procedures to implement this in the UAM, but it is not widely used because it takes significantly more computer time than the standard UAM with the condensed CB4 mechanism. However, Lurmann and co-workers (Lurmann, private communication, 1994) recently developed, under CARB funding, an improved method for implementing such a mechanism in the UAM and other comprehensive models that have much more acceptable running time. Thus, it is now feasible to use more chemically detailed mechanisms in comprehensive models. In view of this, we recommend the use of highly condensed mechanisms such as CB4 or LCC be phased out in modeling applications where effects of changing chemical compositions of emissions are being assessed. This would include assessments of effects of alternative fuel use.

One problem with this recommendation is that at present, in terms of detailed mechanisms that have been evaluated using chamber data, no alternatives to those developed at SAPRC are currently available for use in modeling. Relying on chemical mechanisms (or any other critical model component) developed by a single research group for critical decision making is not prudent public policy. We believe it is important that alternative detailed mechanism development efforts be funded, so effects of using alternative approaches and judgments concerning critical uncertainties can be assessed. We understand there is some independent detailed model development work being carried out in conjunction with EPA's "Models-3" initiative (Gery, private communication, 1994), but it is unclear whether the benefit of this work will be available any time soon.

There is also research under CARB funding, to assess the effects of chemical mechanism uncertainty on airshed model results. The focus of this work is primarily for UAM model applications to the California SoCAB, with the standard $\mathrm{CB} 4$ mechanism being used as the basis for comparison. Clearly this needs to be extended to using more detailed mechanisms as the basis of comparison, and to assessing the effects of the uncertainties on other areas and regional modeling applications. This work would benefit greatly with the existence of alternative detailed mechanisms developed independently of the SAPRC mechanisms, though the CARB project does use other mechanism developers as consultants. Milford and co-workers (Yang et al., 1994) recently completed a study of the effects of uncertainties of rate parameters in reactivity calculations, which provided valuable additional data in this area. However, this work did not address the effects of the uncertainties in product yields and mechanism formulation, which are much more difficult to quantify. The quantification of mechanism uncertainties is a major research effort, and the two programs referenced above (one just starting, one completed) represent only a start in this regard. 
Continuing work in the area of estimating effects of mechanism uncertainty should thus be a major focus of the near-term chemistry-related research relevant to alternative fuel assessment. In addition to providing much needed information for quantifying the impacts of these uncertainties on results of assessments, it will provide a valuable guide as where best to place resources in basic laboratory and environmental chamber research.

\subsection{Modeling}

Comprehensive grid models need to incorporate the relevant processes in as much detail as possible to serve as numerical surrogates of the real system. But in doing so, they incorporate uncertain parameterizations of the relevant processes, which might limit their usefulness. There is clearly a need to improve the current parameterization of processes. Because this is a continuing process, we should also develop a modeling process that explicitly accounts for uncertainties.

To improve process modules, we need to understand the effect of process parameterization on model performance. Although the models differ in their formulation process, model results obtained thus far do not indicate that any model is better than the rest. The main reason for this inconclusive state of affairs is the sparsity of studies on intercomparing the performance of models against common data sets. As far as we know, only one study of this nature has been completed. This is the multi-year project involving the intercomparison of the RADM and ADOM models with an extensive data set collected during the Eulerian Model Evaluation Field Study conducted during 1988-1990 (Barchet et al., 1991). In addition to comparing the estimates of the complete models with common data sets, the study also involved comparison of estimates from the individual process modules. This aspect of the project indicated there were major differences in the formulations of the process modules. However, these did not translate into major differences in the performance of the full models; the model performance statistics were very similar. The reasons for this were not examined because of a lack of funding. AQIRP is now conducting a comparison of urban grid models but has yet to publish the results of this study (Chock, personal communication, 1994).

The errors associated with averaging physical features smaller than the grid scale could be solved using a curvilinear coordinate system whose grid spacing automatically adjusts to the physics of the problem. This dynamic system is mapped onto a rectangular system to allow the application of available numerical solvers. Such grid-generation techniques have been extensively used in the aerospace field, where it is necessary to treat large gradients in the governing variables in certain regions of the flow field, such as near the nose of an aircraft (Thompson, 1985).

Most available air quality models express the mass conservation equation in the flux form [Equation (4.1)], and use associated numerical techniques to solve it. The flux form is sensitive to inevitable divergences in the wind field, which can lead to errors in the concentration estimates. The use of semiLagrangian techniques to solve the advective form [Equation (4.3)] of the mass conservation can avoid these problems.

The uncertainties in model formulation and model inputs are not likely to become small in the foreseeable future. This suggests the need to develop and incorporate methods to account for these uncertainties explicitly in the modeling process. One obvious way of doing this is to apply more than one grid model 
to solve the same problem. The difference in model results is a measure of model formulation uncertainty. Sensitivity studies with the same model provide estimates of model input uncertainty.

The application of most grid models is a computationally demanding exercise that has to be preceded by the compilation of extensive input data sets for emissions, meteorology, and land use for the domain of interest. These computational requirements discourage the type of numerical experimentation required for a thorough analysis of model uncertainties as well as emission reduction strategies. Typically, two or three simulations form the basis of an emission reduction decision, the financial consequences of which could run into millions of dollars. This suggests that we should continue to use semi-empirical EKMA type models to examine the air quality impact of fuel alternatives. What these models might lack in physical realism they make up through observational input that is specific to the problem at hand.

Comprehensive grid models may become more user friendly as soon as their computational efficiency is increased substantially. Several projects are under way (e.g., Hansen et al., 1994) to achieve this objective by designing air quality models to run on multi-processor machines (see Venkatram, 1991). Even if this goal is achieved, we still have to contend with uncertainties such as emissions in model inputs. The most straightforward way of accounting for this type of uncertainty is to use models that can be calibrated with observations. EKMA allows and incorporates calibration with the maximum ozone concentration. Such calibration is very difficult with complex grid models.

We recommend the use of simple parameterized models to supplement that of comprehensive models. These models can be fitted to observations, and are also computationally efficient. One such model, referred to as the Simplified Ozone Modeling System (SOMS, Venkatram et al., 1994), has been developed under the sponsorship of the Electric Power Research Institute. SOMS is one component of a decision analysis framework designed to examine costs and environmental consequences of alternate ozone abatement strategies.

SOMS was developed through systematic simplification of a detailed photochemical model. At each stage of the simplification, the simplified model was tested against observations and results from the detailed model. SOMS uses a semi-empirical chemical mechanism that treats the VOC species as a single lumped class; the species are aggregated using a reactivity scale similar to that developed by Carter (1991). To achieve computational efficiency, SOMS separates transport from chemistry. Because this step leads to most of the reduction in computing time, SOMS can readily incorporate the detailed chemistry needed for evaluation of alternative fuels with little change in computational efficiency.

The results from model testing (Venkatram et al., 1994) indicate that the model can be used to obtain quick estimates of the effects of a large number of $\mathrm{VOC}$ and $\mathrm{NO}_{\mathrm{X}}$ emission control scenarios on ozone concentrations. If required, the results from these calculations can then be used to select a few cases for more detailed study with a comprehensive model. As presently formulated, SOMS can estimate the impact of alternative fuels by accounting for the reactivity of the fuel in calculating the total VOC emissions. If more refined estimates are required, detailed chemistry can be readily used within the framework of SOMS.

In view of the current state of air quality models, it is not prudent to rely on any one model to provide estimates of the impacts of fuel substitution. We recommend the use of range of a wide range of models, from comprehensive grid models to semi-empirical models, such as EKMA or SOMS. We should apply 
at least two models to examine a problem of any importance. This is done routinely in other fields where uncertainty is a dominant factor in modeling. A relevant example is climate modeling, where several models are being used to estimate climatic changes induced by greenhouse gas emissions. A similar exercise was conducted in the examination of the effects of SST emissions on stratospheric ozone.

The application of several types of air quality models to examining the effects of fuel substitution will provide measures of uncertainty in the model estimates. To make best use of these uncertainty estimates in formulating emission control strategies, we recommend the use of techniques of Decision Analysis, which provide the basis for explicit consideration of uncertainty in environmental management (Reckhow, 1994).

It is also important that modeling assessments be based on a variety of airshed conditions, representing the full distribution of atmospheric conditions for which air quality impacts of fuel use is a current, or potential future, concern. Use of simplified models (such as EKMA or other Lagrangian approaches) is obviously better suited for multi-scenario assessments than use of comprehensive models with major computational and data input demands. Clearly, both types of models are important, with the simpler models giving the best indication of the variation of the impacts with conditions, with the more comprehensive models serving as a test for the applicability of the simper models, and examining the impacts of specific substitution scenarios in greater de tail.

In this regard, it is important to recognize that the impacts of any fuel substitution will vary with atmospheric conditions. This is yet another source of uncertainty that needs to be taken into account. A knowledge of this variability and uncertainty is clearly a critical input to decision makers when determining the ultimate effect of any proposed fuel change. One of the challenges of the modeling community is to communicate this to policy makers in a manner that they can understand and incorporate in their decision making. 


\subsection{References}

AFDC (1994): "Emissions Data Show Varied Results on 1992 CNG/Gasoline Conversions," AFDC Update, vol. 3, October.

Altshuller, A. P. and J. J. Bufalini (1971): Environ. Sci. Technol, 5: 39.

Andersson-Skold, Y., P. Grenfelt, and K. Pleijel (1992): "Photochemical Ozone Creation Potentials - A study of Different Concepts," J. Air Waste Mangage. Assoc., 42: 1152-1158.

AQIRP (1990): Initial Mass Exhaust Emissions Results from Reformulated Gasolines, Technical Bulletin No. 1, Coordinating Research Council, Inc., Atlanta, GA, December.

AQIRP (1991a): Effects of Fuel Sulfur Levels on Mass Exhaust Emissions, Technical Bulletin No. 2, Coordinating Research Council, Inc., Atlanta, GA, February.

AQIRP (1991b): Emissions Results of Oxygenated Gasolines and Changes in RVP, Technical Bulletin No. 6, Coordinating Research Council, Inc., Atlanta, GA, September.

AQIRP (1991c): Exhaust Emissions of Toxic Air Pollutants Using Reformulated Gasolines, Technical Bulletin No. 5, Coordinating Research Council, Inc., Atlanta, GA, June.

AQIRP (1991d): Mass Exhaust Emissions Results From Reformulated Gasolines in Older Vehicles, Technical Bulletin No. 4, Coordinating Research Council, Inc., Atlanta, GA, May.

AQIRP (1991e): Air Quality Modeling Results for Reformulated Gasoline in Year 2005/2010, Technical Bulletin No. 3., Coordinating Research Council, Inc., Atlanta, Ga. May.

AQIRP (1992a): Emissions and Air Quality Modeling Results From Methanol/Gasoline Blends in Prototype Flexible/Variable Fuel Vehicles, Technical Bulletin No. 7, Coordinating Research Council, Inc., Atlanta, GA, January.

AQIRP (1992b): Emissions of Three Dedicated-Methanol Vehicles, Technical Bulletin No. 10, Coordinating Research Council, Inc., Atlanta, GA, June.

AQIRP (1993a): Methodology for Modeling the Air Quality Impacts of Changing the Composition of Fuels Used in Light-Duty Gasoline Vehicles, Coordinating Research Council, Inc., Atlanta, GA, January.

AQIRP (1993b): Reactivity Estimates for Reformulated Gasolines and Methanol/Gasoline Mixtures, Auto/Oil Air Quality Improvement Research Program, Technical Bulletin No. 12, June.

Atkinson, R. (1987): "A Structure-Activity Relationship for the Estimation of Rate Constants for the GasPhase Reactions of OH Radicals with Organic Compounds," Int. J. Chem. Kinet., 19: 799-828.

Atkinson, R. (1989): "Kinetics and Mechanisms of the Gas-Phase Reactions of the Hydroxyl Radical with Organic Compounds," J. Phys. Chem. Ref. Data, Monograph No 1.

Atkinson, R. (1990): "Gas-Phase Tropospheric Chemistry of Organic Compounds: A Review," Atmos. Environ., 24A: 1-24.

Atkinson, R. (1994): "Gas-Phase Tropospheric Chemistry of Organic Compounds," J. Phys. Chem. Ref. Data, Monograph No. 2. 
Austin, T. C., T. R. Carlson, F. J. DiGenova, J.M. Lee, and M. Carlock (1992): "Analysis of Driving Patterns in Los Angeles during 1992," in Proceedings of the Third annual CRC-APRAC On-Road Vehicle Emissions Workshop, Coordinating Research Council, Inc., Atlanta, GA.

Bailey, B. (1994): "Advanced Alternative Fuels Utilization and Emissions." Presented at the Windsor Workshop on Alternative Fuels, Toronto, Canada, June.

Barchet et al, 1991: The EMEFS Model Evaluation: An Interim Report. Pacific Northwest Laboratory, Richland, Washington, PNL-7914,UC-000.

Barth, M. and J. Norbeck (1.993): The Development of an Integrated Transportation/Emissions Model to Predict Mobile Source Emissions, Report by the College of Engineering-Center for Environmental Research and Technology, University of California, Riverside, CA, Technical Report No. AB2766/C0004.

Barth, M. and J. Norbeck (1994): Phase Two Development of an Integrated Transportation/Emission Model, Report by the College of Engineering-Center for Environmental Research and Technology, University of California, Riverside, CA, Technical Report No. AB2766/C93050.

Bass, E., B. Bailey and S. Jaeger (1993): LPG Conversion and HC Emissions Speciation of a Light-Duty Vehicle, SAE Technical Paper No. 932745, Society of Automotive Engineers, Inc., Warrendale, PA.

Battelle Memorial Institute, (1994): Vehicle Exhaust Emissions-Early Mileage Results, Report by Battelle Memorial Institute, Columbus, Ohio.

Baugaus, K. (1990): Preliminary Planning Information for Updating the Ozone Regulatory Impact Analysis Version of EKMA, Draft Document, Source Receptor Analysis Branch, Technical Support Division, U. S. Environmental Protection Agency, Research Triangle Park, NC, January.

Beaty, K. S., R. Egnell and M. Eklund (1992): Development of a Low Emission Volvo 9.6L Natural Gas Fueled Bus Engine, SAE Technical Paper No. 921554, Society of Automotive Engineers, Inc., Warrendale, PA.

Bechtold, R. L., T. J. Timbario, M.T. Miller and C. Urban (1991): Performance and Emissions of a DDC 8V-71 Transit Bus Engine Using Ignition-Improved Methanol and Ethanol, SAE Technical Paper No. 912356, Society of Automotive Engineers, Inc., Warrendale, PA.

Benson, P. (1984): A Dispersion Model for Predicting Air Pollutant Concentrations Near Roadways, Caline4, Report by the Federal Highway Administration, Report No. FHWA/CA/TL-84/15

Bishop, G. A., D. H. Stedman, J. E. Peterson, T. J. Hosick and P. L. Guenther (1993): “A CostEffectiveness Study of Carbon Monoxide Emissions Reduction Utilizing Remote Sensing," J. Air Waste Manage. 43:978-988.

Black, F. and P. Gabele (1991): Impact of Methanol and CNG Fuels on Motor Vehicle Toxic Emissions, Report by the United States Environmental Protection Agency, Research Triangle Park, NC, Report No. EPA/600/D-91/240.

Blackburn, B. (1994): California Energy Commission, personal communication.

Bowman, F. M. and J. H. Seinfeld (1994): "Fundamental Basis of Incremental Reactivities of Organics in Ozone Formation in VOC/NO $\mathrm{X}_{\mathrm{x}}$ Mixtures," J. Geophys Res., in press. 
Bruetsch, R. I. and K. H. Hellman (1992): Evaluation of a Passenger Car Equipped with a Direct Injection Neat Methanol Engine, SAE Technical Paper No. 920196, Society of Automotive Engineers, Inc., Warrendale, PA.

Bufalini, J. J., T. A. Walter, and M. M. Bufalini (1977): Envrion. Sci. Technol., 11: 1181-1185.

Bull, S.R., C. Riley, K.S. Tyson and R. Costello (no date) "Biofuels Full Fuel Cycle Analysis," Material obtained from National Renewable Energy Laboratory, Golden, CO.

Burns, V.R., J. D. Benson, A. M. Hochhauser, W. J. Koehl, W. M. Kreucher, and R. M. Reuter (1991): Description of Auto/Oil Air Quality Improvement Research Program, SAE Technical Paper Series No. 912320. Warrendale, Penn.: Society of Automotive Engineers. October.

CARB (1989): Definition of A Low-Emission Motor Vehicle in Compliance with The Mandates of Health and Safety Code Section 39037.05 (Assembly Bill 234, Leonard, 1987), Report by Mobile Sources Division, California Air Resources Board, El Monte, California. May 19.

CARB (1991a): Alternate Fuel and Advanced Technology Vehicle Fleet Test Program Eleventh Interim Report, Report by the California Air Resources Board, Mobile Sources Division, El Monte, CA, July.

CARB (1991b): Proposed Reactivity Adjustment Factors for Transitional Low-Emissions Vehicles Staff Report and Technical Support Document, California Air Resources Board, Sacramento, CA, September 27.

CARB (1992a): Methodology to Calculate Emission Factors for On-Road Motor Vehicles, Report by the California Air Resources Board, Sacramento, CA, January.

CARB (1992b): Public Hearing to Consider Adaption of Amendments to the Certification and Compliance Test Procedures for Alternative Fuel Retrofit Systems for Motor Vehicles, Report by the California Air Resources Board, Sacramento, CA, May.

CARB (1992c): Derivation of the EMFAC7F Speed Correction Factors, Report by the California Air Resources Board, Sacramento, CA, July.

CARB (1992d): Proposed Reactivity Adjustment Factors for Transitional Low-Emissions Vehicles Staff Report and Technical Support Document, 15 Days Notice, California Air Resources Board, Sacramento, CA, April 21.

CARB (1993a): Preliminary RAF Determination for Reformulated Gasoline, Report by the California Air Resources Board, Mobile Sources Division, El Monte, CA.

CARB (1993b): Methodology for Estimating Emissions from On-Road Motor Vehicles, Report by the California Air Resources Board, Sacramento, CA.

CARB (1993c): Proposed Regulations for Low-Emission Vehicles and Clean Fuels - Staff Report and Technical Support Document, California Air Resources Board, Sacramento, CA, August 13, 1990. See also Appendix VIII of California Exhaust Emission Standards and Test Procedures for 1988 and Subsequent Model Passenger Cars, Light Duty Trucks and Medium Duty Vehicles, as last amended September 22, 1993. Incorporated by reference in Section $1960.1(\mathrm{k})$ of Title 13, California Code of Regulations.

CARB (1994a): Certification data for 94 and 95 production models, Report by the California Air Resources Board, Mobile Sources Division, El Monte, CA. 
CARB (1994b) Preliminary Reactivity Adjustment Factors, Report by the California Air Resources Board, Mobile Sources Division, El Monte, CA.

Carlock, M., (1992): "Overview of On-Road Emissions Inventory Models," Presented at the Air and Waste Management Association's Transportation Modeling: Tips and Trip-ups Conference, San Mateo, CA, March.

Carmicheal, G. R., L. K. Peters, and T. Kitada, (1986): "A Second Generation Model for Regional-Scale Transport/Chemistry/Deposition," Atmos. Environ. 20: 173-188

Carroll, J. N., T. L. Ullman and R. E. Winsor (1990): Emission Comparison of DDC 6V-92TA on Alcohol Fuels, SAE Technical Paper No. 902234, Society of Automotive Engineers, Inc., Warrendale, PA.

Carter, W. P. L., R. Atkinson, A. M. Winer, and J. N. Pitts, Jr. (1982): "Experimental Investigation of Chamber-Dependent Radical Sources," Int. J. Chem. Kinet., 14: 1071.

Carter, W. P. L., and R. Atkinson (1985): "Atmospheric Chemistry of Alkanes," J. Atmos. Chem., 3: 377 $405,1985$.

Carter, W. P. L., F. W. Lurmann, R. Atkinson, and A. C. Lloyd (1986a): Development and Testing of a Surrogate Species Chemical Reaction Mechanism, EPA-600/3-86-031, August.

Carter, W. P. L., W. D. Long, L. N. Parker, and M. C. Dodd (1986b): Effects of Methanol Fuel Substitution on Multi-Day Air Pollution Episodes, Final Report on California Air Resources Board Contract No. A3-125-32, April.

Carter, W. P. L. and R. Atkinson (1987): “An Experimental Study of Incremental Hydrocarbon Reactivity," Environ. Sci. Technol., 21: 670-679

Carter, W. P. L. (1989): Ozone Reactivity Analysis of Emissions from Motor Vehicles, Draft Report to the Western Liquid Gas Association, July.

Carter, W. P. L. and R. Atkinson (1989): “A Computer Modeling Study of Incremental Hydrocarbon Reactivity," Environ. Sci. and Technol., 23:864.

Carter, W. P. L. (1990): “A Detailed Mechanism for the Gas-Phase Atmospheric Reactions of Organic Compounds," Atm. Environ., 24A:481-518.

Carter, W. P. L., and F. W. Lurmann (1990): Evaluation of the RADM Gas-Phase Chemical Mechanism, Final Report, EPA-600/3-90-001.

Carter, W. P. L. (1991): Development of Ozone Reactivity Scales for Volatile Organic Compounds, EPA 600/3-91-050. U.S. Environmental Protection Agency, Research Triangle Park, N.C. August.

Carter, W. P. L. and F. W. Lurmann (1991): "Evaluation of a Detailed Gas-Phase Atmospheric Reaction Mechanism using Environmental Chamber Data," Atm. Environ., 25A: 2771-2806.

Carter, W. P. L. (1993): Development and Application of an Up-To-Date Photochemical Mechanism for Airshed Modeling and Reactivity Assessment, Draft final report for California Air Resources Board Contract No. A934-094, April 26.

Carter, W. P. L., J. A. Pierce, I. L. Malkina, D. Luo and W. D. Long (1993): Environmental Chamber Studies of Maximum Incremental Reactivities of Volatile Organic Compounds, Report to Coordinating Research Council, Project No. ME-9, California Air Resources Board Contract No. A032-0692; South Coast Air Quality Management District Contract No. C91323, United States 
Environmental Protection Agency Cooperative Agreement No. CR-814396-01-0, University Corporation for Atmospheric Research Contract No. 59166, and Dow Corning Corporation. April 1.

Carter, W. P. L. (1994a): "Development of Ozone Reactivity Scales for Volatile Organic Compounds," $J$. Air and Waste Manage. Assoc., 44: 881-899.

Carter, W. P. L. (1994b): Calculation of Reactivity Scales Using an Updated Carbon Bond IV Mechanism, Draft Report Prepared for Systems Applications International Under Funding from the Auto/Oil Air Quality Improvement Research Program, April 12.

Carter, W. P. L., D. Luo, I. L. Malkina, and J. A. Pierce (1995a): Environmental Chamber Studies of Atmospheric Reactivities of Volatile Organic Compounds. Effect of varying ROG Surrogate and $N O_{x}$, Final Report to Coordinating Research Council, Inc. Project ME-9, California Air Resources Board Contract A032-0692, and South Coast Air Quality Management District Contract C91323, March 24.

Carter, W. P. L., D. Luo, I. L. Malkina, and D. Fitz (1995b): The University of California, Riverside Environmental Chamber Data Base for Evaluating Oxidant Mechanism for Urban and Regional Models-Indoor Chamber Experiments Through 1993, Report for EPA Cooperative Agreement 815779, AEERL, Research Triangle Park, NC, March 20.

Carter, W. P. L., D. Luo, I. L. Malkina, and J. A. Pierce (1995c): Environmental Chamber Studies of Atmospheric Reactivities of Volatile Organic Compounds. Effect of varying Chamber and Light Source, Final Report to National Renewable Energy Laboratory Contact XZ-2-12075, Coordinating Research Council, Inc. Project ME-9, California Air Resources Board Contract A032-0692, and South Coast Air Quality Management District Contract C91323, March 26.

Cassmaasi, J., S. Mitsotomi, and M. Shepherd (1990): "Three-dimensional Wind Fields for Use in the Urban Airshed Model," Presented at: Tropospheric Ozone and Environment I, March, Los Angeles, CA. Pittsburgh, PA: Air and Waste Management Association.

Chameides, W. L., F. Fehsenfeld, M. O. Rodgers, C. Cardelino, J. Martinez, D. Parrish, W. Lonneman, D. R. Lawson, R. A. Rasmussen, P. Zimmerman, J. Greenburg, P. Middleton and T. Wang (1992): "Ozone Precursor Relationships in the Ambient Atmosphere," J. Geophys. Res., 97: 6037.

Chang, J. S., R. A. Brost, I. S. A. Isaksen, S. Madronich, P. Middleton, W. R. Stockwell, and C. J. Walcek (1987): "A Three-Dimensional Eulerian Acid Deposition Model: Physical Concepts and Formulation," Journal of Geophysical Research , 92(D12): 14,681-14,700.

Chang, T. Y., S. J. Rudy, G. Kuntasal, and R. A. Gorse (1989): "Impact of Methanol Vehicles on Ozone Air Quality," Atmos. Environ., 23: 1629-1644.

Chang, T. Y. and S. J. Rudy (1990): "Ozone-Forming Potential of Organic Emissions from AlternativeFueled Vehicles," Atmos. Environ., 24A: 2421-2430.

Chock, D. (1994): Ford Motor Company, personal communication.

Cicero-Fernandez, P., and J.R. Long (1993): "Modal Acceleration Testing on Current Technology Vehicles," in A\&WMA The Emission Inventory: Perception and Reality, Pasadena, CA, pp. 506-522.

Cole, J. J., R. C. Meyer, E. Kienzle, A. D. Wells (1993): Development of Hercules GTA3.7L and GTA5.6L Engines for Low Emissions Using and Open-Chamber Lean-Burn Combustion System, Preprint obtained from the Southwest Research Institute, San Antonio, TX. 
Colorado Department of Health (1993): Alternative Fuel Vehicle Conversions; In-Use vs. Certification Data, Prepared by the Colorado Department of Health, Air Pollution Control Division, September.

Cox, F. W., J. R. Walls, M. W. Carrel, B. E. Gray and A. G. Clifton (1994): Compressed Natural Gas as an Alternative Fuel for Spark Ignition Engines in Light to Medium Duty Vehicles, Report by the Arizona Department of Environmental Quality, Emissions Research Lab.

Crane, M. E. and S. R. King (1992): "Emission Reductions Through Precombustion Chamber Design in a Natural Gas, Lean Burn Engine," Journal of Engineering for Gas Turbines and Power, 114: 466474.

CRC-APRAC (1991): Presented at the CRC-APRAC On-Road Vehicle Emission Workshop, Los Angeles, CA., September.

CRC-APRAC (1992): Presented at the CRC-APRAC On-Road Vehicle Emission Workshop, San Diego, CA, December.

CRC-APRAC (1994): Presented at the CRC-APRAC On-Road Vehicle Emission Workshop, San Diego, CA, March.

Croes, B. E., J. R. Holmes, and A. C. Lloyd (1992): "Reactivity-Based Hydrocarbon Controls: Scientific Issues and Potential Regulatory Applications," J. Air Waste Manage. Assoc., 42: 657-661.

Darnall, K. R., A. C. Lloyd, A. M. Winer, J. N. Pitts, Jr. (1976): Environ. Sci. Technol., 10: 692.

Darrow, K. G. (1994): "Light Duty Vehicle Full Fuel Cycle Emissions Analysis," Report prepared for the Gas Research Institute, Chicago, IL, Report No. GRI-93/0472.

den Otter, G. J., R. E. Malpas, and T. D. B. Morgan (1993): Effect of Gasoline Reformulation on Exhaust Emissions in Current European Vehicles, SAE Technical Paper No. 930372, Society of Automotive Engineers, Inc., Warrendale, PA.

Department of Energy (1994): Domestic Alternative Fuel Vehicle Outlook, U.S. Department of Energy.

Derwent, R. G. and A. M. Hough (1988): The Impact of Possible Future Emission Control Regulations on Photochemical Ozone Formation in Europe, AERE R 12919, Harwell Laboratory, Oxfordshire, England.

Derwent, R. G. and Hov (1979): Computer Modeling Studies of Photochemical Air Pollution Formation in North West Europe, AERE R 9434, Harwell Laboratory, Oxfordshire, England.

Derwent, R. G. and M. E. Jenkin (1991): "Hydrocarbons and the Long-Range Transport of Ozone and PAN Across Europe," Atmos. Environ., 25A: 1661-1678.

Dodge, M. C. (1984): "Combined effects of organic reactivity and NMHC/NOx ratio on photochemical oxidant formation -- a modeling study," Atmos. Environ., 18: 1657.

Dodge, M. C. (1977): Combined Use of Modeling Techniques and Smog Chamber Data to Derive OzonePrecursor Relationships, in: Dimatriades, B., ed. International conference on photochemical oxidant pollution and its control-proceedings: Volume II, September 1976, Raleigh, NC. Research Triangle Park, NC: U.S.

Drachand, K. D. (1991): "Modal Acceleration Testing," Mailout Report No. 91-12, Mobile Sources Division, California Air Resources Board, El Monte, CA. 
Dumdei, B. E. and R. J. O'Brein (1984): "Toluene Degradation Products in Simulated Atmospheric Conditions," Nature, 311: 248-240.

Dunlap, L. S., V. Pellegrin, R. Ikeda, R. Wilson, S. Stanley, and H. Poter (1993): Chassis Dynamometer Emissions Testing Results for Diesel and Alternative-Fueled Transit Buses, SAE Technical Paper No. 931783, Society of Automotive Engineers, Inc., Warrendale, PA.

Eliassen, A., and O. Hov (1987): Status of Calculations of a European Country-by-Country NO $\mathrm{X}_{x}$ Budget. EMEP MSCW Note 1/87, The Norwegian Meteorological Institute, Oslo, Norway.

EPA (1989): User's Guide to MOBILE4, Report prepared by the Office of Mobile Sources, US. Environmental Protection Agency, Ann Arbor, MI, March.

EPA (1992): Mobile 5 Workshop Materials, Report by the Office of Mobile Services, U.S. Environmental Protection Agency, Ann Arbor, MI, March 5.

EPA (1993a): "Lifetime Emissions for Clean-Fuel Fleet Vehicles," Report by the Office of Mobile Services, U.S. Environmental Protection Agency, Ann Arbor, MI.

EPA (1993b): “Air Pollution Control," Federal Register, 58, n.25, February 1993.

External Review Panel of the Eulerian Model Evaluation Field Study (EMEFS), July 1994.

Fritz, S. G. and R. I. Egbuonu (1993): Emissions From Heavy-Duty Trucks Converted to Compressed Natural Gas, SAE Technical Paper No. 932950, Society of Automotive Engineers, Inc., Warrendale, PA.

FTP (1989): Code of Federal Regulations. Title 40. Parts 86-99 (portion of CFR which contains the Federal Test Procedure), Office of the Federal Register., Technical Report, 1989.

Fujita, et al. (1991): "Comparison of Emission Estimates and Ambient Concentrations of CO, NMOC, and NOx in California's South Coast Air Basin," Presented at the International Specialty Conference on Emission Inventory Issues in the 1990's, Durham, NC, September.

Gabele, P. A., K. T. Knapp, W. D. Ray, R. Snow, W. Crews, N. Perry and J. Lanning (1990): Ambient Temperature and Driving Cycle Effects on CNG Motor Vehicle Emission, SAE Technical Paper No. 902069, Society of Automotive Engineers, Inc., Warrendale, PA.

Gabele, P. A. (1990): "Characterization of Emissions from a Variable Gasoline/Methanol Fueled Car," Journal of Air \& Waste Management Association, 40: 296-304.

Gabele, P. A. and K. T. Knapp (1993): "A Characterization of Emissions from an Early Model FlexibleFuel Vehicle," Air \& Waste , 43: 851-858.

Gabele, P. A. and F. Black (1993): "Emissions and Fuel Economy of Federal Alternatively Fueled Fleet Vehicles," presented at International Symposium on Alcohol Fuels "The Road to Commercialization," Colorado Springs, CO, November.

Gabele, P. A. (1994): U.S. Environmental Protection Agency, Research Triangle Park, NC, Personal Communication, 1994.

Gery, M. W. (1991): Review of the SAPRC-90 Chemical Mechanism, Report to the California Air Resources Board, Contract No. A132-055, Sacramento, CA.

Gery, M. W., G. Z. Whitten, and J. P. Killus (1988): Development and Testing of the CBM-IV For Urban and Regional Modeling, EPA-600/ 3-88-012, January. 
Gery, M. W., R. D. Edmond and G. Z. Whitten (1987): Tropospheric Ultraviolet Radiation. Assessment of Existing Data and Effects on Ozone Formation, Final Report, EPA-600/3-87-047, October.

Gery M. W., (1994): Atmospheric Research Associates, Boston, MA, private communication.

Goodin, W. R., McRae, G. J., Seinfeld, J. H. (1980): "An Objective Analysis Technique for Constructing Three-Dimensional Urban-Scale Wind Fields," J. Apple. Meteorol. 19: 98-108

Gorse Jr., R. A., (1994): Ford Motor Company, Dearborn, MI, Personal Communication, June 24,.

Gray, Jr., C. L. and J. A. Alson (1989): "The Case for Methanol," Scientific American, 261: p. 108.

Guensler, R., D. Sperling, and S. Washington (1993): "IVHS Technologies and Motor Vehicle Emissions," in Proceedings: IVHS America Third Annual Meeting, IVHS America, Washington, DC, April.

Hansen, D. A., Dennis R. L., Ebel, A., Hanna, S. R., Kaye., J., and Thuillier, R., (1994): "CAMRAQ: The Quest for Modern Solutions to Regional Air Quality Problems," Environ. Sci. Technol. (in press).

Harley R. A., Russell A. G., McRae G. J., Cass G. R. and Seinfeld J. H. (1993): "Photochemical Modeling of the Southern California Air Quality Study," Environ. Sci. Technol. 27: 378-388.

Hellman, K. H. and G. K. Piotrowski (1990): Recent Results from Prototype Vehicle and Emission Control Technology Evaluation Using Methanol Fuel, SAE Technical Paper No. 901112, Society of Automotive Engineers, Inc., Warrendale, PA.

Hicks, B. B., R. R. Draxler, D. L. Albritton, et al. (1990): Atmospheric Processes Research and Process Model Development, NAPAP Report 2, Acidic Deposition: State of Science and Technology, National Acid Precipitation Assessment Program, Washington D. C.

Hilden, D. L., P. A. Mulawa, and S. H. Cadle (1991): Liquefied Petroleum Gas as an Automotive Fuel: Exhaust Emissions and Their Atmospheric Reactivity, Report by the General Motors Research Laboratory, Warren, MI, Report No. GMR-7442 F\&L-913, September.

Hill, A. (1994), California Energy Commission, personal communication.

Hoekman, S. K. (1992): "Speciated Measurements and Calculated Reactivities of Vehicle Exhaust Emissions from Conventional and Reformulated Gasolines," Environ. Sci. Technol., 26: 12061216.

Hoekman, S. K. and T. E. Jensen (1993): Methanol Vehicle Emissions Round Robin Test Program, SAE Technical Paper No. 932773, Society of Automotive Engineers, Inc., Warrendale, PA.

Jaaskelainen, H. E. and J. S. Wallace (1993a): Performance and Emissions of a Natural Gas-Fueled 16 Valve DOHC Four-Cylinder Engine, SAE Technical Paper No. 930380, Society of Automotive Engineers, Inc., Warrendale, PA.

Jaaskelainen, H. E. and J. S. Wallace (1993b): Effect of Increasing Compression Ratio in a Light-Duty Natural Gas Fueled Engine on Efficiency and Emissions, SAE Technical Paper No. 932746, Society of Automotive Engineers, Inc., Warrendale, PA.

Jeffries, H. E., K. G. Sexton, T. P. Morris, H. Jackson, R. G. Goodman, R. M. Kamens, and M. S. Holleman (1985): Outdoor Smog Chamber Experiments Using Automobile Exhaust, Final Report, EPA-600/3-85-032. 
Jeffries, H. E. and R. Crouse (1991): Scientific and Technical Issues Related to the Application of Incremental Reactivity. Part II: Explaining Mechanism Differences, Report prepared for Western States Petroleum Association, Glendale, CA, October.

Jeffries, H. E., M. W. Gery and W. P. L. Carter (1992): Protocol for Evaluating Oxidant Mechanisms for Urban and Regional Models, Report for U. S. Environmental Protection Agency Cooperative Agreement No. 815779, Atmospheric Research and Exposure Assessment Laboratory, Research Triangle Park, NC.

Jeffries, H. E. (1993): "Fuel Reformulation Alone May Not Reduce Urban Ozone," Fuel Reformulation, January/February issue: 58-68.

Jeffries, H. E. and K. G. Sexton (1993): The Relative Ozone Forming Potential of Methanol-Fueled Vehicle Emissions and Gasoline-Fueled Vehicle Emissions in Outdoor Smog Chambers, Draft Final Report to the Coordinating Research Council, Project No. ME-1, September.

Jesion, G., J. W. Butler, D. P. Chock, C.A. Gierczak, and B. I. Nance (1994): "Studies Relating On-Board Emissions Measurements with Engine Parameters and Driving Modes," in Proceedings of the Fourth CRC-APRAC On-Road Vehicle Emissions Workshop, Coordinating Research Council, Inc., Atlanta, GA, pp. 3-41 - 3-58, March.

Jeske, F. R., M. J. Jennings and T. Morel (1991): Computational Fluid Dynamics and Engine Design Analysis Support for 6V-92TA Natural Gas Engine Development, Prepared for the Gas Research Institute, Chicago, IL, Report No. GRI-91/0145, March.

Joshi, S. B, M. C. Dodge, and J. J. Bufalini (1982): Atmos. Environ., 16: 1301-1310.

Kajima, K., T. Hirota, K. Yakushiji, Y. Iwakiri, K. Oda, and Y. Akutsu (1991): Effect of Reformulated Gasoline and Methanol on Exhaust Emissions, SAE Technical Paper No. 912431, Society of Automotive Engineers, Inc., Warrendale, PA.

Karaosmanoglu, F., A. Isigigur, and H. A. Aksoy (1993): Unleaded Gasoline-Azeotropic Ethanol Blends as Fuels for Spark Ignition Engines, SAE Technical Paper No. 932771, Society of Automotive Engineers, Inc., Warrendale, PA.

Karim, G. A., Z. Liu, and W. Jones (1993): Exhaust Emissions From Dual Fuel Engines at Light Load, SAE Technical Paper No. 932822, Society of Automotive Engineers, Inc., Warrendale, PA.

Kelly, K. (1994): National Renewable Energy Laboratory, Golden, CO, Personal Communication.

Kelly, N. A., P. Wang, S. M. Japar, M. D. Hurley, T. J. Wallington (1994): Measurement of the Atmosphere Reactivity of Emissions from Gasoline and Alternative-Fueled Vehicles: Assessment of Available Methodologies, First-Year Final Report, CRC Contract No. AQ-6-1-92, Environmental Research Consortium.

Kelly, N. A. and P. J. Groblicki (1993); "Real-World Emissions from a Modern Production Vehicle Driven in Los Angeles," J. Air Waste Manage. Assoc., 42: 1351-1357.

King, L. J. and C. B. Prakash (1992): Field Trials of Ethanol in Transit Buses, SAE Technical Paper No. 922272, Society of Automotive Engineers, Inc., Warrendale, PA.

Kirwan, J. E. (1993): Effects of Methanol and Fuel Sulfur Concentration on Tailpipe emissions in a Production Variable Fuel Vehicle, SAE Technical Paper No. 932774, Society of Automotive Engineers, Inc., Warrendale, PA. 
Laity, J. L., F. G. Burstain, and B. R. Appel (1973): "Photochemical Smog and The Atmospheric Reactions of Solvents," in Solvents Theory and Practice, Tess, R. W., Ed., Adv. Chem. Series, 124: 95 .

Lamb, R. G. (1983): Regional Scale (1000km) Model of Photochemical Air Pollution, Part 1. Theoretical Formulation, EPA/600/3-83-035, U.S. Environmental Protection- Agency, Environmental Sciences Research laboratories, Research Triangle Park, N.C.

Lawson, D. R., P. J. Groblicki, D. H. Stedman, G. A. Bishop and P.L. Guenther (1990): "Emissions from In-Use Motor Vehicles in Los Angeles: A Pilot Study of Remote Sensing and the Inspection and Maintenance Program," J. Air Waste Manage. Assoc. 40:1096-1105.

Lesco, J. (1994): Denver Research Institute, University of Denver, personal communication.

Liotta, F. J., Jr. and D. M. Montalvo (1993): The Effect of Oxygenated Fuels on Emissions from a Modern Heavy-Duty Diesel Engine, SAE Technical Paper No. 932734, Society of Automotive Engineers, Inc., Warrendale, PA.

Lippincott, A. L., J. S. Segal, and S.-C. Wang (1993): Emissions of California Phase 2 Gasoline in Advanced Technology Vehicles, SAE Technical Paper No. 932677, Society of Automotive Engineers, Inc., Warrendale, PA.

Lowi, A. L., and W. P. L. Carter (1990): "A Method for Evaluating the Atmospheric Ozone Impact of Actual Vehicle Emissions," Presented at the SAE International Congress and Exposition, Detroit, Michigan, February 26 - March 2, 1990.

Lurmann, F. W., W. P. L. Carter, and R. A. Coyner (1987): A Surrogate Species Chemical Reaction Mechanism for Urban-Scale Air Quality Simulation Models. Volume I - Adaptation of the Mechanism, EPA-600/3-87-014a.

Lurmann, F. W., M. Gery, and W. P. L. Carter (1991): Implementation of the 1990 SAPRC Chemical Mechanism in the Urban Airshed Model, Final Report to the California South Coast Air Quality Management District, Sonoma Technology, Inc. Report STI-99290-1164-FR, Santa Rosa, CA.

Lurmann, F. W. (1993): "Comparison of the SAPRC and CB4 Chemical Mechanisms Using a SCAQS Episode," Proceedings of the Intentional Specialty Conference: Southern California Air Quality Study, Data Analysis, Los Angeles, California, July, 1992: 284-290.

Lyons, J. K. and G. A. McCoy (1993): Gaseous-Fueled Vehicles: An Alternative Fuels Vehicle Emissions, Refueling Infrastructure Technology Assessment, Report by the Washington State Energy Office, Olympia, WA, Report No. WSEO 93-117, June.

Maldonado, H., (1991): "Methodology to Calculate Emission Factors for On-Road Motor Vehicles," Technical Report, California Air Resources Board.

Maldonado, H., (1992): "Supplement to Methodology to Calculate Emission Factors for On-Road Motor Vehicles July 1991," Technical Report, California Air Resources Board.

Maldonado, H., M. Carlock, E. Yotter, M. Ahuja (1993): "Air Resources Board's Research Projects to Improve the Mobile Source Emissions Inventory," in A\&WMA The Emission Inventory: Perception and Reality, Pasadena, CA, pp. 51-70.

Markey, J. (1993): "Federal Test Procedure Review Project: Technical Report," Technical Report No. EPA 420-R-93-007, Certification Division, Office of Mobile Sources, Environmental Protection Agency, Ann Arbor, MI. 
McNair, L., A. Russell, and M. T. Odman (1992): "Airshed Calculations of the Sensitivity of Pollutant Formation to Organic Compound Classes and Oxygenates Associated with Alternative Fuels," $J$. Air Waste Manage. Assoc., 42:174.

McNair, L. A., A. G. Russell, M. T. Odman, B. E. Croes, and L. Kao (1994): "Airshed Model Evaluation of Reactivity Adjustment Factors Calculated with the Maximum Incremental Reactivity Scale for Transitional Low-Emissions Vehicles," J. Air Waste Manage. Assoc., 44: 900-907.

McRae G. J., W. R. Goodin, and J. H. Seinfeld (1982): Mathematical Modeling of Photochemical Air Pollution, EQL Report No. 18, Final Report to the State of California Air Resources Board.

Meyer, R. C., J. J. Cole, E. Kienzle, and A. D. Wells (1991): Development of a CNG Engine, SAE Technical Paper No. 910881, Society of Automotive Engineers, Inc., Warrendale, PA.

Meyer, R., D. Meyers, S. M. Shahed and V. K. Duggal (1992): Development of a Heavy Duty OnHighway Natural Gas-Fueled Engine, SAE Technical Paper No. 922362, Society of Automotive Engineers, Inc., Warrendale, PA.

Miller, S. P. and C. L. Savonen (1990): Development Status of the Detroit Diesel Corporation Methanol Engine, SAE Technical Paper No. 901564, Society of Automotive Engineers, Inc., Warrendale, PA.

Montemayor, A., C. Sullivan, and J. Wiens (1992): City of Los Angeles Experience With a MethanolFueled Dump Trunk, SAE Technical Paper No. 921536, Society of Automotive Engineers, Inc., Warrendale, PA.

Myung, C.-L., S.-S. Hwang, and H.-S. Lee (1991): Unburned Methanol and Formaldehyde Emission Measurements from Methanol-Flexible Fuel Vehicle (FFV), SAE Technical Paper No. 912557, Society of Automotive Engineers, Inc., Warrendale, PA.

Myung, C.-L., S.-H. Lee, Y.-G. Shin, K.-S. Park, S.-S. Park, and H.-S. Lee (1993): Research and Development of Hyundai Flexible Fuel Vehicles (FFVs), SAE Technical Paper No. 930330, Society of Automotive Engineers, Inc., Warrendale, PA.

NCAR (1987): Development and Implementation of Chemical Mechanisms for the Regional Acid Deposition Model (RADM), Final Report on EPA Interagency Agreement DW49930144-01-4, Atmospheric Sciences Research Laboratory, Research Triangle Park, NC 27711, April 1.

Nichols, R. J. (1983): Further Development of the Methanol-Fueled Escort, SAE Technical Paper No. 830900 , Society of Automotive Engineers, Inc., Warrendale, PA.

Nichols, R. J. and J. M. Norbeck (1985): "Assessment of Emissions from Methanol-fueled Vehicles: Implications for Ozone Air Quality," Paper 85-38.3, Presented at the 78th Annual Meeting of the Air Pollution Control Association, Detroit, Michigan, June 16-21.

Nishide, H., T. Yata, T. Hirota, H. Fujiwara, Y. Nakagawa, and T. Ohta (1992): Performance and Exhaust Emissions of Nissan FFV NX Coupe, SAE Technical Paper No. 920299, Society of Automotive Engineers, Inc., Warrendale, PA.

Norman, T. (1991): Utilization of Compressed Natural Gas in Medium-and Heavy-Duty Engine Route Vehicles, Prepared for the Gas Research Institute, Chicago, IL, Report No. GRI-92/0153, December.

NRC (1991): Rethinking the Ozone Problem in Urban and Regulated Air Pollution, NRC Report to the National Academy Press, Washington, D.C. 
Nylund, N. and A. Riikonen (1991): Low-Polluting Gas Fueled Heavy-Duty Vehicles, SAE Technical Paper No. 912365, Society of Automotive Engineers, Inc., Warrendale, PA.

Nylund, N-O and M. Kyto (1993), Propane Fueled Heavy-Duty Vehicles, SAE Technical Paper No. 932817, Society of Automotive Engineers, Inc., Warrendale, PA.

O’Toole, R. P., E. Dutzi, R. Gersham, R. Heft, W. Kaleama, and D. Maynard (1983): California Methanol Assessment, Vol. 2, Technical Report, Ch. 6: Air Quality Impact of Methanol-Using Vehicles, JPL Publication 83-18, Jet Propulsion Laboratory, Division of Chemical Engineering, CalTech, Pasadena, CA.

Pefley, R. K., J. B. Pullman, and G. Z. Whitten (1984): The Impact of Alcohol Fuels on Urban Air Pollution: Methanol Photochemistry Study, Final Report, U. S. Department of Energy, Office of Vehicle and Engine R\&D, Washington DC 20583.

Pielke, R. A. (1984): Mesoscale Meteorological Modeling, Orlando, FL: Academic Press.

Pollack, A. K., J. P. Cohen, J. L. Fieber, R. E. Morris, and G. Yarwood (1993): Methodology for Modeling the Air Quality Impacts of Changing the Composition of Fuels Used in Light-Duty Gasoline Vehicles, Auto/Oil Air Quality Improvement Research Program, Phase I, Final Report, Systems Applications International, San Rafael, California.

Quissek, F., P. Zelenka, K. Hulak, and P. Kapus, (1992) Cold Start Performance Comparison of Alcohol Fueled Engines with In-Cylinder and Port Fuel Injection, SAE Technical Paper No. 920003, Society of Automotive Engineers, Inc., Warrendale, PA.

Reynolds, S. D., P. M. Roth, and J. H. Seinfeld (1973): "Mathematical Modeling of Photochemical Air Pollution- I. Formulation of the Model," Atmos. Environ., 7: 1033-1061.

Reynolds, S. D., T. W. Tesche, and L. E. Reid (1979): An Introduction to the SAI Airshed Model and its Usage, San Rafael, CA: Systems Application Inc., Report No. RTI/3999/18-04F.

Richards, B. G. (1990): Methanol-Fueled Caterpillar 3406 Engine Experience in On-Highway Trucks, SAE Technical Paper No. 902160, Society of Automotive Engineers, Inc., Warrendale, PA.

Rodgers, M. O., M. D. Meyer, C. B. Ross, F. M. Saunders, R. S. DuBose, A. Gilliland, M. Fogelson, G. Grodzinsky, T. Barker, J. R. Pearson, R. Breiwish, D. LeBlanc, J. Martinez, M. B. Canon, P. Cessarani, P. J. Groblicki, and C. T. Ripberger (1994): "The Impact of Enrichment on Atlanta Vehicle Emissions," in Proceedings of the Fourth CRC-APRAC On-Road Vehicle Emissions Workshop, Coordinating Research Council, Inc., Atlanta, GA, pp.5-3 - 5-10.

Roth, P.M., C. E. Blanchard, and S.D. Reynolds (1989): The Role of Grid-Based Reactive Air Quality Modeling in Policy Analysis: Perspectives and Implications as Drawn from a Case Study, EPA/600/3-89-082, U.S. Environmental Protection Agency, Atmospheric Research and Exposure Assessment Laboratory, Research Triangle Park, N.C.

Russell, A. G., J. N. Harris, D. St. Pierre, J. B. Milford (1989): Quantitative Estimates of Air Quality Impacts of Methanol Fuel Use. Prepared for the California Resources Board and South Coast Air Quality Management District under ARB Agreement No., A6-048-32, Carnegie Mellon University, Pittsburgh, PA, April.

Russell, A. G. (1990): "Air Quality Modeling of Alternative Fuel Use in Los Angeles, CA: Sensitivity of Pollutant Formation to Individual Pollutant Compounds," Paper 90-96.9, Presented at: The 83rd Annual Meeting and Exhibition of the Air and Waste Management Association, Pittsburgh, Pennsylvania, June 24-29. 
Russell, A. G., St. Pierre, D., and J. B. Milford (1990): “Ozone Control and Methanol Fuel Use," Science 247:201-205.

Russell, A. G. (1994): Carnegie Mellon University, Pittsburgh, PA, personal communication.

SAI (1991): "Assessment of Computer Models for Estimating Vehicle Emission Factors," Report by Systems Applications International, San Rafael, CA, July.

Samulski, M. (1994): Exhaust Emission Testing of Two Ethanol Variable Fueled 1992 Chevrolet Luminas: Test Results 1993, Report by the Office of Mobile Sources, United States Environmental Protection Agency, Ann Arbor, MI, Report No. EPA-AA-EVRB-94-01.

Schere, K., and E. Wayland (1989): EPA Regional Oxidant Model (ROM 2.0). Evaluation on 1980 NEROS Data Bases, EPA-600/S3-89/057, U.S. Environmental Protection Agency, Research Triangle Park, N.C. 351 pp.

Seaman, N. L. (1990): "Meteorological Modeling Applied to Regional Air-Quality Studies Using Four Dimensional Data Assimilation," Proceedings of the IBM Summer Institute on Environmental Modeling, July, Oberlech, Austria.

Sharp, C. A., T. L. Ullman, and K. R. Stamper (1993): Transient Emissions from Two Natural GasFueled Heavy-Duty Engines, SAE Technical Paper No. 932819, Society of Automotive Engineers, Inc., Warrendale, PA.

Shepson, P. B., E. O. Edney, and E. W. Corse (1984): "Ring Fragmentation Reactions in the Photooxidations of Toluene and o-Xylene," J. Phys. Chem, 88: 4122-4126.

Smylie, G. M., G. Z. Whitten, R. E. Morris, L. F. Feiber, and K. O'Connor (1990): Technical Analysis of the ARB Staff Proposal for Hydrocarbon Reactivity Adjustment Factors for Clean Fuel/Low Emission Vehicle Regulations, Final report to Western States Petroleum Association, Glendale, CA. Systems Applications Inc. Report SYSAPP-90/092, September.

Snyder, C. and C. Boschi (1993): Sequential Multi-Point Injection of a Natural Gas Engine, Prepared for the Gas Research Institute, Chicago, IL, Report No. GRI-93/0182, April.

St. Denis, M. J. and A. M. Winer (1993): "Prediction of On-Road Emissions and Comparison of Modeling On-Road Emissions to Federal Test Procedure Emissions," in AWMA's The Emissions Inventory-Perception and Reality, Pasadena, CA, October, 1993.

St. Denis, M. J., P Cicero-Fernandez, A. M. Winer, J. W. Butler and G. Jesion (1994): "Effects of In-Use Driving Conditions and Vehicle/Engine Operating Parameters on 'Off-Cycle' Events: Comparison with Federal Test Procedure Conditions" J. Air Waste Manage. Assoc., 44: 31-38.

Stephens, R. D. and S. H. Cadle (1991): "Remote Sensing Measurements of Carbon Monoxide Emissions from On-Road Vehicles," J. Air Waste Manage. 41:39-46.

Stockwell, W. R., P. Middleton, J. S. Chang, and X. Tang (1990): "The Second Generation Regional Acid Deposition Model Chemical Mechanism for Regional Air Quality Modeling," J. Geophys. Res., 95: 16343- 16376.

Swain, M. R., M. J. Yusef, Z. Dulger, and M. N. Swain (1993): The Effects of Hydrogen Addition on Natural Gas Engine Operation, SAE Technical Paper No. 932775, Society of Automotive Engineers, Inc., Warrendale, PA.

Thompson, J. F. (1985): Numerical Grid Generation: Foundations and Applications, Elsevier Science Publishing Company, New York. 
Unnasch, S., D. Lowell, F. Lonyai, L. Dunlap and C. Sullivan (1993): Performance and Emissions of Clean Fuels in Transit Buses with Cummins L10 Engines, SAE Technical Paper No. 931782, Society of Automotive Engineers, Inc., Warrendale, PA.

Urban Consortium Energy Task Force (1994): Compressed Natural Gas Fueled Vehicles: The Houston Experience. Report by the Urban Consortium Energy Task Force, available from PTI Publications Center, Annapolis JCT, MD.

Varde, K. S., J. C. Cherng, C. J. Bailey, and W. A. Majewski (1992): Emissions and Their Control in Natural Gas Fueled Engines, SAE Technical Paper No. 922250, Society of Automotive Engineers, Inc., Warrendale, PA.

Venkatram, A., K. Kashanian, P. K. Karamchandani, and T. Avitzur (1990): "Probing the Acid Deposition System with a Semi-empirical Model: the Role of Oxidant Limitation," Atmospheric Environment, Vol. 24A, pp. 125-131.

Venkatram, A. (1991): "Comprehensive Models for Environmental Systems," Air Pollution Modeling and its Application VIII (ed. Han van Dop and D. G. Steyn), Plenum Press, New York, pp. 661-672.

Venkatram, A., (1993): The Parameterization of the Vertical Dispersion of a Scalar in the Atmospheric Boundary Layer, Atmospheric Environment, Vol. 27A, No. 13, pp. 1963-1966.

Venkatram, A., P. K. Karamchandani, P. Prasad, R. Goldstein (1994): “The Development and Application of a Simplified Ozone Modeling System (SOMS)," Atmos. Environ., in press.

Waldman, D.J., (1990): Heavy Duty Liquid and Gaseous Fuel Emissions Database Test Results from Four Alternative Fuel Configurations of Caterpillar 3406 Engines, Report prepared for the Oak Ridge National Laboratory, Oak Ridge, TN, Report No. ORNL/Sub/86-SB195/1.

Wang, W., M. Gautam, X. Sun, R. Bata, N. Clark, G.M. Palmer and D. Lyons (1993a): Emissions Comparisons of Twenty-Six Heavy-Duty Vehicles Operating on Conventional and Alternative fuels, SAE Technical Paper No. 932952, Society of Automotive Engineers, Inc., Warrendale, PA.

Wang, W., X. Sun, R. Bata, M. Gautam, N. Clark, G. M. Palmer, and D. Lyons (1993b): A Study of Emissions from CNG and Diesel Fueled Heavy-Duty Vehicles, SAE Technical Paper No. 932826, Society of Automotive Engineers, Inc., Warrendale, PA.

Weir, B. R., A. S. Rosenbaum, L. A. Gardner, G. Z. Whitten and W. Carter, (1988): Architectural Coatings in the South Coast Air Basin: Survey, Reactivity, and Toxicity Evaluation, Final Report to the South Coast Management District, SYSAPP-88/137, Systems Applications, Inc. San Rafael, CA, December.

Whitten, G. Z., N. Yonkow, and T.C. Meyers (1986): Photochemical Modeling of Methanol-Use Scenarios in Philadelphia, EPA146013-86-001, USEPA, Emission Tech. Control Div., Ann Arbor

Whitten, G. Z. (1988): Evaluation of the Impact of Ethanol Gasoline Blends on Urban Ozone Formation, Systems Applications, Inc., San Rafael, CA, SYSAPP-88/029

Whitten, G. Z. and H. Hogo (1983): Impact of Methanol and Smog: A Preliminary Estimate, SAI Pub. No. A3044, Systems Applications, Inc., San Rafael, CA.

Williams, R. L., F. Lipari, and R. A. Potter (1990): "Formaldehyde, Methanol, and Hydrocarbon Emissions from Methanol-Fueled Cars," Air and Waste Management, 40: 747-756.

Wilson, K. W., and G. J. Doyle (1970): Investigation of Photochemical Reactivities of Organic Solvents, Final Report, SRI Project PSU-8029, Stanford Research Institute, Irvine, CA, September. 
Yang, Yueh-jiun, M. Das, J. B. Milford, M. S. Bergin, A. G. Russell, and W. R. Stockwell (1994): Quantification of Organic Compound Reactivities and Effects of Uncertainties in Rate Parameters. An Integrated Approach Using Formal Sensitivity and Uncertainty Analysis and Three Dimensional Air Quality Modeling. Report prepared for the Auto/Oil Air Quality Improvement Research Program, August.

Yarwood (1994): System Application Inc., San Rafael, CA. private communication

Yasuda, A., Y. Tsukasaki, S. Ito, H. Nohira, and T. Inoue (1989): Development of the Second Generation Methanol Lean Burn System, SAE Technical Paper No. 892060, Society of Automotive Engineers, Inc., Warrendale, PA.

Yocke. M. A. (1981): A Three Dimensional Wind Model for Complex Terrain [Ph.D. dissertation]. Berkeley ,CA. University Of California. 


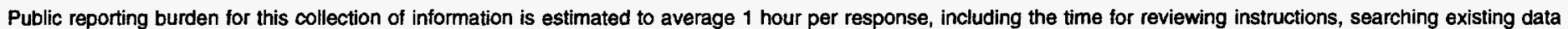

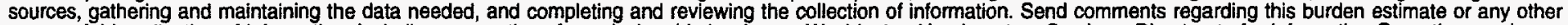

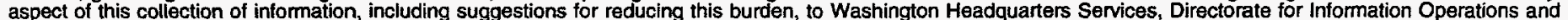

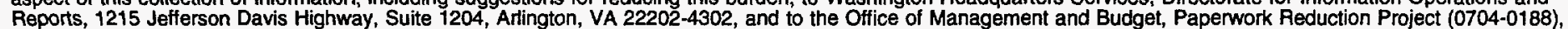
Washington, DC 20503.

\begin{tabular}{|l|l|l|}
\hline 1. AGENCY USE ONLY (Leave blank) & $\begin{array}{l}\text { 2. REPORT DATE } \\
\text { July } 1995\end{array}$ & $\begin{array}{l}\text { 3. REPORT TYPE AND DATES COVERED } \\
\text { subcontract report }\end{array}$ \\
\hline
\end{tabular}

\section{TITLE AND SUBTITLE}

5. FUNDING NUMBERS

Atmospheric Process Evaluation of Mobile Source Emissions

(C) XCC-4-14161-01

(TA) FU522010

\section{AUTHOR(S)}

Center for Environmental Research and Technology

University of Califomia

\section{PERFORMING ORGANIZATION NAME(S) AND ADDRESS(ES)}

Center for Environmental Research and Technology

University of California

Riverside, CA 92521

8. PERFORMING ORGANIZATION REPORT NUMBER

DE95009224

9. SPONSORING/MONITORING AGENCY NAME(S) AND ADDRESS(ES)

10. SPONSORING/MONITORING AGENCY REPORT NUMBER

National Renewable Energy Laboratory

1617 Cole Boulevard

Golden, CO 80401-3393

NRELTP-425-7518

\section{SUPPLEMENTARY NOTES}

12a. DISTRIBUTION/AVAILABILITY STATEMENT

National Technical Information Service

U.S. Department of Commerce

5285 Port Royal Road

Springfield, VA 22161 12b. DISTRIBUTION CODE

UC 1504

\section{ABSTRACT (Maximum 200 words)}

During the past two decades, there has been a considerable effort in the United States to develop and introduce into society alternatives to the use of gasoline and other conventional fuels for transportation. The primary motives behind this effort are twofold: energy security and air quality improvement. Before decisions are made on adopting alternative fuels, quantification of their air quality impacts is needed. The purpose of this report is to present a critical review of the procedures and database used to assess the impact on air quality of mobile source emissions from both alternative and conventional fuels. The report also makes recommendations on improving the existing processes.

\section{SUBJECT TERMS}

Altemative fuels, air quality, emissions

17. SECURITY CLASSIFICATION
OF REPORT

\author{
18. SECURITY CLASSIFICATION \\ OF THIS PAGE
}

19. SECURITY CLASSIFICATION OF ABSTRACT
15. NUMBER OF PAGES

16. PRICE CODE

20. LIMITATION OF ABSTRACT

Standard Form 298 (Rev. 2-89) Prescribed by ANSI Std. 239-18 298-102 